Vivian Rotman

\title{
Avaliação de estratégia ventilatória seqüencial em pacientes com lesão pulmonar aguda (LPA) / síndrome do desconforto respiratório agudo (SDRA)
}

Tese apresentada à Faculdade de Medicina da Universidade de São Paulo para obtenção do título de Doutor em Ciências

Área de concentração: Pneumologia

Orientador: Prof. Dr. Carlos Roberto Ribeiro de Carvalho

São Paulo

2008 
Dados Internacionais de Catalogação na Publicação (CIP)

Preparada pela Biblioteca da

Faculdade de Medicina da Universidade de São Paulo

Greprodução autorizada pelo autor

\section{Rotman, Vivian}

Avaliaçào de estratégia ventilatória sequiencial em pacientes com lesz̃o pulmonar aguda (LPA) : símirome do desconforto respiratónio agudo (SDRA) / Vivian Rotman. - Sỉo Paulo, 2008.

Tese(doutorado)-Faculdade de Mecticina da Universidade de São Paulo. Departamento de Carcio-Peermologia.

Area de concentraxcão: Poetmologia

Orientador: Carlos Roberto Ribeiro de Carvalho.

Descritoros: 1.Pulmâo/lesbles 2.Studrome do desconforto respiratorio do adulto 3.Rospiraçto artificial 4.Expiraçżo 5.Citocinas 6.Tomografia 


\section{DEDICATÓRIA}

Esta tese é dedicada ao Gustavo,

que me ensinou o significado de amor incondicional,

ao Estevão, pelo amor, ajuda e pelos momentos felizes,

aos meus pais, por tudo que fazem por mime por terem

tornado possível a realização dos meus sonhos,

a Gustavo Fraga Filho, pelo exemplo de médico e de pessoa que sempre foi para mim. 


\section{AGRADECIMENTOS}

Ao Prof. Carlos Carvalho, meu orientador, pelo imenso apoio e dedicação durante todo meu Doutorado e por ter acreditado neste trabalho.

A Fernando Bozza, meu amigo, que tanto me ajudou e incentivou.

A Alysson Carvalho, pelo incentivo e entusiasmo e pela grande ajuda com o processamento das imagens.

A Rosana Souza Rodrigues, por todo o auxílio com a análise das imagens.

A todos os meus amigos do Hospital Copa D’OR, pela ajuda na seleção dos pacientes.

À Patrícia Bozza, pelos ensinamentos no laboratório e ajuda com a análise das citocinas.

A José Eduardo Couto de Castro, por sempre me apoiar nos meus projetos.

A João Pantoja, por ter tornado possível a realização deste trabalho no Hospital Copa D’Or.

A Emmanuel Salgueiro, meu grande amigo, que me socorreu quando eu mais precisei.

A Ronir Baggio, pelos preciosos ensinamentos de estatística e por todo tempo dedicado em me ajudar.

Aos fisioterapeutas João, Lafayete, Alessandro, Maurício e Daniela, que muito me ajudaram com o protocolo.

À enfermeira Bruna, Bruna Oriental e aos técnicos de radiologia Felipe e Anderson, todos sempre dispostos a colaborar.

Às secretárias Carmem e Luciana Vitalle, pela dedicação aos pós-graduandos.

Aos pacientes que participaram deste trabalho e a seus parentes.

A toda a minha família, pelo amor que dedicam a mim e pela compreensão nos momentos em que não pude estar presente. 


\section{SUMÁRIO}

$\begin{array}{lll}\text { Dedicatória } & \text { II }\end{array}$

Agradecimentos III

$\begin{array}{lll}\text { Sumário } & \text { IV }\end{array}$

Lista de siglas $\quad$ V

$\begin{array}{lll}\text { Lista de tabelas } & \text { VI }\end{array}$

$\begin{array}{lll}\text { Lista de figuras e gráficos } & \text { VII }\end{array}$

Resumo

$\begin{array}{ll}\text { Summary IX } & \text { IX }\end{array}$

$\begin{array}{ll}\text { 1. Introdução } & 01\end{array}$

2. Revisão da literatura e fundamentos teóricos $\quad 01$

3. Objetivos 24

4. Pacientes e Métodos 25

5. Resultados 35

$\begin{array}{ll}\text { 6. Discussão } & 77\end{array}$

7. Conclusão

8. Referências Bibliográficas 86

Anexo I - Tratamentos de resgate para acidose respiratória e para hipoxemia refratária durante ventilação segundo OLC 92

Anexo II - Principais protocolos terapêuticos do Hospital Copa D’Or 93

Anexo III - Escala de Agitação e Sedação de Richmond (RASS) 107

Anexo IV - Informações ao paciente e consentimento livre e esclarecido 108

$\begin{array}{ll}\text { Anexo V - Ficha de coleta de dados } & 113\end{array}$ 


\section{LISTA DE SIGLAS}

ARDSnet

$\mathrm{BH}$

Cest

CPAP

PxV

$\mathrm{FIO}_{2}$

FR

$\mathrm{HU}$

IL

LBA

LPA

MINIP

MPT

$\mathrm{N} \mathrm{TC}$

OLC

$\mathrm{P}$

$\mathrm{PaCO}_{2}$

PAM

$\mathrm{PaO}_{2}$

PCV

Pdist

PEEP

Pflex

Ppico

Pplatô

PRVC

PSV

RASS

$\mathrm{RX}$

$\mathrm{SaO}_{2}$

SDRA
Acute Respiratory Distress Syndrome Network

Balanço hídrico

Complacência estática

Pressão positiva contínua nas vias aéreas

Pressão versus volume

Fração inspirada de oxigênio

Freqüência respiratória

Unidades Hounsfield

Interleucina

Lavado broncoalveolar

Lesão Pulmonar Aguda

Minimum intensity projection

Massa pulmonar total

Número de tomografia computadorizada

Open Lung Concept

Pressão

Pressão parcial arterial de gás carbônico

Pressão arterial média

Pressão parcial arterial de oxigênio

Ventilação cotrolada à pressão

Pressão de distensão

Pressão positiva ao final da expiração

Ponto de inflexão inferior

Pressão de pico

Pressão de platô

Ventilação controlada à pressão, regulada à volume

Ventilação com suporte pressórico

Richmond Agitation Sedation Scale

Raio X

Saturação arterial de oxigênio

Síndrome do Desconforto Respiratório do Adulto 
$\mathrm{S}_{\mathrm{VC}} \mathrm{O}_{2}$

$\mathrm{SvO}_{2}$

TC

TI

TOT

TQT

VALI

$\mathrm{VM}$

Vmin

VPT

VT

ZEEP
Saturação venosa central de oxigênio

Saturação venosa mista de oxigênio

Tomografia computadorizada

Tempo inspiratório

Tubo orotraqueal

Traqueostomia

Injúria pulmonar associada à ventilação mecânica

Ventilação mecânica

Ventilação por minuto

Volume pulmonar total

Volume corrente

Pressão positiva ao final da expiração igual a zero 
Tabela 1. Características demográficas e clínicas dos pacientes na admissão. 36

Tabela 2. Variáveis respiratórias dos pacientes na admissão. 36

Tabela 3. Concentrações basais (ng/mL)de IL-8 e IL-6 no plasma e mini-Bal. 37

Tabela 4. Concentrações plasmáticas e pulmonares de IL-8 e IL-6 (ng/mL) no momento basal e com ARDSnet 24horas.

Tabela 5. Medidas de parâmetros ventilatórios e de $\mathrm{PaO}_{2} / \mathrm{FIO}_{2}$ com ARDSnet 24 horas e OLC 24 horas.

Tabela 6. Medidas de parâmetros ventilatórios e gasométricos com ARDSnet 24 horas e OLC 24 horas.

Tabela 7. Análises quantitativas volumétricas das imagens tomográficas com ARDS net 24 horas e OLC 24 horas (nos 9 pacientes submetidos à OLC) e com ARDSnet $48 \mathrm{~h}$ (no paciente 10, com resposta à ARDSnet $24 \mathrm{~h})$.

Tabela 8. Análises quantitativas das imagens tomográficas com relação à massa pulmonar total com ARDS net 24 horas e OLC 24 horas (nos 9 pacientes submetidos à OLC) e com ARDSnet 48 h (no paciente 10, com resposta à ARDSnet $24 \mathrm{~h}$ ).

Tabela 9. Concentrações de IL-8 e IL-6 no plasma e mini-Bal (ng/mL) com ARDSnet 24 horas e OLC 24 horas.

Tabela 10.Concentrações de IL-6 e IL-8 no plasma e mini-BAL nas diferentes fases do estudo.

Tabela 11.Evolução ventilatória. 73

Tabela 12.Escores SOFA 76

Tabela 13.Desfechos clínicos 76 
Fig. 1. Curva PxV em um modelo experimental de SDRA induzida por ácido oléico em cachorros.

Fig. 2. Fases e procedimentos do protocolo.

Fig. 3. Recrutamento e titulação da PEEP

Fig. 4. Cortes tomográficos de um paciente com boa resposta à OLC $24 \mathrm{~h}$.

Fig. 5. Reconstruções tridimensionais de um paciente com boa resposta à OLC $24 \mathrm{~h}$.

Fig. 6. Histogramas da distribuição de freqüências das unidades Hounsfield de um paciente com boa resposta à OLC $24 \mathrm{~h}$.

Fig. 7. Histogramas das zonas de West e de todo pulmão, de um paciente com boa resposta à OLC $24 \mathrm{~h}$.

Fig. 8. Cortes tomográficos de um paciente com hiperinsuflação após OLC 24 h.

Fig. 9. Reconstruções tridimensionais de imagens tomográficas de um paciente com hiperinsuflação após OLC 24 h.

Fig. 10. Histogramas da distribuição de freqüências das unidades Hounsfield de um paciente com hiperinsuflação após OLC $24 \mathrm{~h}$.

Fig. 11. Histogramas das zonas de West e de todo pulmão, de um paciente com hiperinsuflação após OLC 24 h.

Fig. 12 Cortes tomográficos de um paciente com boa resposta à ARDSnet $24 \mathrm{~h}$.

Fig. 13. Reconstruções tridimensionais de imagens tomográficas um paciente com boa resposta à ARDSnet $24 \mathrm{~h}$.

Fig. 14. Histogramas da distribuição de freqüências das unidades Hounsfield de um paciente com boa resposta à ARDSnet $24 \mathrm{~h}$. 
Fig. 15. Histogramas das zonas de West e de todo pulmão, de um paciente com boa resposta à ARDSnet $24 \mathrm{~h}$.

Fig 16. Corte tomográfico do paciente 7 após 24 h de OLC, evidenciando pneumotórax.

Fig. 17. Tomografia computadorizada do paciente 8 após 24 h de OLC demonstrando ausência de pneumotórax.

Gráfico 1. Histograma das P/F após 24 h de ARDSnet.

Gráfico 2. Evolução da relação $\mathrm{PaO}_{2} / \mathrm{FIO}_{2}$ entre valores basais e ARDSnet $24 \mathrm{~h}$.

Gráfico 3. Evolução da complacência estática entre valores basais e ARDSnet $24 \mathrm{~h}$.

Gráfico 4. Evolução da $\mathrm{PaCO}_{2}$ entre valores basais e ARDSnet $24 \mathrm{~h}$.

Gráfico 5. Evolução da $\mathrm{P}$ distensão entre valores basais e ARDSnet $24 \mathrm{~h}$.

Gráfico 6. Evolução da PEEP entre ARDSnet 24 h e OLC $24 \mathrm{~h}$

Gráfico 7. Valores de PEEP entre ARDSnet 24 h e OLC $24 \mathrm{~h}$

Gráfico 8. Evolução da relação $\mathrm{PaO}_{2} / \mathrm{FIO}_{2}$ entre ARDSnet $24 \mathrm{~h}$ e OLC 24 h.

Gráfico 9. Evolução da P distensão entre ARDSnet 24 h e OLC $24 \mathrm{~h}$.

Gráfico 10. Evolução da Pplatô entre ARDSnet 24 h e OLC 24 h.

Gráfico 11. Evolução da $\mathrm{PaCO}_{2}$ entre ARDSnet 24 h e OLC $24 \mathrm{~h}$

Gáfico 12. Evoluçào do pH arterial entre ARDSnet 24 h e OLC $24 \mathrm{~h}$.

Gráfico 13. Evolução da ventilação-minuto entre ARDSnet 24 h e OLC $24 \mathrm{~h}$.

Gráfico 14. Evolução da complacência estática entre ARDSnet $24 \mathrm{~h}$ e OLC $24 \mathrm{~h}$.

Gráfico 15. Variação do percentual de volume pulmonar total (VPT) não aerado entre ARDSnet 24 h e OLC 24 h 
Gráfico 16. Variação do percentual de volume pulmonar total (VPT) hiperinsuflado entre ARDSnet $24 \mathrm{~h}$ e OLC $24 \mathrm{~h}$.

Gráfico 17 Variação do percentual de massa pulmonar total (MPT) não aerada entre ARDSnet $24 \mathrm{~h}$ e OLC $24 \mathrm{~h}$.

Gráfico 18. Variação do percentual de massa pulmonar total (MPT) hiperinsuflada entre ARDSnet $24 \mathrm{~h}$ e OLC $24 \mathrm{~h}$.

Gráfico 19. Evolução da média dos valores diários de PAMs entre ARDSnet $24 \mathrm{~h}$ e OLC $24 \mathrm{~h}$.

Gráfico 20. Evolução da infusão de noradrenalina entre ARDSnet 24 h e OLC 24 h.

Gráfico 21. Evolução do balanço hídrico entre ARDSnet 24 h e OLC $24 \mathrm{~h}$.

Gráfico 22. Evolução dos níveis plasmáticos de IL-6 entre ARDSnet $24 \mathrm{~h}$ e OLC $24 \mathrm{~h}$.

Gráfico 23. Evolução dos níveis de IL-6 no mini-BAL entre ARDSnet $24 \mathrm{~h}$ e OLC $24 \mathrm{~h}$.

Gráfico 24. Evolução dos níveis de IL-8 no mini-BAL entre ARDSnet $24 \mathrm{~h}$ e OLC $24 \mathrm{~h}$.

Gráfico 25. Evolução dos níveis plasmáticos de IL-8 entre ARDSnet $24 \mathrm{~h}$ e OLC $24 \mathrm{~h}$.

Gráfico 26. Número de manobras de recrutamento realizadas por paciente durante titulação de PEEP

Gráfico 27. Evolução da relação $\mathrm{PaO}_{2} / \mathrm{FIO}_{2}$ entre 20 minutos pós-recrutamento e OLC $24 \mathrm{~h}$. 


\section{RESUMO}

Rotman, V. Avaliação de estratégia ventilatória seqüencial em pacientes com Lesão Pulmonar Aguda (LPA) / Síndrome do Desconforto Respiratório Agudo (SDRA).

A utilização de baixos volumes correntes na Injuria Pulmonar Aguda (LPA) / Síndrome do Desconforto Respiratório Agudo (SDRA) está comprovadamente associada à redução de mortalidade. No entanto, a aplicação de manobras de recrutamento e a utilização de níveis elevados de PEEP ainda são controversos. O objetivo do presente estudo foi comparar os efeitos da estratégia ARDSnet e de uma estratégia baseada no Open Lung Concept (OLC), aplicadas de forma seqüencial, com relação à função pulmonar, imagem tomográfica e atividade inflamatória, em pacientes com LPA / SDRA. Dez pacientes que preencheram os critérios de LPA / SDRA segundo a Conferência de Consenso de 1994 com tempo de evolução até 48 horas foram incluídos. Para seleção definitiva, gasometria arterial para cálculo da relação $\mathrm{PaO}_{2} / \mathrm{FIO}_{2}$ foi coletada após 30 minutos de ventilação com volume corrente (VT) $=10 \mathrm{~mL} / \mathrm{kg}$, $\mathrm{PEEP}=5 \mathrm{cmH}_{2} \mathrm{O}$ e $\mathrm{FIO}_{2}=100 \%$. Nas primeiras 24 horas os pacientes foram ventilados segundo o protocolo ARDSnet. Após este período, caso $\mathrm{PaO}_{2} / \mathrm{FIO}_{2}=350$, adotava-se a estratégia de OLC, que consistia na realização de manobra de recrutamento e titulação de PEEP. A manobra de recrutamento foi realizada em PCV, com delta de pressão de 20 $\mathrm{cmH}_{2} \mathrm{O}$, com incrementos seqüenciais de PEEP em $5 \mathrm{cmH}_{2} \mathrm{O}$, partindo-se de $20 \mathrm{cmH}_{2} \mathrm{O}$ até $30 \mathrm{cmH}_{2} \mathrm{O}$. O objetivo durante a titulação de PEEP foi alcançar $\mathrm{PaO}_{2} / \mathrm{FIO}_{2}>350$, sendo três níveis testados $\left(17,19\right.$ e $21 \mathrm{cmH}_{2} \mathrm{O}$ ). Ventilação segundo OLC (com PEEP determinado durante a titulação e VT $=6 \mathrm{ml} / \mathrm{kg}$ ) foi mantida por $24 \mathrm{~h}$ adicionais. Após $24 \mathrm{~h}$ de cada estratégia, TC de todo o pulmão $(1,25 \mathrm{~mm}$ de espessura com $15 \mathrm{~mm}$ de espassamento) foi realizada após $24 \mathrm{~h}$ de cada estratégia. A instituição de OLC foi necessária em 9 dos 10 pacientes estudados. PEEP foi significativamente superior com OLC (17 [17 - 19] vs. $8 \mathrm{cmH}_{2} \mathrm{O}$ [7,25 - 11]; $\left.\mathrm{p}=0,007\right)$ e resultou em melhora significativa de oxigenação, sustentada após $24 \mathrm{~h}$ de seguimento, sem diferença na pressão de platô, pressão de distensão, complacência estática, ventilação-minuto, $\mathrm{PaCO}_{2}$ e $\mathrm{pH}(\mathrm{p}>0,05)$. OLC determinou redução significativa na percentagem de volume pulmonar total (VPT) não aerado (13\% [10,5 - 22,5] vs. 37\% [31 - 40,5]; $\mathrm{p}=0,008)$, sem aumento significativo na percentagem de VPT hiperinsuflado $(5 \%$ [1 - 13,5] vs. $2 \%[0-6,5] ; p=0,079)$. A análise baseada em massa pulmonar total (MPT) evidenciou resultados semelhantes: a percentagem de MPT não aerada com OLC foi significativamente menor $(30 \%$ [23 - 48,5] vs. 58\% [51- 60]; $\mathrm{p}=0,008)$, sem aumento significativo na percentagem de MPT hiperinsuflada $(1 \%[0-2]$ vs. $0 \%[0-1]$; $\mathrm{p}=0,084)$. Não houve diferenças significativas nas doses infundidas de vasopressores, balanço hídrico ou pressão arterial. Observou-se, também, redução significativa nos níveis plasmáticos de IL-6 com OLC $(3,32$ [2,16 - 9,46] vs. 4,11 ng/mL [3,26 - 11,02]; $\mathrm{p}=0,018$ ) Concluimos que, quando comparada à ARDSnet, OLC melhorou a oxigenação, reduzindo a fração de regiões pulmonares não aeradas, sem aumento significativo nas regiões hiperinsufladas, com níveis semelhantes de pressão arterial e balanço hídrico. 


\section{SUMMARY}

Rotman, V. Effects of open lung concept following ARDSNet ventilatory strategy in patients with early acute lung injury (ALI) / acute respiratory distress syndrome (ARDS).

Low tidal volumes are associated with a reduction in mortality in ALI / ARDS.. Nevertheless, the application of recruitment maneuvers and high levels of PEEP are still controversial. The aim of this study was to compare the ARDSnet protocol with a strategy based on Open Lung Concept (OLC), applied in a sequential way, in terms of pulmonary function, computed tomography images and inflammation, in patients with ALI / ARDS. Ten patients fulfilling criteria for ALI /ARDS, based on the AmericanEuropean Consensus Conference, with less than 48 hours of evolution, were included. For definitive selection, blood gas collected after $30 \mathrm{~min}$ application of $5 \mathrm{cmH}_{2} \mathrm{O}$ PEEP and $\mathrm{VT}=10 \mathrm{~mL} / \mathrm{kg}$ had to demonstrate $\mathrm{a} \mathrm{PaO}_{2} / \mathrm{FIO}_{2}<300 \mathrm{mmHg}$. The patients were initially ventilated for 24 hours according to the ARDS net protocol. After this period, if the $\mathrm{PaO}_{2} / \mathrm{FIO}_{2}$ was $=350$, an OLC strategy was adopted, with recruitment maneuver and PEEP titration. The recruitment maneuver was applied in PCV, with sequential 5 $\mathrm{cmH}_{2} \mathrm{O}$ increments in PEEP, starting from $20 \mathrm{cmH}_{2} \mathrm{O}$ until PEEP $=30 \mathrm{cmH}_{2} \mathrm{O}$, maintaining a delta pressure of $20 \mathrm{cmH}_{2} \mathrm{O}$. The aim of PEEP titration was to reach $\mathrm{PaO}_{2} / \mathrm{FIO}_{2}>350$ and three levels were tested: 17, 19 and $21 \mathrm{cmH}_{2} \mathrm{O}$. Ventilation according to OLC (VT $=6 \mathrm{~mL} / \mathrm{kg}$ and PEEP's level found during titration) was applied for the next 24 hours. Whole lung computed tomography images $(1.25 \mathrm{~mm}$ thickness with $15 \mathrm{~mm}$ gap) were acquired after 24 hours of each strategy. The institution of OLC was necessary in 9 of the 10 studied patients. The PEEP was significant ly higher during OLC $\left(17\right.$ [17-19] vs $8 \mathrm{cmH}_{2} \mathrm{O}$ [8-11]; $\left.\mathrm{p}=0,007\right)$ and resulted in a significant improvement on oxygenation sustained for 24 hours of follow-up, with no significant differences in plateau pressure, static compliance, minute-ventilation, $\mathrm{PaCO}_{2}$ and $\mathrm{pH}(\mathrm{p}$ $>0.05)$. OLC resulted in a significant reduction of the fraction of total lung volume that was non-aerated, as compared to ARDS net protocol (13\% [10,5 - 22,5] vs. 37\% [31 $40,5] ; \mathrm{p}=0,008)$, without a significant increase of the fraction of total lung volume that was hyperinsuflated $(5 \%[1-13,5] v s .2 \%[0-6,5] ; \mathrm{p}=0,079)$. The results based on lung mass analysis were similar. OLC was associated with a reduction of the fraction of total lung mass that was non-aerated $30 \%$ [23 - 48,5] vs. 58\% [51-60]; $\mathrm{p}=0,008$ ), without a significant increase of the fraction of total lung mass that was hyperinsuflated $(1 \%[0-2]$ vs. $0 \%[0-1] ; \mathrm{p}=0,084)$. There was also a reduction in plasma levels of IL6 with OLC $(3,32$ [2,16 - 9,46] vs. 4,11 ng/mL [3,26-11,02]; $\mathrm{p}=0,018)$. We concluded that, when compared with ARDSnet protocol, OLC improved oxygenation, reducing the fraction of non-aerated regions without significant increment in hyperinflated areas, with comparable levels of hemodynamics and fluid balance. 



\section{1-Introducão:}

Lesão Pulmonar aguda (LPA) / Síndrome do Desconforto Respiratório Agudo (SDRA) é uma condição freqüente em pacientes graves internados em terapia intensiva. Apesar dos avanços nos conhecimentos fisiopatológicos e no tratamento, morbidade e mortalidade permanecem elevadas. ${ }^{(1)}$ Os pacientes que sobrevivem após terem desenvolvido SDRA apresentam redução de qualidade de vida após um ano. ${ }^{(2)}$

Estudo prospectivo recente, realizado nos Estados Unidos, identificou a ocorrência de 78,9 casos / 100.000 pessoas-ano de LPA e de 58,7 casos / 100.000 pessoas-ano de SDRA, com mortalidade intrahospitalar de $38,5 \% .^{(1)}$

Apenas $20 \%$ dos não sobreviventes falecem por causa primariamente respiratória. A maioria morre por falência orgânica múltipla, tendo como evento desencadeante fundamental a liberação sistêmica de citocinas produzidas no próprio pulmão. ${ }^{(3)} \mathrm{O}$ desenvolvimento de falência orgânica múltipla está associado, entre outros fatores, ao estresse e estiramento alveolares excessivos determinados pela ventilação mecânica. Diversas estratégias ventilatórias protetoras vêm sendo estudadas, não havendo ainda consenso sobre a melhor técnica a ser utilizada. ${ }^{(4)}$

\section{2-Revisão da literatura e fundamentos teóricos:}

\section{1-Definição:}

Lesão Pulmonar Aguda e SDRA são produzidas a partir de uma resposta inflamatória que promove destruição do endotélio capilar pulmonar e do epitélio alveolar, com consequiente liberação de mediadores 
inflamatórios e bactérias na circulação. Esta translocação bacteriana é, potencialmente, uma das bases para o desenvolvimento de falência orgânica múltipla. ${ }^{(5)}$

As definições de LPA e de SDRA são baseadas no consenso de $1994^{(6)}$ que estabeleceu como critério para LPA uma relação pressão parcial arterial de oxigênio $\left(\mathrm{PaO}_{2}\right)$ / fração inspirada de oxigênio $\left(\mathrm{FIO}_{2}\right)-\left(\mathrm{PaO}_{2} / \mathrm{FIO}_{2}\right)=300$ e para SDRA uma $\mathrm{PaO}_{2} / \mathrm{FIO}_{2}=200$, associados à presença de infiltrado pulmonar bilateral, na ausência de sinais de insuficiência ventricular esquerda. A mensuração da relação $\mathrm{PaO}_{2} / \mathrm{FIO}_{2}$ independe da pressão positiva ao final da expiração (PEEP) utilizada, o que vem sendo objeto de críticas. ${ }^{(7 ; 8)}$

É reconhecido que o nível de PEEP é capaz de alterar o grau de hipoxemia e a não definição deste critério permite a inclusão de pacientes com diferentes gravidades e mortalidades em um mesmo grupo. Villar e colaboradores ${ }^{(7)}$ demonstraram que em 56 pacientes ventilados com $\mathrm{PEEP}=5 \mathrm{cmH}_{2} \mathrm{O}$ e $\mathrm{FIO}_{2}=0,5$, nas primeiras 24 horas após determinação do diagnóstico de SDRA pelos critérios do consenso de 1994, dois grupos com diferentes mortalidades podiam ser identificados. Aqueles com $\mathrm{PaO}_{2} / \mathrm{FIO}_{2}>150$ apresentaram mortalidade significativamente inferior em relação aqueles com $\mathrm{PaO}_{2} / \mathrm{FIO}_{2}=150$ (22,6 versus $68 \%$, respectivamente $-\mathrm{p}=0,0016) .{ }^{(7)}$

Em outro estudo, Villar e associados ${ }^{(8)}$ ventilaram 170 pacientes com diagnóstico de SDRA estabelecido pelos critérios do consenso, de quatro formas diferentes, no momento do diagnóstico e 24 horas após, na seguinte seqüência: $\mathrm{PEEP}=5 \mathrm{cmH}_{2} \mathrm{O}$ e $\mathrm{FIO}_{2}=0,5, \quad \mathrm{PEEP}=5 \mathrm{cmH}_{2} \mathrm{O}$ e $\mathrm{FIO}_{2}=1$, $\mathrm{PEEP}=10 \mathrm{cmH}_{2} \mathrm{O}$ e $\mathrm{FIO}_{2}=0,5$ e $\mathrm{PEEP}=10 \mathrm{cmH}_{2} \mathrm{O}$ e $\mathrm{FIO}_{2}=1$. Cada período teve a duração de 30 minutos. Os parâmetros que melhor identificaram diferenças de mortalidade na unidade de terapia intensiva $(\mathrm{p}<0,0001)$ foram PEEP $=10 \mathrm{cmH}_{2} \mathrm{O}$ e $\mathrm{FIO}_{2}=0,5$ aplicados 24 horas após o diagnóstico. Com estes valores, apenas 99 pacientes $(58,2 \%)$ continuaram a preencher critérios diagnósticos de SDRA $\left(\mathrm{PaO}_{2} / \mathrm{FIO}_{2}=155 \pm 29,8\right)$ com mortalidade na terapia intensiva de 45,5\%, enquanto que 55 foram 
reclassificados como LPA $\left(\mathrm{PaO}_{2} / \mathrm{FIO}_{2}=246,5 \pm 25,6\right)$ com mortalidade na terapia intensiva de $20 \%$. O restante (16 pacientes) apresentou critérios de insuficiência respiratória aguda, com valores médios de $\mathrm{PaO}_{2} / \mathrm{FIO}_{2}=370 \pm 54$ e mortalidade na terapia intensiva de $6,3 \% .{ }^{(8)}$

Estudos como os anteriormente citados demonstram a necessidade de melhores critérios definidores de LPA e SDRA, capazes de identificar diferentes grupos de pacientes de acordo com o grau de injúria pulmonar e mortalidade.

\section{2-Mecanismos da injúria pulmonar associada à ventilação mecânica (VALI):}

O potencial da ventilação mecânica em induzir ou exacerbar a injúria pulmonar já está bem estabelecido. ${ }^{(9)}$ Diversos estudos já demonstraram que estratégias ventilatórias determinadoras de estiramento alveolar excessivo e / ou abertura e fechamento cíclicos de unidades alveolares têm o potencial de intensificar a lesão pulmonar através da indução de volutrauma e atelectrauma, respectivamente. Estes mecanismos de lesão induzirão liberação de citocinas (biotrauma) que irão disseminar-se sistemicamente contribuindo para falência orgânica múltipla. As áreas de interseção entre alvéolos aerados e aqueles não aerados são as mais susceptíveis às forças de estiramento e conseqüente lesão. Assim, quanto maior for o número de constantes de tempo existentes, maior será a predisposição para injúria. ${ }^{(10)}$ Isto é particularmente verdadeiro em pacientes com LPA / SDRA, nos quais o comprometimento pulmonar é heterogêneo, identificando-se uma pequena região onde os alvéolos permanecem aerados ao final da expiração baby lung) e são mais suceptíveis à hiperinsuflação ao final da inspiração. ${ }^{(11)}$ Gattinoni e colaboradores ${ }^{(12)} \mathrm{em}$ estudos com tomografia computadorizada (TC), demonstraram que em pulmões com LPA / SDRA existe um gradiente cefalocaudal e antero-posterior de comprometimento, com os alvéolos das regiões ínferoposteriores mais colapsados e consolidados. Este padrão não homogêneo faz com que as regiões menos comprometidas sejam as que mais suportem forças de estresse (tensão do sistema de fibras do esqueleto 
pulmonar) e de estiramento (alongamento das fibras) enquanto as áreas com maior grau de colapso e consolidação permanecem mais protegidas, ficando submetidas apenas às forças de estresse (e poupadas de estiramento) ${ }^{(13)}$. Sabe-se que o principal mecanismo iniciador de VALI é o estiramento excessivo, que promove deformação das células endoteliais e epiteliais ancoradas na matriz extracelular. Ocorre aumento de permeabilidade da camada endotelial através de vários mecanismos, tais como aumento no tamanho das fenestrações endoteliais, contração aiva das células endoteliais e produção de citocinas. Há ativação de sensores presentes nas células epiteliais e nos macrófagos, com conseqüente liberação de interleucina (IL) 8 e metaloproteinases. A IL-8 tem papel fundamental na quimiotaxia e ativação de neutrófilos, desencadeando a inflamação pulmonar. ${ }^{(14)}$

\section{3-Cinética das citocinas:}

As citocinas estão envolvidas na fase inicial de inflamação (citocinas pró-inflamatórias, tais como TNF-a e IL1-ß), no recrutamento de células imunes para o local da inflamação (quimocinas: IL-8) e na ativação de macrófagos e polimorfonucleares (IL-6). A produção e a atividade das citocinas próinflamatórias são reguladas por citocinas antiinflamatórias (IL-10) e anticitocinas (tais como receptores solúveis de TNF-a - sTNF-r? e r??, antagonistas de receptores IL-1- IL1-ra) ${ }^{(15)}$. Park e colaboradores ${ }^{(16)}$ demonstraram haver um predomínio da resposta antiinflamatória em relação à inflamatória nos primeiros dias de SDRA, com os mediadores antiinflamatórios (dentre eles IL1-ra, sTNF-R? e R?? e IL-10) atingindo concentrações máximas no lavado broncoalveolar (LBA) entre o primeiro e terceiro dias de SDRA. Com relação aos mediadores inflamatórios no LBA, observaram concentrações máximas de TNF-a no primeiro dia de SDRA estabelecida (com declínio progressivo até níveis indetectáveis no sétimo dia de evolução) e níveis máximos de IL-6 nas primeiras 72 horas, com persistência de valores acima do normal por até 21 dias nos pacientes com SDRA persistente. ${ }^{(16)}$ Concentrações elevadas de IL-6 e IL-8 no LBA durante todo o 
curso de SDRA têm sido observadas em não sobreviventes. ${ }^{(17) ~}{ }^{(18)}$ Níveis plasmáticos de IL-6 e IL1-ß persistentemente altos também estão associados à mortalidade elevada. ${ }^{(19)}$

Os processos de reparação celular e fibrose também são desencadeados por citocinas e outros mediadores liberados em resposta à lesão pulmonar. Madtes e associados ${ }^{(20)}$ demonstraram a participação do transforming growth factor-a (TGF-a) na resposta fibroproliferativa da SDRA. Observaram que aumento nos níveis de TGF-a no LBA correlaciona-se com níveis elevados de pró-colágeno tipo ??? (um marcador biológico de fibroproliferação) e que elevação simultânea de TGF-a e pró-colágeno tipo ??? no LBA, no sétimo dia de SDRA, está associada a um risco quatro vezes maior de mortalidade. ${ }^{(20)}$ Dhainaut e colaboradores ${ }^{(21)}$ constataram que TGF-ß participa não só da fase fibroproliferativa, mas também da fase inicial de edema pulmonar. ${ }^{(21)}$ As metaloproteinases-MMP (enzimas que degradam a matriz extracelular) também estão implicadas no remodelamento durante a fase fibroproliferativa da SDRA, particularmente as gelatinases (MMP-2 e MMP-9) o mesmo acontecendo com seus antagonistas (tissue inhibitors of metalloproteinases- TIMPs). ${ }^{(22)}$

Estudos que compararam as concentrações de citocinas no LBA e no plasma, mostraram valores significativamente mais elevados no LBA, sugerindo uma origem pulmonar destes mediadores. ${ }^{(15)}$

\section{4- Citocinas e VALI:}

Diversos estudos in vitro demonstraram que estiramento repetido de células pulmonares (efeito equivalente ao determinado por elevados volumes correntes) induz produção de citocinas. Vlahakis e cols. (23) demonstraram que células epiteliais alveolares humanas submetidas a estiramento cíclico associaram-se a maior liberação de IL-8 quando comparadas a controles estáticos. Essa diferença permaneceu após 12, 24 e 48 horas do estiramento. ${ }^{(23)}$ Experimentos in vivo com modelos animais também corroboraram a associação entre ventilação mecânica lesiva e liberação de citocinas. (15) 
Diversos estudos clínicos vêm utilizando mensurações de citocinas como marcadores de VALI para a análise comparativa entre estratégias ventilatórias indutoras de estiramento e estratégias protetoras. Está estabelecido que a aplicação de vlumes correntes elevados induz maiores concentrações pulmonares e sistêmicas de citocinas. ${ }^{(9)}{ }^{(24)}$ No entanto, dependendo do estudo, ventilação lesiva pode orientar o balanço das citocinas (pulmonares e plasmáticas) para inflamação ${ }^{(9)}$ ou para exacerbação das duas respostas (inflamatória e antiinflamatória). ${ }^{(24)}$

O intervalo de tempo utilizado pelos estudos para aferição das citocinas (no plasma e no LBA) varia. Ranieri e cols ${ }^{(9)}$ realizaram as medidas em dois momentos: após 24 a 30 horas e após 36 a 40 horas de cada ventilação estudada. Observaram redução progressiva nas concentrações plasmáticas e pulmonares de citocinas apenas no grupo submetido à estratégia ventilatória protetora. ${ }^{(9)}$ Stuber e cols ${ }^{(24)}$ mensuraram citocinas após uma mudança transitória de ventilação, de uma forma protetora para uma lesiva. Neste estudo, as medidas foram feitas após 1 e 6 horas de cada estratégia. Uma hora após retorno de ventilação lesiva para protetora houve redução significativa nos níveis de IL-6 no plasma, com tendência a valores plasmáticos mais baixos de TNF, IL-10, IL-1ra. Após 6 horas de ventilação protetora, os níveis plasmáticos das citocinas retornaram aos valores basais. As concentrações das citocinas no LBA também foram maiores após adoção de ventilação lesiva, mas com uma cinética diferente da do plasma, uma vez que não retornaram aos níveis basais após adoção de ventilação protetora. ${ }^{(24)}$ Estudo multicêntrico com 861 pacientes com LPA realizado pelo National Heart Lung and Blood Institute's (NHLBI) ARDS Network ${ }^{(25)}$, comparando duas estratégias ventilatórias, realizou dosagens de citocinas imediatamente antes do início do estudo e após 3 dias de cada estratégia. Demonstraram que, quando comparado ao grupo ventilado com volumes correntes elevados, aquele submetido a baixos volumes correntes apresentou maior redução nos níveis plasmáticos de IL-6 e de IL-8. Observaram também que níveis basais elevados de IL-6, IL-8 e IL-10 estavam associados com maiores morbidade e mortalidade. ${ }^{(25)}$ 


\section{5-Estratégias ventilatórias protetoras:}

No intuito de evitar VALI estratégias ventilatórias protetoras vêm sendo aplicadas. Elas são baseadas na limitação da pressão (P) de platô através do uso de baixos volumes correntes (diminuindo com isso as forças de estiramento e o biotrauma $)^{(26)}$ e na aplicação de PEEP suficiente para evitar o desrecrutamento ao final da expiração, com conseqüentes atelectrauma e também biotrauma. ${ }^{(27)}$

A ventilação com baixos volumes correntes (VT) apesar de efetiva em limitar a injúria associada com o estiramento alveolar, pode induzir atelectasia progressiva e hipóxia. Apesar do uso de altos níveis de PEEP proporcionar maior estabilização dos alvéolos, algumas regiões atelectásicas podem persistir. ${ }^{(28)}$ Manobras de recrutamento têm sido usadas em conjunto com a ventilação protetora objetivando maior homogeneização pulmonar, minimizando áreas de interseção entre regiões com constantes de tempo diferentes. ${ }^{(29)}$ Várias manobras de recrutamento vêm sendo utilizadas (suspiros intermitentes ${ }^{(30)}$, insuflação sustentada com alta pressão ${ }^{(31 ; 32)}$, ventilação controlada à pressão com aumento progressivo do PEEP ${ }^{(33)}$. No entanto, até o momento, não existe consenso sobre qual manobra é a mais adequada.

As controvérsias na forma de ventilação de pacientes com LPA / SDRA englobam desde a necessidade de aplicação de manobras de recrutamento até o nível de PEEP a ser utilizado. Alguns autores preconizam a abertura total do pulmão (open lung concept - OLC) através de manobras de recrutamento com altas pressões inspiratórias, associadas à ventilação com PEEP ideal (aquele capaz de manter todos os alvéolos abertos ao final da expiração). ${ }^{(34)}$ Os que discordam da OLC acreditam que considerar todo o parênquima comprometido como potencialmente recrutável não é certo e que esta estratégia ventilatória determina hiperinsuflação alveolar, com potencial para indução de VALI. ${ }^{(35)}$

Diversos estudos não demonstraram aumento de liberação de citocinas após manobras de recrutamento. ${ }^{(36)(37)}$ Puls e cols ${ }^{(36)}$ avaliaram prospectivamente 16 pacientes em ventilação mecânica e com sinais clínicos e radiológicos de atelectasia, que foram submetidos a uma manobra recrutativa (insuflação 
sustentada com $\mathrm{P}=40 \mathrm{cmH}_{2} \mathrm{O}$ por 7 segundos) Dez dos 16 pacientes preencheram critérios para LPA / SDRA. Não observaram elevações significativas nos níveis plasmáticos de citocinas entre valores basais e os aferidos entre 5 a 360 minutos após a manobra. ${ }^{(36)}$ Em outro estudo, Talmor e cols ${ }^{(37)}$ avaliaram prospectivamente 26 pacientes com SDRA, submetidos à manobra de recrutamento única (insuflação com $\mathrm{P}$ $=40 \mathrm{cmH}_{2} \mathrm{O}$ ) com duração de 30 segundos (superior ao estudo anterior). Após mensuração de citocinas antes da manobra e após 5 minutos e 1 hora de sua realização, não identificaram aumentos significativos em seus níveis plasmáticos. ${ }^{(37)}$ Apesar dos estudos existentes, a literatura ainda não respondeu claramente quais são os efeitos das manobras de recrutamento após um tempo intermediário (não tão precoce quanto uma hora, quando uma liberação posterior não seria identificada e nem tão tardio quanto três dias, quando outros fatores provavelmente já estarão influenciando na resposta inflamatória). ${ }^{(37)}$ A cinética da liberação de citocinas com formas de recrutamento diferentes da insuflação mantida e com pressões mais elevadas não é bem conhecida.

Rouby e colaboradores ${ }^{(38)}$ preconizam a adoção de manobras de recrutamento apenas para melhora da oxigenação e manutenção da saturação arterial de oxigênio $\left(\mathrm{SaO}_{2}\right)=90 \%$ com $\mathrm{FIO}_{2}<0,6$. Em contrapartida, os defensores do OLC advogam que em pulmões não homogêneos, a abertura de regiões colapsadas induz diminuição da hiperinsuflação alveolar nas áreas previamente abertas, através de uma redistribuição de forças de estiramento. Estudos experimentais, com tomografia com impedância elétrica, já demonstraram este comportamento. ${ }^{(39)}$ Diversos estudos clínicos vêm sendo realizados no intuito de determinar a melhor estratégia, porém com resultados conflitantes. ${ }^{(40)}$

Em 2000, foi publicado pelo Acute Respiratory Distress Syndrome Network (ARDSnet) ${ }^{(26)}$ um estudo multicêntrico que demonstrou os benefícios da ventilação com baixos VT em comparação ao uso de VT elevados. Este estudo envolveu 861 pacientes com LPA / SDRA com evolução inferior a 36 horas, que foram randomizados em dois grupos: o primeiro (432 pacientes) foi ventilado de forma "convencional", 
com VT $=12 \mathrm{~mL} / \mathrm{kg}$ e Pplatô $=50 \mathrm{cmH}_{2} \mathrm{O}$; o segundo (429 pacientes) recebeu uma estratégia protetora, com VT $=6 \mathrm{~mL} / \mathrm{kg}$ e Pplatô $=30 \mathrm{cmH}_{2} \mathrm{O}$. Nos dois grupos, os ajustes de PEEP e $\mathrm{FIO}_{2}$ foram baseados em uma tabela que objetivava uma $\mathrm{SaO}_{2}$ entre 88 e 95\%. Demonstrou-se uma redução de mortalidade pré-alta hospitalar em $22 \%$ com a estratégia protetora. Houve também um maior número de dias livres de ventilação mecânica nos pacientes submetidos à estratégia protetora $(12 \pm 11$ versus $10 \pm 11$, respectivamente $-\mathrm{p}=$ 0,007). ${ }^{(26)}$ Apesar de rão haver diferença nos níveis de PEEP utilizados nos dois grupos $\left(8-12 \mathrm{cmH}_{2} \mathrm{O}\right)$ houve diferença significativa na ventilação - minuto $(13,4 \pm 4,3 \mathrm{~L} / \mathrm{min}$ no grupo da ventilação protetora versus $12,7 \pm 4,3$ no grupo convencional $-p=0,01)$. É possível que o volume-minuto mais elevado no grupo da ventilação protetora tenha gerado auto-PEEP e que isto tenha tido papel fundamental na diferença de mortalidade entre os grupos. Durante e colaboradores ${ }^{(41)}$ ao reproduzirem o protocolo ARDS net ${ }^{(26)} \mathrm{em}^{2}$ 10 pacientes com SDRA (ventilados inicialmente com estratégia protetora e posteriormente de forma convencional) demonstraram haver diferença nas PEEP total e intrínseca entre as duas estratégias $\left(16,3 \pm 2,9\right.$ e $5,8 \pm 3 \mathrm{cmH}_{2} \mathrm{O}$ respectivamente, durante estratégia protetora, versus $11,7 \pm 0,9$ e $1,4 \pm 1 \mathrm{cmH}_{2} \mathrm{O}$, respectivamente, durante estratégia convencional $\left.-\mathrm{p}<0,01\right)$. Concluíram que a diferença de mortalidade observada entre os grupos neste estudo do ARDS net pode ter sido causada pelo efeito protetor de níveis de PEEP totais mais elevados no grupo da ventilação protetora. ${ }^{(41)}$ Lee e colaboradores (42), após análise retrospectiva de um subgrupo de pacientes incluídos no estudo ARDSnet ${ }^{(26)}$, já haviam demonstrado que a estratégia com baixos VT era geradora de PEEP intrínseco nos pacientes ventilados com frequiência respiratória superior à 24 irpm. ${ }^{(42)}$

Amato e associados ${ }^{(27)}$ demonstraram os benefícios do OLC em um estudo prospectivo realizado em dois centros brasileiros, envolvendo 53 pacientes com SDRA precoce. Os pacientes foram randomizados para ventilação convencional (24 pacientes) ou protetora (29 pacientes). O primeiro grupo era ventilado com a menor PEEP necessária para oxigenação adequada $\left(\mathrm{PaO}_{2}=80 \mathrm{mmHg}\right), \mathrm{VT}=12 \mathrm{~mL} / \mathrm{kg}$ e $\mathrm{PaCO}_{2}$ entre 35 
e $38 \mathrm{mmHg}$. O grupo da estratégia protetora foi ventilado com $\mathrm{VT}<6 \mathrm{~mL} / \mathrm{kg}$, hipercapnia permissiva, com limitação da Ppico abaixo de $40 \mathrm{cmH}_{2} \mathrm{O}$ e da pressão de distensão (diferença entre Pplatô e Ppico - driving pressure) abaixo de $20 \mathrm{cmH}_{2} \mathrm{O}$. Os valores da PEEP foram determinados pela curva pressão x volume (PxV), utilizando-se os valores situados $2 \mathrm{~cm}$ acima do ponto de inflexão inferior- Pflex. Quando Pplex não pôde ser identificado pela curva $\mathrm{PxV}$, o valor empírico de $16 \mathrm{cmH}_{2} \mathrm{O}$ de $\mathrm{PEEP}$ total foi utilizado. Manobras de recrutamento foram aplicadas. Os níveis de PEEP nas primeiras 36 horas do estudo neste grupo foram em média de 16,4 $\pm 0,4 \mathrm{cmH}_{2} \mathrm{O}$ versus $8,7 \pm 0,4 \mathrm{cmH}_{2} \mathrm{O}$ no grupo de ventilação convencional $(\mathrm{p}<0,001)$. Houve redução significativa de mortalidade em 28 dias com a estratégia protetora (38\% versus $71 \%$, respectivamente $-\mathrm{p}<0,001)$ e foram identificados três fatores com importância prognóstica: APACHE II, PEEP médio utilizado nas primeiras 36 horas (com efeito protetor indicado pelo coeficiente de $-0,15$ ) e $\mathrm{P}$ de distensão ( $\mathrm{P}$ dist) nas primeiras 36 horas (com efeito deletério de elevadas Pdist indicado pelo coeficiente de 0,06). ${ }^{(27)}$

O ARDS net publicou outro estudo (The ARDS Network Assessment of Low Tidal Volume and Elevated End-Expiratory Lung Volume to Obviate Lung Injury - ALVEOLI) ${ }^{(43)}$ no qual não demonstrou diferença de mortalidade intra-hospitalar e de tempo de ventilação mecânica, entre um grupo ventilado com PEEP baixas ajustadas pela tabela PEEP/FIO 2 do estudo ARDS net ${ }^{(26)}$ anterior (PEEP média alcançada de $8,3 \pm 3,2 \mathrm{cmH}_{2} \mathrm{O}$ ) e um segundo grupo ventilado com PEEP altas ajustadas por uma tabela altas PEEP/baixas $\mathrm{FIO}_{2}\left(\mathrm{PEEP}\right.$ média utilizada de 13,2 $\left.\pm 3,5 \mathrm{cmH}_{2} \mathrm{O}\right)$. Os outros parâmetros ventilatórios foram semelhantes nos dois grupos, objetivando VT=6 mL/kg e Pplatô $=30 \mathrm{cmH}_{2} \mathrm{O} .{ }^{(43)}$ No entanto, algumas dúvidas em relação à metodologia deste estudo persistem. ${ }^{(44)}$ Grasso e associados ${ }^{(45)}$ reproduziram as estratégias ventilatórias do ALVEOLI ${ }^{(43)}$ em 19 pacientes com SDRA, que foram inicialmente ventilados com baixas PEEP (segundo a tabela ARDS net original) ${ }^{(26)}$ por 12 horas e, posteriormente, com altas PEEP (obedecendo a tabela altas PEEP/baixas $\mathrm{FIO}_{2}$ do ALVEOLI) ${ }^{(43)}$ por mais 12 horas. Durante cada estratégia 
curva PxV foi realizada. O volume recrutado foi definido como a diferença de volume pulmonar para a mesma pressão de abertura estática, observada quando a ventilação com baixas PEEP era substituída por PEEP elevadas. Os pacientes que obtive ram uma diferença de volume pulmonar maior do que $150 \mathrm{~mL}$ foram considerados recrutados pela estratégia com PEEP altas. As ventilações com baixas PEEP e com altas PEEP foram feitas com PEEP médias significativamente diferentes $\left(9 \pm 2\right.$ e $16 \pm 1 \mathrm{cmH}_{2} \mathrm{O}$, respectivamente $-\mathrm{p}<0,05)$. Observaram que apenas 9 dos 19 pacientes foram recrutados quando ventilados com PEEP altas. No grupo de pacientes classificados como recrutados, houve significativa elevação da $\mathrm{PaO}_{2} / \mathrm{FIO}_{2}(\mathrm{de}$ $150 \pm 36$ para $396 \pm 138$ - p < 0,05) e importante redução da elastância estática (de $23 \pm 3$ para $\left.20 \pm 2 \mathrm{cmH}_{2} \mathrm{O} / \mathrm{L}-\mathrm{p}<0,05\right)$ quando altas PEEP foram utilizadas (em relação aos valores basais). Nos 10 pacientes não recrutados, PEEP altas não resultaram em melhor oxigenação e promoveram aumento da elastância. A conclusão foi a de que o protocolo ALVEOLI ${ }^{(43)}$ provavelmente não é capaz de induzir recrutamento alveolar significativo em um grande número de pacientes, podendo promover hiperinsuflação. Isto pode ter contribuído para a ausência de benefício da ventilação com altas PEEP observada neste estudo. $^{(45)}$

Em 2006, Villar e colaboradores ${ }^{(46)}$, fazendo parte do ARIES Network (Acute Respiratory Insufficiency: España Study) divulgaram outro estudo multicêntrico que corroborou os benefícios do OLC. Cento e três pacientes, que após $24 \mathrm{~h}$ do diagnóstico de $\mathrm{SDRA}^{(6)}$ permaneceram com $\mathrm{PaO}_{2} / \mathrm{FIO}_{2}=200$ durante ventilação com PEEP $=5 \mathrm{cmH}_{2} \mathrm{O}$ e $\mathrm{FIO}_{2}=0,5$, foram incluídos. Em seguida, foram divididos em duas estratégias ventilatórias: convencional (grupo controle com 50 pacientes) e protetora (53 pacientes). No primeiro grupo, utilizou-se VT entre 9 e $11 \mathrm{~mL} / \mathrm{kg}, \mathrm{PEEP}=5 \mathrm{cmH}_{2} \mathrm{O}$ e $\mathrm{FIO}_{2}$ necessária para manter $\mathrm{SaO}_{2}>90 \%$ e $\mathrm{PaO}_{2}$ entre 70 e $100 \mathrm{mmHg}$. Os pacientes da estratégia protetora foram ventilados com VT entre 5 e $8 \mathrm{~mL} / \mathrm{kg}$, nível da PEEP colocado $2 \mathrm{~cm}$ acima do ponto de inflexão inferior da curva $\mathrm{PxV}_{\mathrm{x}}$ FIO 2 necessária para manter $\mathrm{SaO}_{2}>90 \%$ e $\mathrm{PaO}_{2}$ entre 70 e $100 \mathrm{mmHg}$. A FIO 2 era reduzida antes da PEEP caso 
a oxigenação permanecesse acima dos limites determinados e a PEEP era elevada antes da $\mathrm{FIO}_{2}$ caso a oxigenação fosse inferior ao estabelecido. A estratégia protetora determinou redução significativa de mortalidade no CTI (32\% versus 53,3\% - $\mathrm{p}=0,04)$ e hospitalar $(34 \%$ versus $55,5-\mathrm{p}<0,04) .{ }^{(46)}$

Dois recentes estudos multicêntricos, randomizados e controlados avaliaram os efeitos da PEEP no prognóstico de pacientes com LPA / SDRA. No estudo LOV (Lung Open Ventilation), ${ }^{(47)}$ todos os participantes foram ventilados com VT $=6 \mathrm{~mL} / \mathrm{kg}$. No grupo da estratégia convencional (508 pacientes) adotou-se o protocolo ARDSnet ${ }^{(26)}$, sendo a PEEP ajustada de acordo com uma tabela de oxigenação. $\mathrm{O}$ grupo experimental (com 475 pacientes) foi ventilado de acordo com o OLC: manobras de recrutamento com insuflação sustentada de $40 \mathrm{cmH}_{2} \mathrm{O}$ por $40 \mathrm{~s}$ foram realizadas, utilizando-se para ajuste da PEEP uma tabela de oxigenação baseada no protocolo ARDSnet ${ }^{(26)}$, porém com níveis de PEEP superiores. A média dos valores de PEEP no primeiro dia no grupo experimental foi de 15,6 versus 10,1 no grupo convencional. Não houve diferença estatisticamente significativa na mortalidade intra-hospitalar entre os dois grupos (36,4\% no grupo experimental versus $40,4 \%$ no grupo convencional $-\mathrm{p}=0,19)$. Porém, no grupo experimental houve menor grau de hipoxemia refratária $(4,6 \%$ versus $10,2 \%$, risco relativo $-\mathrm{RR}-0,54 ; 95$ $\%$ IC 0,34 - 0,86; $\mathrm{p}=0,01)$, menor número de mortes por hipoxemia refratária $(4,2 \%$ versus $8,9 \%$; $\mathrm{RR}=$ $0,56 ; 95 \% \mathrm{IC}=0,34-0,93 ; \mathrm{p}=0,03)$ e menor necessidade de terapias de regate $(5,1 \%$ versus $9,3 \%$; $\mathrm{RR}=0,61 ; 95 \% \mathrm{IC}=0,38-0,99 ; \mathrm{p}=0,45) .{ }^{(47)} \mathrm{O}$ segundo estudo, Express $\left(\right.$ Expiratory Pressure Study) ${ }^{(48)}$ também utilizou ventilação com $6 \mathrm{~mL} / \mathrm{kg}$ nos dois grupos avaliados. No grupo da "estratégia de mínima distensão" (382 pacientes) PEEP e Pplatô foram mantidos nos valores mais baixos possíveis para alcançar os objetivos de oxigenação. No grupo da "estratégia de máximo recrutamento" (385 pacientes) PEEP foi mantida o mais elevada possível, desde que a Pplatô não ultrapassasse 28 a $30 \mathrm{cmH}_{2} \mathrm{O}$, sem que os efeitos na oxigenação fossem levados em consideração. No primeiro dia do estudo, a PEEP média no grupo de mínima distensão foi de 8,4 versus 15,8 no grupo de máximo recrutamento. Igualmente ao LOV ${ }^{(38 \mathrm{~A})}$ não se 
observou diferença de mortalidade intra-hospitalar entre os dois grupos (35,4 \% no grupo de máximo recrutamento versus $39 \%$ no grupo de mínima distensão - p =0,30). No entanto, a estratégia de máximo recrutamento quando comparada à de mínima distensão determinou melhor função pulmonar $(\mathrm{p}=0,01$ para complacência do sistema respiratório e p $<0,001$ para $\mathrm{PaO}_{2} / \mathrm{FIO}_{2}$ aferidos no primeiro dia do estudo) e menores durações de ventilação mecânica $(p=0,04)$ e de falência orgânica $(p=0,04){ }^{(48)}$

\section{6-Determinação da PEEP “ideal":}

Após análise dos estudos existentes com estratégias protetoras descritos anteriormente, fica claro que a melhor forma de ajuste da PEEP ainda não foi definida. O nível ideal da PEEP é aquele capaz de manter o máximo de recrutamento alveolar com o mínimo de hiperdistensão (a melhor relação entre recrutamento e hiperinsuflação), minimizando também abertura e fechamento cíclico dos alvéolos. ${ }^{(49)} \mathrm{O}$ limite superior a partir do qual a PEEP deixa de ser benéfica e passa a ser lesiva é de difícil determinação. Diversas técnicas são utilizadas objetivando uma melhor definição do nível adequado de PEEP, porém a superioridade de uma sobre as outras ainda não foi identificada. ${ }^{(50)}$

\section{A-Curva PxV:}

A interpretação da curva $\mathrm{PxV}$ era inicialmente baseada em dois pontos de inflexão presentes na porção ascendente, o inferior (abaixo do qual haveria desrecrutamento alveolar) e o superior (acima do qual existiria hiperinsuflação). ${ }^{(51)}$ Porém, estudos mais recentes demonstraram que o recrutamento alveolar é contínuo ao longo da alça inspiratória, não estando restrito a um ponto específico da curva (figura 1 ). ${ }^{(52 ; 53)}$ 


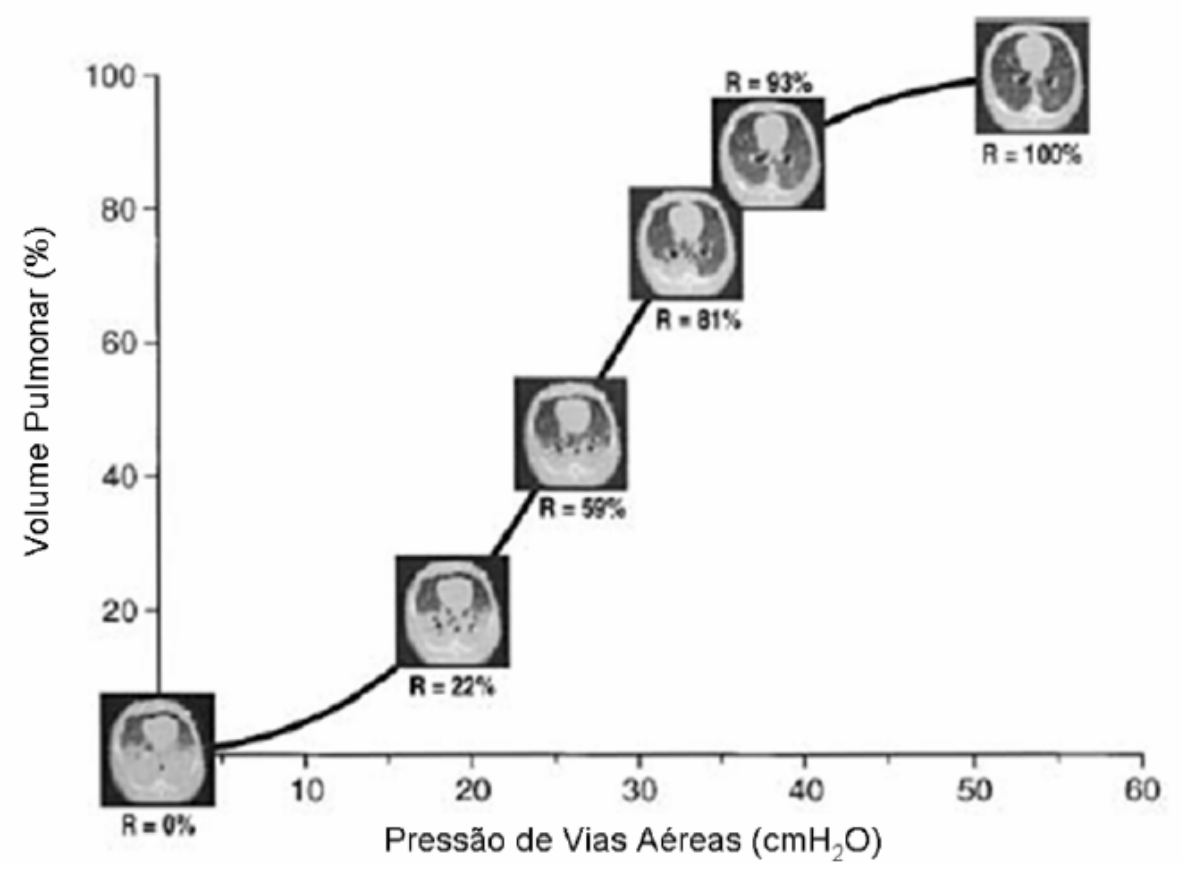

Figura 1. Curva PxV em um modelo experimental de SDRA induzida por ácido oléico em cachorros. Observar o recrutamento contínuo das unidades alveolares ao longo de toda a faixa da curva PxV. R representa a percentagem de recrutamento que ocorre para o respectivo incremento de pressão. ${ }^{(52)}$

O ponto de inflexão inferior reflete, na realidade, o início do recrutamento e o ponto de inflexão superior retrata, de forma mais fidedigna, perda gradual do recrutamento e não necessariamente hiperdistensão. ${ }^{(54)}$ Assim, a presença de um ponto de inflexão inferior indica que, a partir de uma certa pressurização, uma porção maior de unidades alveolares passaram a ser aeradas. Albaiceta e colaboradores ${ }^{(55)}$ estudaram o comportamento da curva PxV através de imagens tomográficas realizadas em 12 pacientes com SDRA. Constataram que aumento de aeração e de recrutamento aconteceu de forma contínua ao longo do eixo de pressão, durante insuflação e que a perda de aeração e o desrecrutamento só foram significativos em níveis pressóricos localizados abaixo do ponto de máxima curvatura no ramo descendente da curva PxV. Este ponto estava associado a maior quantidade de tecido normalmente aerado e a menor quantidade de tecido não aerado, quando comparado aos pontos de inflexão inferior das alças ascendente e descendente. ${ }^{(55)}$ 
Recentemente, diversos trabalhos vêm demonstrando a superioridade da análise de múltiplas curvas PxV para identificação do grau de recrutamento determinado por diferentes PEEP. ${ }^{(56)}$

A construção da curva PxV é feita tradicionalmente nos laboratórios desconectando-se as vias aéreas da ventilação mecânica e utilizando-se uma superseringa para administração e retirada de pequenas alíquotas de volume com a concomitante mensuração dos níveis pressóricos. Esta técnica de pesquisa é de difícil realização na prática clínica, podendo não ser totalmente relevante para a seleção da PEEP ideal. A desconexão do ventilador representa um risco para o paciente, alterando também as características do pulmão. Além disto, a realização da curva PxV em um único procedimento, por ser uma manobra de recrutamento, pode hiperestimar o número de unidades alveolares aeradas para uma dada pressão da alça inspiratória, dificultando sua interpretação. ${ }^{(50)}$

\section{B-Complacência pulmonar:}

Hickling ${ }^{(57)}$, utilizando um modelo matemático de um pulmão com SDRA, demonstrou não haver relação entre o nível de PEEP associado à máxima inclinação da curva PxV e a PEEP mínima necessária para prevenir o colapso expiratório de 97,5\% dos alvéolos recrutados ao final da inspiração (open lung PEEP), durante manobra de PEEP crescentes. No entanto, quando foi utilizada a manobra de PEEP decrescentes, a relação entre PEEP e a inclinação da curva PxV tornou-se consistente, com PEEP associada à máxima inclinação da curva PxV estando muito próximo do valor do open lung PEEP. Estes resultados são importantes porque a inclinação estática média da curva PxV pode ser estimada à beira do leito a partir da Pplatô e do nível de PEEP. Assim, a determinação do valor do open lung PEEP à beira do leito pode ser realizada utilizando-se PEEP decrementais versus melhor complacência. ${ }^{(57)}$ 
C-Análises quantitativas de imagens tomográficas:

Análises quantitativas das densidades radiológicas das imagens tomográficas do pulmão forneceram informações cruciais com relação à fisiopatologia da LPA/SDRA. É possível avaliar os efeitos de diferentes PEEP, quantificando-se o grau de recrutamento e hiperinsuflação alveolar. Estas análises são baseadas na estreita correlação entre a atenuação do RX em um determinado volume de tecido (voxel - unidade tomográfica de volume) e a densidade física deste volume pulmonar (a razão massa/volume). O grau de atenuação do RX em imagens tomográficas pode ser expresso por número de TC (N TC) ou unidades Hounsfield (HU). Este número de TC é determinado em um dado voxel a partir do percentual de radiação absorvida por este volume pulmonar. Desta forma, quanto maior for a absorção de RX pelo tecido, menos radiação será coletada pelo detector. A escala de atenuação arbitrariamente assume que o osso apresenta máxima absorção (+1000 HU) atribuindo ao ar mínima absorção (-1000 HU) e, à água o valor de zero HU. O sangue e o tecido conjuntivo apresentam valores entre 20 e $40 \mathrm{HU}$. A relação entre a densidade física, em qualquer região pulmonar de interesse, assumindo que o peso específico do tecido é igual a 1, pode ser expressa como a equação à seguir (Equação E1):

Volume gás $_{\text {g }}\left(\right.$ Volume gás $_{\text {golume }}+$ tecido $)=$ Média do N TC observado / $\left(\mathrm{N} \mathrm{TC}_{\text {gás }}-\mathrm{N} \mathrm{TC}_{\text {água }}\right)$ Rearrumando a equação E1 é possível computar para qualquer região de interesse (voxels contíguos), onde o volume total é conhecido, o volume de gás, o volume (e o peso) do tecido e a relação gás / tecido. ${ }^{(12)}$ A massa de cada voxel, representando sua massa de parênquima, pode ser calculada como: Massa voxel $=(\mathrm{N} \mathrm{TC}+1000) \mathrm{x}$ Volume $_{\text {voxel }} / 1000$. Conhecendo a freqüência de distribuição do número de TC em uma região de interesse, assim como seu volume total é possível estimar a quantidade de tecido ou de massa de parênquima. ${ }^{(12)}$

É importante atentar que a densidade de um voxel é determinada pela soma das densidades das estruturas contidas neste volume. No caso do parênquima pulmonar, estas estruturas são a água, o tecido 
pulmonar e o ar. Como a densidade física é uma razão, o aumento de densidade em um voxel pode ser causado por menos gás ou mais tecido. Isto pode representar um problema principalmente na fase aguda da LPA/SDRA, onde os volumes de líquido intersticial e alveolar são altos fazendo com que a densidade do voxel aumente subestimado a real aeração alveolar. Na dependência das dimensões do voxel e do pulmão tomografado, diferentes estruturas anatômicas podem estar contidas neste voxel. Um voxel com dimensões entre $16-22 \mathrm{~mm}^{3}$ engloba cerca de 2000 unidades alveolares e possui o mesmo volume de um ácino normal na capacidade residual funcional. Aumentos de insuflação fazem com que o voxel contenha menos estruturas, uma vez que com $75 \%$ da capacidade pulmonar total, os volumes dos ácinos tornam-se maiores do que os dos voxel. Quando, no entanto, o ácino colapsa perdendo todo o seu gás, um voxel conterá 15 a 20 ácinos colapsados e seu volume será representado apenas por capilares e sangue. ${ }^{(12)}$

A definição de recrutamento nos protocolos de análises quantitativas varia. Alguns autores definem como a diferença de tecido não aerado observada em condições ventilatórias diversas. ${ }^{(58)}$ Outros determinam como recrutamento não só a quantidade de tecido não aerado, mas também a de tecido pouco aerado que se torna preenchida por ar. ${ }^{(59)}$ As medidas podem ser realizadas sob a forma de alterações de volume de tecido pulmonar não aerado (número de voxels) ${ }^{(60)}$ ou computando-se alterações de peso (em gramas) de tecido normalmente aerado ou pela determinação do peso de tecido consolidado ${ }^{(61)}$.

A técnica adotada para a obtenção das imagens que serão estudadas é de extrema importância, pois pode modificar o resultado final. A análise do grau de recrutamento em uma seção (justadiafragmática) subestima o recrutamento alveolar, já que retrata o comportamento da área menos recrutável do pulmão. Por outro lado, a avaliação de recrutamento em três seções $(2 \mathrm{~cm}$ acima da carina, $1 \mathrm{~cm}$ abaixo da carina e $1 \mathrm{~cm}$ acima da cúpula diafragmática) hiperestima o recrutamento, pois as regiões apical e hilar são mais representativas dos lobos superiores, que são as porções mais recrutáveis do pulmão. ${ }^{(62)}$ Puybasset e associados ${ }^{(60)}$ realizaram imagens tomográficas de pulmões com LPA (com cortes do ápice ao diafragma) 
inicialmente em ZEEP e, posteriormente, com PEEP $=10 \mathrm{cmH}_{2} \mathrm{O}$. Observaram que as áreas não aeradas predominaram nas regiões justadiafragmáticas e que o recrutamento alveolar induzido por PEEP foi mais pronunciado nas regiões não dependentes do que nas dependentes e nas regiões cefálicas em relação às regiões caudais. O grau de recrutamento alveolar induzido por PEEP foi inversamente correlacionado ao volume de pulmão não aerado observado em ZEEP. ${ }^{(60)}$

A medida de hiperinsuflação também é influenciada pelo número de cortes tomográficos e suas espessuras. Nieszkowska e colaboradores ${ }^{(63)}$ ao avaliarem imagens tomográficas (cortes de $10 \mathrm{~mm}$ ) de 32 pacientes com LPA, realizadas em ZEEP e em PEEP $=15 \mathrm{cmH}_{2} \mathrm{O}$, ao final da expiração, comprovaram que a hiperinsuflação também possui distribuição regional ao longo do pulmão, predominando nas regiões caudais e anteriores, $2 \mathrm{~cm}$ abaixo da cúpula diafragmática. Este resultado demonstra que para avaliar hiperinsuflação, a TC de todo o pulmão também é mais fidedigna em comparação com cortes regionais. ${ }^{(63)}$ Vieira e associados ${ }^{(64)}$ demonstraram que TC com baixa resolução espacial subestima a hiperinsuflação induzida por PEEP. Compararam análises quantitativas de imagens tomográficas realizadas com cortes espessos $(10 \mathrm{~mm})$ e finos $(1,5 \mathrm{~mm})$, em 30 pacientes com LPA ventilados em ZEEP e com $\mathrm{PEEP}=10 \mathrm{cmH}_{2} \mathrm{O}$. Cortes espessos subestimaram o volume de hiperinsuflação em $3 \%$ em ZEEP e em $5 \%$ com PEEP $=10 \mathrm{cmH}_{2} \mathrm{O}$. Nos pacientes com perda difusa de aeração em ZEEP, os valores subestimados de hiperinsuflação, apesar de estatisticamente significativos, não tiveram relevância clínica $(0,6 \pm 0,8 \mathrm{~mL}$ com cortes espessos versus $16 \pm 10 \mathrm{~mL}$ com cortes finos em ZEEP $-\mathrm{p}<0,01$ e $8 \pm 9 \mathrm{~mL}$ com cortes espessos versus $73 \pm 62 \mathrm{~mL}$ com cortes finos, em PEEP - p < 0,05). No entanto, naqueles com perda focal de aeração em ZEEP, a magnitude de subestimação foi mais pronunciada $(18 \pm 56 \mathrm{~mL}$ com cortes espessos versus $127 \pm 140 \mathrm{~mL}$ com cortes finos em ZEEP $-\mathrm{p}<0,01$ e $85 \pm 161 \mathrm{~mL}$ com cortes espessos versus $322 \pm 292 \mathrm{~mL}$ com cortes finos, com PEEP $\left.=10 \mathrm{cmH}_{2} \mathrm{O}-\mathrm{p}<0,01\right){ }^{(64)}$ 
A fase do ciclo respiratório em que são feitas as imagens tomográficas também altera a quantificação de recrutamento e hiperinsuflação. Medidas com imagens obtidas ao final da expiração subestimam o grau de hiperinsuflação. ${ }^{(63)}$

Rouby e colaboradores ${ }^{(65-67)}$ utilizando um sistema de codificação em cores (Lungview) demonstraram que, de acordo com a morfologia pulmonar observada na TC realizada com PEEP $=0$ (ZEEP) existem diferenças na mecânica pulmonar e na resposta à aplicação da PEEP. Em pulmões com atenuações difusas na TC (SDRA difusa), a aplicação de $\mathrm{PEEP}=10 \mathrm{cmH}_{2} \mathrm{O}$ induz recrutamento alveolar sem hiperinsuflação. Por outro lado, em pulmões onde as atenuações na TC predominam nos lobos inferiores (SDRA lobar), $\mathrm{PEEP}=10 \mathrm{cmH}_{2} \mathrm{O}$ induz menos recrutamento alveolar à custa de maior hiperinsuflação e maior comprometimento hemodinâmico. Os pulmões com padrão de atenuações bilaterais, porém salteadas (SDRA patchy, salteada), possuem um comportamento intermediário. ${ }^{(65-67)}$

\section{7-Estudos tomográficos quantitativos com estratégias ventilatórias protetoras:}

Estudos quantitativos de imagens tomográficas ofereceram uma forma alternativa de análise do comportamento pulmonar durante estratégias ventilatórias protetoras, porém sem oferecer resposta definitiva às dúvidas existentes.

Terragni e associados ${ }^{(68)}$ estudaram o comportamento pulmonar de 30 pacientes com SDRA precoce ventilados com o protocolo ARDS net. ${ }^{(26)}$ Imagens tomográficas de todo o pulmão foram realizadas ao final de expiração e da inspiração. Insuflação protegida e hiperinsuflação foram definidas como as diferenças entre os volumes dos compartimentos pulmonares normalmente aerados e hiperinsuflados observados ao final da inspiração e os observados ao final da expiração, respectivamente. Lavado broncoalveolar para mensuração de citocinas foi coletado após TC. Após análise dos resultados, dois grupos de pacientes foram identificados: o grupo dos mais protegidos (20 pacientes) onde insuflação protegida e hiperinsuflação 
representaram, respectivamente, $69,9 \pm 6,9 \%$ versus $8,1 \pm 5,4 \%$ das alterações inspiratórias visualizadas na TC e o grupo dos menos protegidos (10 pacientes) onde insuflação protegida e hiperinsuflação determinaram, respectivamente, $23,1 \pm 14,4 \%$ versus $63 \% \pm 12,7 \%$ das alterações inspiratórias visualizadas na TC. Durante a inspiração, observoutse aumento progressivo do compartimento normalmente aerado nos pacientes mais protegidos, enquanto que nos pacientes menos protegidos a inspiração determinou redução progressiva do compartimento normalmente aerado e aumento do compartimento hiperinsuflado. Quando comparados ao grupo dos menos protegido, os pacientes mais protegidos apresentaram menores compartimentos não aerados e maiores compartimentos normalmente aerados. As concentrações de IL-6, IL-1ß, IL-8 e dos receptores solúveis de TNF-a foram significativamente superiores no grupo menos protegido em relação ao mais protegido $(\mathrm{p}<0,05)$. O número de dias livres de ventilação mecânica foi de $7 \pm 8$ dias no grupo mais protegido versus $1 \pm 2$ dias no grupo menos protegido $(\mathrm{p}=0,01)$. Os valores da Pplatô no grupo mais protegido estiveram entre 25 e $26 \mathrm{cmH}_{2} \mathrm{O}$ e no grupo menos protegido entre 28 e 30 $\mathrm{cmH}_{2} \mathrm{O}(\mathrm{p}=0,006)$. Não houve diferença estatisticamente significativa na mortalidade em 28 dias $(30 \%$ no grupo mais protegido versus $40 \%$ no menos protegido). Hiperinsuflação foi a única variável independentemente associada com concentrações de citocinas e número de dias de ventilação mecânica. Os resultados deste estudo demonstraram que a estratégia ARDS net ${ }^{(26)}$ (mesmo limitando o VT em $6 \mathrm{~mL} / \mathrm{kg}$ e a Pplatô em $30 \mathrm{cmH}_{2} \mathrm{O}$ ) pode não conferir proteção para pacientes com SDRA que possuem um compartimento normalmente aerado pequeno e um grande compartimento não aerado. Nestes pacientes níveis mais baixos de Pplatô parecem ser necessários para reduzir hiperinsuflação. ${ }^{(68)}$

Gattinoni e colaboradores ${ }^{(69)}$ no intuito de determinar a relação entre percentagem de pulmão potencialmente recrutável, definida por TC e os efeitos da PEEP, avaliaram 68 pacientes com um tempo médio de ventilação mecânica de $5 \pm 6$ dias. Destes, 19 possuíam LPA e 49 SDRA. Tomografias computadorizadas de todo o pulmão foram realizadas, com cortes e intervalos de $5 \mathrm{~mm}$.As imagens foram 
feitas com Pplatô $=45 \mathrm{cmH}_{2} \mathrm{O}$, após 15 a 25 segundos de pausa ao final da inspiração e posteriormente com valores de PEEP de 5 e $15 \mathrm{cmH}_{2} \mathrm{O}$, durante 15 a 25 segundos de pausa expiratória. Imediatamente antes de cada imagem, realizava-se uma manobra de recrutamento, que consistia em ventilação por 2 min em PCV, com Pinspiratória de $45 \mathrm{cmH}_{2} \mathrm{O}$ e $\mathrm{PEEP}=5 \mathrm{cmH}_{2} \mathrm{O}$, com freqüência respiratória de 10 irpm e relação $\mathrm{I}: \mathrm{E}=1: 1)$. A percentagem de pulmão potencialmente recrutável foi definida como a proporção do peso total do pulmão representada por tecido pulmonar não aerado (definida por TC) na qual a aeração era restaurada por uma pressão de vias aéreas de $45 \mathrm{cmH}_{2} \mathrm{O}$, partindo-se de uma pressão de $5 \mathrm{cmH}_{2} \mathrm{O}$. Os pacientes foram separados em quatro quartis de acordo com o percentual de pulmão potencialmente recrutável. Observaram que, em todos os quartis, elevação na pressão das vias aéreas de 5 para 15 e para $45 \mathrm{cmH}_{2} \mathrm{O}$ determinou aumento progressivo na percentagem de tecido hiperinsuflado e normalmente aerado $(\mathrm{p}<0,01$, para cada uma das variáveis) em paralelo a uma redução na percentagem de tecido não aerado ( $p<0,01)$. Nos quatro quartis $24 \%$ do pulmão não puderam ser recrutados, mesmo com pressão de vias aéreas de $45 \mathrm{cmH}_{2} \mathrm{O}$. $\mathrm{A}$ redução na percentagem de tecido não aerado com elevação da $\mathrm{PEEP}$ de 5 para $15 \mathrm{cmH}_{2} \mathrm{O}$ apresentou elevada correlação com a percentagem de tecido pulmonar potencialmente recrutável $\left(R^{2}=0,72 ; p<0,001\right)$. Os pacientes com a maior percentagem de tecido recrutável apresentaram maiores pesos pulmonares totais $(\mathrm{p}<0,01)$ e valores inferiores de $\mathrm{PaO}_{2} / \mathrm{FIO}_{2}(\mathrm{p}<0,01)$ e de complacências do sistema respiratório $(\mathrm{p}=$ 0,002), maiores níveis de espaço morto $(\mathrm{p}=0,02)$ e maior taxa de mortalidade $(\mathrm{p}=0,02)$ quando comparados ao grupo com menor percentagem de pulmão potencialmente recrutável. SAPS II e percentagem de pulmão potencialmente recrutável foram fatores independentemente associados a maior risco de morte. A combinação de medidas fisiológicas que melhor identificou os pacientes com elevado potencial de recrutamento foi a presença de pelo menos dois dos critérios: $\mathrm{PaO}_{2} / \mathrm{FIO}_{2}<150$ com $\mathrm{PEEP}=5 \mathrm{cmH}_{2} \mathrm{O}$, qualquer redução no espaço morto alveolar ou qualquer incremento na complacência do sistema respiratório quando a PEEP foi elevada de 5 para $15 \mathrm{cmH}_{2} \mathrm{O}$ (sensibilidade $=79 \%$; 
especificidade $=81 \%$ ). Concluíram que a percentagem de pulmão potencialmente recrutável em pacientes com SDRA é variável e está diretamente relacionada à resposta a PEEP. Assim, preconizam que valores de PEEP > $15 \mathrm{cmH}_{2} \mathrm{O}$ sejam utilizados apenas nos pacientes com elevada percentagem de pulmão recrutável. Nos demais, preconizam valores de PEEP $<10 \mathrm{cmH}_{2} \mathrm{O} .{ }^{(69)}$

Borges e colaboradores ${ }^{(70)}$ utilizaram análises quantitativas de TC para determinar o grau de aplicabilidade clínica de uma estratégia de recrutamento capaz de reverter hipoxemia e colapso, em mais de 95\% das unidades alveolares, em pacientes com LPA/SDRA recente. Vinte e seis pacientes foram submetidos a uma estratégia de recrutamento máxima, realizada em modo pressão-controlada (PCV) com ? $\mathrm{P}=15 \mathrm{cmH}_{2} \mathrm{O}$. Nos primeiros 4 minutos os pacientes foram ventilados com $\mathrm{PEEP}=25 \mathrm{cmH}_{2} \mathrm{O}$. Posteriormente, os níveis de PEEP foram elevados seqüencialmente em $5 \mathrm{cmH}_{2} \mathrm{O}$ e a ventilação mantida por dois minutos com cada valor de PEEP (mantendo-se ? $\mathrm{P}=15 \mathrm{cmH}_{2} \mathrm{O}$ ) havendo sempre entre cada incremento, períodos de repouso (ventilações com PEEP $=25 \mathrm{cmH}_{2} \mathrm{O}$ ). Os aumentos nos valores de PEEP foram realizados até que $\mathrm{PaO}_{2}+\mathrm{PaCO}_{2}=400 \mathrm{mmHg}$. A manobra foi considerada ineficaz caso o objetivo gasométrico não fosse atingido com Pinspiratória $=60 \mathrm{cmH}_{2} \mathrm{O}$. A manobra de recrutamento máximo foi realizada sempre após ventilação basal ou OLC $\left(\mathrm{CPAP}=40 \mathrm{cmH}_{2} \mathrm{O}\right.$ por $40 \mathrm{~s}$, seguido de ventilação com PEEP titulado pela curva $\mathrm{PxV}, 2 \mathrm{~cm}$ acima do ponto de inflexão inferior). Após a manobra de recrutamento máximo titulação de PEEP foi realizada, sendo o nível de PEEP ótimo determinado pelo menor valor capaz de manter $\mathrm{PaO}_{2}+\mathrm{PaCO}_{2}=400 \mathrm{mmHg}$. Nova manobra de recrutamento com as mesmas pressões utilizadas na última etapa da manobra de recrutamento máximo foi realizada posteriormente à titulação da PEEP ótima. A manutenção da eficácia da manobra de recrutamento máximo foi avaliada em 11 pacientes através de TC durante pausa expiratória, realizada 30 minutos após titulação da PEEP ótima. Nos demais a avaliação foi feita através de medidas oxihemodinâmicas e de radiografia de tórax, após 6 horas de ventilação com PEEP ótima e VT < 6 mL/kg. Observou-se melhora significativa da oxigenação $(\mathrm{p}=0,001$ 
quando comparada a ventilação basal ou OLC) e redução na percentagem de tecido colapsado (p $<0,01$ quando comparada com OLC ou ventilação basal). Recrutamento total foi alcançado na maioria dos pacientes (24 / 26) e nenhum apresentou aumento de hiperinsuflação. Oxigenação foi mantida, ou aumentou, durante o período de manutenção do recrutamento. Houve uma forte correlação inversa entre oxigenação arterial e quantidade de massa de tecido colapsado na TC multislice $(\mathrm{R}=-0,91)$. Níveis de $\mathrm{PaO}_{2}$ $>320 \mathrm{mmHg}$ com $\mathrm{FIO}_{2}=1$ (equivalente a índice $\mathrm{PaO}_{2}+\mathrm{PaCO}_{2}=400 \mathrm{mmHg}$ ) foi um bom indicador de recrutamento pulmonar máximo ( $<5 \%$ de unidades pulmonares colapsadas - área $\mathrm{ROC}=0,943)$. A curva de freqüência de distribuição do limiar das pressões de abertura apresentou forma bimodal, sugerindo haver duas populações de alvéolos em termos de pressão de abertura. Aqueles situados nas regiões mais dependentes do pulmão apresentam atelectasias completas, necessitando de pressões de abertura superiores a 35-40 $\mathrm{cmH}_{2} \mathrm{O}$ para serem recrutados. Após a aplicação de Pplatô $=60 \mathrm{cmH}_{2} \mathrm{O}$ apenas 2 dos 26 pacientes não atingiram os critérios de recrutamento máximo. Durante a manobra de titulação da PEEP (descrita anteriormente) o nível ótimo de PEEP situou-se em torno de $20 \mathrm{cmH}_{2} \mathrm{O}$. Com relação aos efeitos colaterais, observou-se redução transitória de índice cardíaco durante a manobra de recrutamento máximo, sem consequiências clínicas. Foram relatados dois casos de barotrauma, que aconteceram após o término do protocolo. Os autores concluíram ser possível reverter hipoxemia e alcançar recrutamento total dos pulmões em pacientes com LPA/SDRA. No entanto, em decorrência dos efeitos colaterais transitórios, são necessários mais estudos antes da utilização clínica da manobra de recrutamento máximo. ${ }^{(70)}$

\section{8-Questionamentos:}

Apesar de ser consenso que pacientes com LPA/ SDRA devem ser ventilados com baixos VT e com limitação de pressão em vias æéreas, controvérsia ainda existe com relação a melhor estratégia para definição da PEEP ótima. Deve-se utilizar uma escala arbitrária de oxigenação ou procurar formas mais 
fisiológicas de ajuste? Qual o papel do recrutamento? Quais seriam os efeitos da combinação de diferentes estratégias ventilatórias protetoras de acordo com a resposta individual? ${ }^{(26)(27)(71)}$ Estudos com modelos animais de SDRA demonstram que níveis mais elevados de PEEP previnem VALI. ${ }^{(72)}$ No entanto, os modelos animais de SDRA são caracterizados por intenso edema pulmonar, onde elevados níveis de PEEP são efetivos. Em humanos a proporção de casos com predomínio de edema pulmonar e colapso pode variar. Assim, estudos clínicos que elucidem estas perguntas são necessários. ${ }^{(71)}$

Níveis plasmáticos de citocinas têm sido associados com mortalidade na LPA / SDRA. ${ }^{(17-19)}$ Ventilação utilizando elevados VT está associada a maiores concentrações plasmáticas e pulmonares de citocinas quando comparada a estratégias protetoras. ${ }^{(9)}$

Existe diferença com relação à liberação de citocinas entre duas estratégias protetoras? Poucos estudos compararam diferentes estratégias protetoras com relação à cinética das citocinas. ${ }^{(43)}$ Porém, esta comparação no que concerne análises quantitativas de imagens tomográficas ainda não foi realizada. Os efeitos de estratégias ventilatórias protetoras aplicadas de forma seqüencial, de acordo com o grau de resposta individual, também não foram determinados.

\section{3-Objetivos:}

\section{Objetivo Primário:}

- Avaliar estratégias protetoras de ventilação aplicadas a pacientes com LPA / SDRA, no que concerne à função pulmonar (oxigenação), imagem tomográfica e atividade inflamatória (liberação de citocinas).

\section{Objetivo Secundário:}

- Comparar a cinética das citocinas nos compartimentos estudados (pulmão e circulação sistêmica). 


\section{4-Pacientes e métodos:}

Este estudo fisiológico foi realizado no Hospital Copa D’Or (hospital terciário da cidade do Rio de Janeiro) nas suas três unidades de terapia intensiva: unidade neurointensiva (oito leitos) unidade clínica (14 leitos) e unidade pós-operatória (12 leitos). Os pacientes foram recrutados de forma prospectiva e aberta, em dois períodos: de agosto de 2005 a dezembro de 2005 e de junho de 2006 a novembro de 2007. O protocolo foi delineado de acordo com as Diretrizes e Normas Regulamentadoras de Pesquisas Envolvendo Seres Humanos (Resolução 196/1996 do Conselho Nacional de Saúde), aprovado pelo Comitê de Ética da istituição e consentimento informado foi obtido dos familiares dos pacientes.

Foram incluídos pacientes intubados que preencheram os critérios para LPASDRA, de acordo com a Conferência de Consenso de $1994^{(6)}$, com um tempo máximo de evolução de 48 horas. Para cálculo da $\mathrm{PaO}_{2} / \mathrm{FIO}_{2}$ gasometria arterial foi coletada após 30 minutos de ventilação com $\mathrm{VT}=10 \mathrm{~mL} / \mathrm{kg}$ (peso ideal), PEEP $=5 \mathrm{cmH}_{2} \mathrm{O}, \mathrm{FIO}_{2}=1$, freqüência respiratória $(\mathrm{FR})=15$, em modo ventilatório PCV ou PRVC, sendo o peso ideal determinado pela fórmula:

Homem: $50+0,91($ altura $-152,4)$

Mulher: 45,5 + 0,91 (altura - 152,4)

A idade mínima para inclusão foi de 18 anos.

Os critérios de exclusão foram presença de doença pulmonar obstrutiva crônica com bolhas subpleurais pré-existentes (detectadas através de radiografia de tórax ou de tomografia computadorizada) instabilidade hemodinâmica definida por má perfusão tissular (configurada por: $\mathrm{SvO}_{2}<65 \%$ ou $\mathrm{SvcO}_{2}<$ $70 \%$ - e/ou lactato $>2,0 \mathrm{ng} / \mathrm{mL}$ em pacientes sem insuficiência hepática e / ou débito urinário $<50 \mathrm{~mL} / \mathrm{h}$ nas últimas 4 horas) e/ou PAM $<65$ mmHg em pacientes euvolêmicos ou em uso de aminas vasopressoras, história de fibrilação ventricular ou taquicardia ventricular durante a internação, barotrauma estabelecido (definido como a presença de enfisema subcutâneo, pneumomediastino ou pneumotórax evidenciados na 
radiografia de tórax da rotina diária ou em TC), fístula broncopleural, presença de dreno de tórax, afecções com potencial de desenvolvimento de hipertensão intracraniana (traumatismo crânio-encefálico, hemorragia subaracnoidea, etc), parada cardio-respiratória nas últimas 48 horas, risco iminente de morte nas próximas 48 horas, doença terminal com decisão de limitação de cuidados terapêuticos, gravideze peso superior ao limite tolerado pelo aparelho de TC $(140 \mathrm{~kg})$.

\subsection{Protocolo:}

Os pacientes permaneceram durante todas as fases do estudo sedados e em posição supina. Ventilação segundo o protocolo ARDS net ${ }^{(26)}$ foi aplicada nas primeiras 24 horas. Os pacientes que com 24 horas de ventilação de acordo com o protocolo ARDS net ${ }^{(26)}$ (obedecendo-se um período mínimo de estabilidade nos parâmetros ventilatórios de 2 horas) alcançaram $\mathrm{PaO}_{2} / \mathrm{FIO}_{2}>350$, foram mantidos com esta estratégia por mais um dia. Aqueles com $\mathrm{PaO}_{2} / \mathrm{FIO}_{2}=350$ após 24 horas de protocolo ARDSnet ${ }^{(26)}$, foram submetidos à estratégia ventilatória baseada no Open Lung Concept ${ }^{(34)}$ nas 24 horas seguintes (com a realização de manobra de recrutamento alveolar seguida de titulação de PEEP). Imediatamente antes do estudo e após 24 e 48 horas do início do protocolo, sangue arterial e Mini-BAL foram coletados para mensuração de citocinas. Relação $\mathrm{PaO}_{2} / \mathrm{FIO}_{2}$, mecânica pulmonar (medida de complacência estática) e parâmetros hemodinâmicos foram também avaliados nos mesmos momentos. TC de tórax foi realizada após 24 e 48 horas do início do estudo. Os pacientes foram acompanhados até o desfecho (alta hospitalar ou óbito). As fases e os procedimentos do protocolo estão demonstrados na Figura 2. 
Sangue art. (citocinas; $\mathrm{PaO}_{2} / \mathrm{FIO}_{2}$ )

Mini-Bal

Mec. pulmonar
Sangue art.

(citocinas; $\mathrm{PaO}_{2} / \mathrm{FIO}_{2}$ )

Mini-Bal

Mec. Pulmonar

TC tórax
Sangue art. (citocinas; $\mathrm{PaO}_{2} / \mathrm{FIO}_{2}$ )

Mini-Bal

Mec. Pulmonar

TC tórax

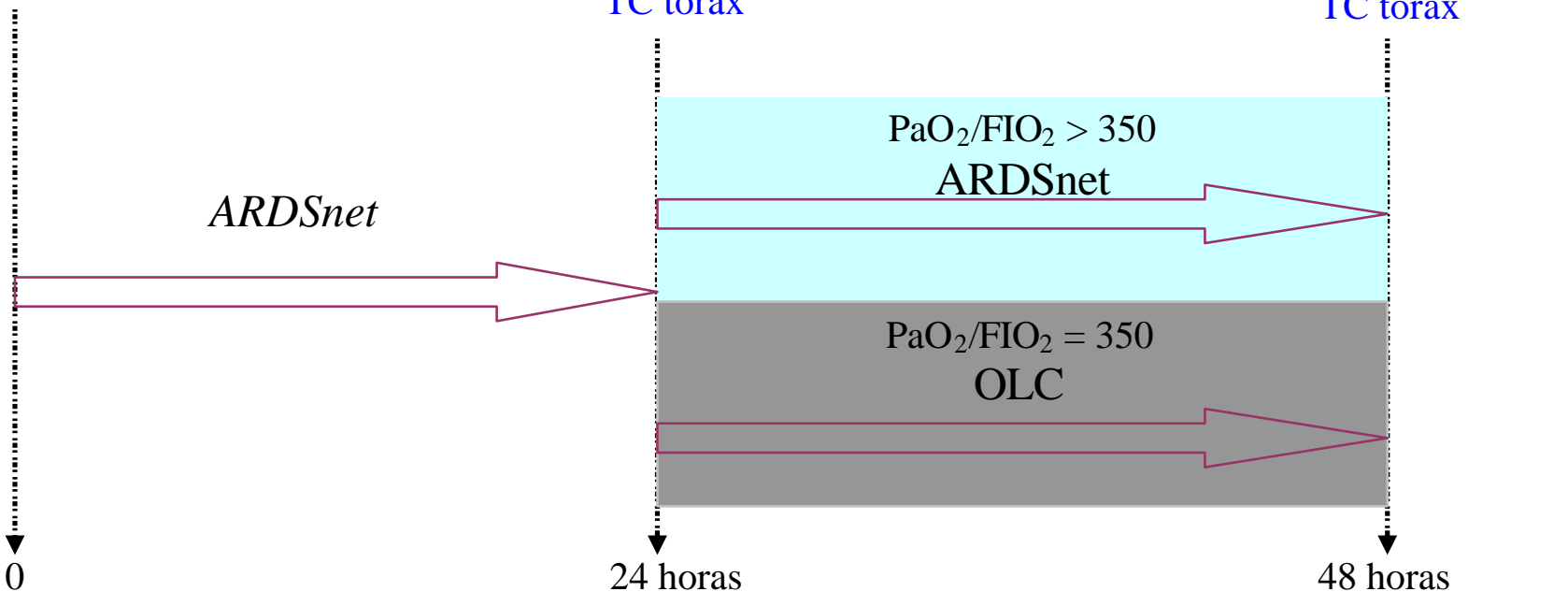

Figura 2. Fases e procedimentos do protocolo.

$\underline{\text { Protocolo ARDS net }}{ }^{(26)}$ 24horas:

Adotou-se ventilação segundo o protocolo ARDSnet ${ }^{(26)}$ definida por onda de fluxo decrescente, com VT inicial $6 \mathrm{~mL} / \mathrm{kg}$ de peso ideal, que foi ajustado em alíquotas de $1 \mathrm{~mL} / \mathrm{kg}$ de peso ideal, para manutenção de Pplatô entre 25 - $30 \mathrm{cmH}_{2} \mathrm{O}$. Os valores mínimo e máximo de VT permitidos foram, respectivamente 4 e $6 \mathrm{~mL} / \mathrm{kg}$ de peso ideal. A Pplatô foi determinada, com pausa de 0,5 s, a cada 4 h e após mudanças de VT ou de PEEP. Nos pacientes que desenvolvessem acidose respiratória com $\mathrm{pH}$ arterial $<7,15$ e que precisassem manter VT $<6 \mathrm{~mL} / \mathrm{kg}$ de peso ideal para controle da Pplatô, esta poderia ser mantida acima de $30 \mathrm{cmH}_{2} \mathrm{O}$. Nos pacientes ventilados com $\mathrm{VT}=6 \mathrm{~mL} / \mathrm{kg}$ de peso ideal que apresentassem acidose respiratória com pH arterial $<7,15$, o VT poderia ser elevado para 7 a $8 \mathrm{~mL} / \mathrm{kg}$, desde que o limite máximo da Pplatô fosse mantido em $30 \mathrm{cmH}_{2}$ O.A freqüência respiratória foi ajustada em15 irpm. Caso ajustes no VT (obedecendo 
as regras anteriores) não fossem suficientes para manter o $\mathrm{pH}$ arterial > 7,15, a FR poderia ser elevada. A relação I:E permaneceu entre 1:1 e 1:3.

O ajuste da PEEP obedeceu a seguinte relação (aguardando-se 10 minutos entre cada ajuste):

\begin{tabular}{|cc|}
\hline FIO $_{2}$ & PEEP \\
\hline \hline 0,3 & 5 \\
0,4 & 5 \\
0,4 & 8 \\
0,5 & 8 \\
0,5 & 10 \\
0,6 & 10 \\
0,7 & 10 \\
0,7 & 12 \\
\end{tabular}

O objetivo do ajuste $\mathrm{PEEP} / \mathrm{FIO}_{2}$ foi a manutenção da $\mathrm{SaO}_{2}$ entre 88 - 95\%, através de monitorização por oximetria de pulso.

\section{Ventilação segundo OLC: $:^{(34)}$}

1. Manobra de recrutamento:

Partindo-se de 24 horas de ventilação segundo protocolo ARDSnet ${ }^{(26)}$, os pacientes com $\mathrm{PaO}_{2} / \mathrm{FIO}_{2}$ $=350^{(59)}$ foram submetidos à manobra de recrutamento alveolar realizada em $\mathrm{PCV}, \mathrm{com} ? \mathrm{P}=20 \mathrm{cmH}_{2} \mathrm{O}$, $\mathrm{FR}=10$ irpm e relação $\mathrm{I}: \mathrm{E}=1: 1$ (tempo inspiratório = 3 segundos). PEEP foi inicialmente mantida em 20 $\mathrm{cmH}_{2} \mathrm{O}$ por 2 minutos (determinando uma pressão de pico $=40 \mathrm{cmH}_{2} \mathrm{O}$ ). Após este período, PEEP foi 
aumentada para $25 \mathrm{cmH}_{2} \mathrm{O}$ por mais 2 minutos e finalmente para $30 \mathrm{cmH}_{2} \mathrm{O}$ nos 2 minutos finais (com Ppico nos últimos 2 minutos de manobra $=50 \mathrm{cmH}_{2} \mathrm{O}$ ).

Para a realização da manobra de recrutamento foi necessário constatar estabilidade hemodinâmica, definida por PAM > $65 \mathrm{mmHg}$, lactato dentro dos limites da normalidade e, nos pacientes com monitorização oxihemodinâmica, $\mathrm{SvcO}_{2}>70 \%\left(\right.$ ou $\left.\mathrm{SvO}_{2}>65 \%\right)$ e índice cardíaco entre 3,5 e $5 \mathrm{~L} / \mathrm{min}$. Os pacientes que não preenchessem estes critérios ou que desenvolvessem hipotensão durante o recrutamento receberiam alíquotas de volume (cristalóide e/ou colóide) e aminas vasoativas. Monitorização dos parâmetros hemodinâmicos disponíveis em cada paciente foi realizada imediatamente antes das manobras de recrutamento e no último segundo da última etapa de recrutamento

\section{Titulação da PEEP alvo:}

PEEP alvo foi definida como aquela associada à relação $\mathrm{PaO}_{2} / \mathrm{FIO}_{2}>350^{(70)}$ após a realização da manobra de recrutamento e 20 minutos de ventilação com parâmetros ventilatórios específicos: ventilação em modo PCV, com ?P ajustado para um VT=6 mL/kg de peso ideal, FR=15, relação I:E entre 1:1 a 1:3, $\mathrm{FIO}_{2}=1$ e Pplatô $<30 \mathrm{cmH}_{2} \mathrm{O}$. Caso a Pplatô excedesse o limite de $30 \mathrm{cmH}_{2} \mathrm{O}$ o VT seria reduzido, desde que respeitado um mínimo de $4 \mathrm{~mL} / \mathrm{kg}$ de peso ideal. Caso $\mathrm{pH}$ arterial < 7,15, o VT poderia ser elevado para 7 - $8 \mathrm{~mL} / \mathrm{kg}$ desde que a Pplatô fosse limitada em $35 \mathrm{cmH}_{2} \mathrm{O}$.

O primeiro nível de PEEP avaliado foi de $17 \mathrm{cmH}_{2} \mathrm{O}{ }^{(27)}$. Nos pacientes que obtiveram $\mathrm{PaO}_{2} / \mathrm{FIO}_{2}>350$ após 20 minutos de ventilação com PEEP = 17 esta foi definida como PEEP alvo. Naqueles com $\mathrm{PaO}_{2} / \mathrm{FIO}_{2} \leq 350$, nova manobra de recrutamento utilizando apenas a última etapa $(? \mathrm{P}=20+\mathrm{PEEP}=$ $30 \mathrm{cmH}_{2} \mathrm{O}$ por 2 minutos) foi realizada e a PEEP elevada em $2 \mathrm{cmH}_{2} \mathrm{O}$, para nova avaliação de PEEP alvo. Esta estratégia foi repetida até alcançar $\mathrm{PaO}_{2} / \mathrm{FIO}_{2}>350$. O limite máximo da PEEP foi de $21 \mathrm{cmH}_{2} \mathrm{O} .{ }^{(70)}$ 
Nos casos em que houve redução da $\mathrm{PaO}_{2} / \mathrm{FIO}_{2}$ após elevação da PEEP, a PEEP alvo foi definida como aquela determinante da maior $\mathrm{PaO}_{2} / \mathrm{FIO}_{2}$ (Figura 3).

\section{Recrutamento:}

$\mathrm{FR}=10+\mathrm{TI}=3 \mathrm{~s}+? \mathrm{P}=20$

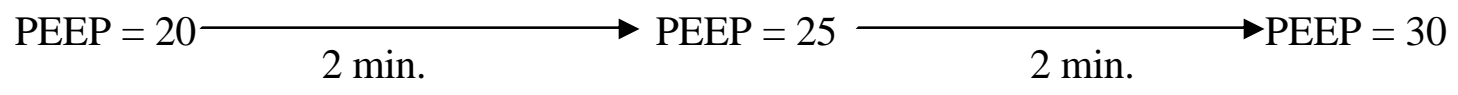

Titulação da PEEP:

$\mathrm{PCV}, \mathrm{VC}=6 \mathrm{~mL} / \mathrm{kg}, \mathrm{FR}=15, \mathrm{FIO}_{2}=1$, Pplatô $=30 \mathrm{cmH}_{2} \mathrm{O}$

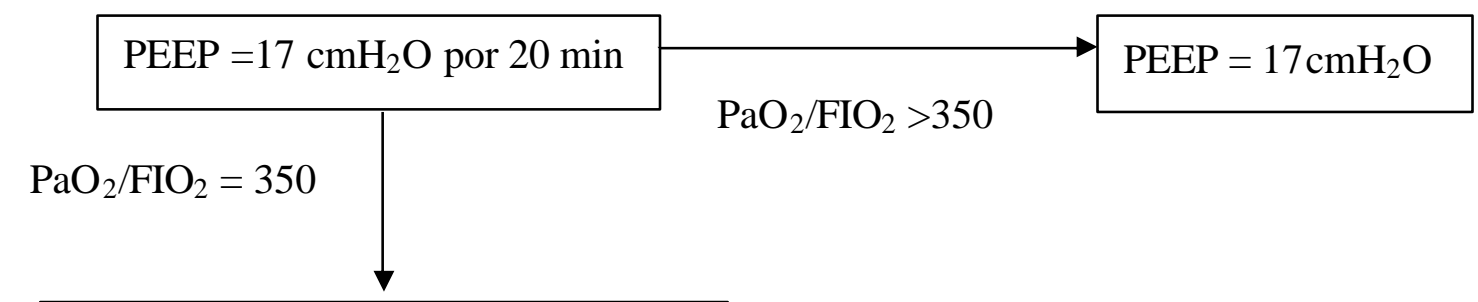

Recrutamento: $? \mathrm{P}=20+\mathrm{PEEP}=30$

$\mathrm{PEEP}=19$ por $20 \mathrm{~min}$

$\left(\mathrm{PEEP}=21 \mathrm{cmH}_{2} \mathrm{O}\right)$

Figura 3. Recrutamento e titulação da PEEP. Abreviaturas: FR = Frequênmcia respiratória; $\mathrm{TI}=$ Tempo inspiratório; $\min =$ minutos; $\mathrm{PCV}=$ Ventilação controlada à pressão; VT = Volume corrente; FIO2 = Fração inspirada de oxigênio; Pplatô = Pressão de platô; $\mathrm{PEEP}=$ Pressão positiva ao final da expiração; $\mathrm{PaO}_{2} / \mathrm{FIO}_{2}=$ Relação entre pressão parcial de oxigênio e fração inspirada de oxigênio

Após definição da PEEP alvo, o VT foi ajustado de acordo com o necessário para manter a $\mathrm{PaCO}_{2} \mathrm{o}$ mais próximo do normal, atentando para o limite da Pplatô $=35 \mathrm{cmH}_{2} \mathrm{O}$. Estes parâmetros ventilatórios foram mantidos por 24 horas.

Os protocolos de tratamento de resgate em casos de acidose respiratória $\left(\mathrm{PaCO}_{2}>70 \mathrm{mmHg}\right.$ e pH<7,15) e de hipoxemia $\left(\mathrm{PaO}_{2}<70 \mathrm{mmHg}\right)$ durante ventilação segundo OLC, são descritos no anexo I. 


\section{5-Cuidados com o paciente:}

O transporte do CTI para a radiologia (que foi feito por, pelo menos, dois médicos, um enfermeiro e um fisioterapeuta) e as imagens tomográficas foram realizados com monitorização contínua de oximetria, eletrocardiograma e pressão arterial.

Os pacientes foram ventilados em todas as fases do estudo no respirador Servoi (Siemens $\left.{ }^{\circledR}\right)$. Monitorização hemodinâmica foi realizada com cateter de pressão arterial invasiva. O emprego de outra formas de monitorização hemodinâmica (cateter de artéria pulmonar, doppler esofageano-Cardio-Q®, LiDCO®, FloTrac-Vigileo $\left.{ }^{\circledR}\right)$ ficou a cargo da equipe médica assistente.

Para serem transportados para a TC todos os pacientes necessitavam apresentar estabilidade oxihemodinâmica, definida pelos critérios a seguir descritos:

- $\quad \mathrm{PAM}>65 \mathrm{mmHg}$

- $\mathrm{SO}_{2}>90 \%$

- Lactato dentro da normalidade ou decrescente

- Índice cardíaco > 3,0 L/ min, quando disponível

- $\mathrm{SvcO}_{2}>70 \%\left(\right.$ ou $\mathrm{SvO}_{2}>65 \%$ ), quando disponíveis

Os demais protocolos clínicos das unidades de terapia intensiva do Hospital Copa D'Or foram seguidos em todos os pacientes do estudo (anexo II).

\section{6-Aquisição da TC espiral de alta resolução:}

As imagens tomográficas foram feitas em aparelho helicoidal multislice (quatro carreiras de detectores) Lightspeed da GE. Foram feitas varreduras do pulmão do ápice até o diafragma, em posição supina. As imagens helicoidais foram adquiridas durante pausa expiratória de 6 segundos, com cortes axiais 
de $1,25 \mathrm{~mm}$ de espessura e intervalos de $15 \mathrm{~mm}(120 \mathrm{KV} ; 150 \mathrm{~mA})$, sendo utilizado filtro standard. Posteriormente, foram realizadas reconstruções com filtro de alta resolução.

Durante o exame os pacientes foram ventilados com $\mathrm{FIO}_{2}=1$ e permaneceram sedados para alcançarem escore da Richmond Agitation Sedation Scale $\left(\right.$ RASS ${ }^{(73)}=-5$ (anexo III). Utilizou-se bloqueio neuromuscular com alíquotas de pancurônio quando a sedação não foi suficiente para inibição de musculatura respiratória.

\section{7-Avaliação das imagens tomográficas:}

A análise das imagens tomográficas foi realizada através de um programa desenvolvido para este propósito pelo laboratório de engenharia pulmonar da COPPE-UFRJ (COPPE-TC) operando em Matlab® (The Mathworks, EUA). Este software é capaz de gerar histogramas das distribuições de densidades de regiões de interesse. Para a determinação das regiões de interesse o contorno interno de cada hemitórax foi manualmente desenhado na tela do computador, em cada corte tomográfico, excluindo a parede torácica, mediastino, derrame pleural e áreas de efeito de volume parcial.

Foram definidos quatro compartimentos pulmonares de acordo com a freqüência de distribuição das atenuações radiológicas dos tecidos (expressas por números de TC ou unidades Hounsfield-HU):

1000 até $-900 \mathrm{HU} \rightarrow$ hiperinsuflado

- 900 até $-500 \mathrm{HU} \rightarrow$ normalmente aerado

- 500 até $-100 \mathrm{HU} \rightarrow$ pobremente aerado

- 100 até $+100 \mathrm{HU} \rightarrow$ não aerado

Em cada região de interesse computou-se o número de voxels em cada um dos quatro compartimentos. O volume (em mililitros) e a massa (em gramas) de cada compartimento e de todo o 
pulmão foram calculados, conforme descrito por Gattinoni e colaboradores. ${ }^{(12)}$ Os resultados foram expressos em percentuais de volume de cada compartimento em relação ao volume pulmonar total e em em percentuais de massa de cada compartimento em relação à massa pulmonar total.

Para facilitar a visualização da distribuição da aeração pulmonar em cada fase do estudo os compartimentos foram representados com um sistema de cores. As regiões hiperinsufladas foram pintadas em vermelho, as normalmente aeradas em azul, as pobremente aeradas em branco e as não aeradas em preto.

Reconstruções volumétricas tridimensionais foram feitas através do mapeamento dos limites pulmonares de cada compartimento, utilizando um programa escrito em Matlab® (The MathWorks, EUA) desenvolvido pelo Departamento de Anestesiologia e Medicina Intensiva da Universidade Carl Gustav Carus, Dresden (Alemanha).

\section{8-Análise dos mediadores de inflamação:}

Amostras de sangue arterial $(10 \mathrm{~mL})$ foram obtidas e centrifugadas e o plasma foi congelado a $20^{\circ} \mathrm{C}$.

Amostras de mini-BAL (3 mL) foram coletadas e congeladas a $-20^{\circ} \mathrm{C}$. Este material foi obtido através de trach-care para aspiração de tubo orotraqueal (TOT). Para isto o trach-care era introduzido totalmente através do TOT, instilava-se $10 \mathrm{~mL}$ de soro fisiológico através de seu introdutor lateral e aspirava-se o conteúdo respiratório sem tracionamento do trach-care.

Plasma e mini-BAL foram enviados ao laboratório de imunofarmacologia do Departamento de Fisiologia e Farmacodinâmica, IOC, FIOCRUZ para análise de citocinas.

Os níveis de IL-6 e IL-8 foram dosados no plasma e mini-BAL através da técnica enzime-linked immunoassay (Elisa), utilizando kits da R \& D Systems (R \& D Systems, Minneapolis, Minnesota, EUA). 


\section{9-Acompanhamento e avaliação prognóstica:}

A-Parâmetros ventilatórios:

Após as primeiras 48 horas de intervenções do estudo, todos os pacientes foram ventilados no CTI em PRVC ou PCV com os parâmetros a seguir:

- VT máximo $\rightarrow$ Em torno de $6 \mathrm{~mL} / \mathrm{kg}$, desde que Pplatô $\leq 30 \mathrm{cmH}_{2} \mathrm{O}$ no grupo mantido com estratégia ARDS net ${ }^{(26)}$ ou Pplatô $\leq 35 \mathrm{cmH}_{2} \mathrm{O}$ no grupo submetido a recrutamento alveolar e titulação de PEEP alvo.

- VT mínimo $\rightarrow$ Aquele necessário para manter Pplatô $=25 \mathrm{cmH}_{2} \mathrm{O}$ e pH arterial = 7,25 com $\mathrm{PaCO}_{2}$ $\leq 60 \mathrm{mmHg}$

- Relação I:E entre 1:1 e 1:3

No momento em que houve recuperação do estímulo respiratório e melhora nos parâmetros inflamatórios e de perfusão, os pacientes passaram a ventilar em PSV.

O desmame ventilatório foi feito da mesma forma nos dois grupos. A redução da PEEP só foi iniciada (a cada $2 \mathrm{cmH}_{2} \mathrm{O}$ ) quando os pacientes passaram a ventilar em PSV.

B-Índices prognósticos e evolutivos:

Apache ?? e SAPS ?? foram medidos nas primeiras 24 horas de terapia intensiva.

SOFA foi medido no primeiro dia de internação no CTI, imediatamente antes do início do protocolo (SOFA basal) após 24 e 48 horas do início do protocolo e após 2 e 7 dias do término do protocolo.

\section{C-Seguimento:}

Os pacientes foram acompanhados até a alta hospitalar ou óbito. Foram incluídos nos registros data de início e término do suporte ventilatório, alta do CTI e alta hospitalar. 
D-Monitorização das complicações:

Todas as complicações que surgiram ao longo da internação que pudessem estar associadas ao protocolo (barotrauma, alterações hemodinâmicas, etc) foram registradas e monitoradas até resolução. E-Análise evolutiva das $\mathrm{PaO}_{2} / \mathrm{FIO}_{2}$ :

Gasometria arterial com cálculo da relação $\mathrm{PaO}_{2} / \mathrm{FIO}_{2}$ foi realizada no $14^{\circ}$ dia após o início do estudo nos pacientes que ainda permaneciam em ventilação mecânica.

\subsection{0-Análise Estatística:}

Os valores foram apresentados como mediana e quartis (primeiro quartil - terceiro quartil). As comparações foram feitas através do teste de Wilcoxon para dados pareados, utilizando-se o pacote estatístico SPSS 12.0 (SPSS Inc ${ }^{\mathrm{TM}}$ ). Diferenças foram consideradas estatisticamente significativas para $\mathrm{p}$ (bicaudado) $<0,05$

\section{5- $\underline{\text { Resultados: }}$}

No período de realização do estudo, 14 pacientes preencheram os critérios de inclusão Destes, quatro foram excluídos por ausência de consentimento informado assinado. As características de entrada dos 10 pacientes estudados são mostradas na tabela 1 (demográficas e clínicas) e na tabela 2 (respiratórias).

Concentrações de IL-8 e de IL-6, no plasma e no mini-BAL, foram medidas em 8 dos 10 pacientes estudados e seus valores basais são demonstrados na tabela 3 .

Para facilitar a comparação dos resultados, os pacientes foram sempre representados pelo mesmo número. 
Tabela 1. Características demográficas e clínicas dos pacientes na admissão:

\begin{tabular}{ccccccc}
\hline Paciente & Idade (anos) & Sexo & Apache II & $\begin{array}{c}\text { SAPS } \\
\text { II }\end{array}$ & $\begin{array}{c}\text { SOFA } \\
\text { basal }\end{array}$ & Fator \\
& & & & & & \\
precipitante
\end{tabular}

Abreviaturas:APACHE II=Acute Physiology and Chronic Health Evaluation II score; SAPS II = Simplified Acute Physiology II score; SOFA basal = Sepsis-related Organ Failure Assessment medido no dia de admissão no Centro de Terapia Intensiva.

Tabela 2. Variáveis respiratórias dos pacientes na admissão:

\begin{tabular}{ccccc}
\hline Paciente & $\begin{array}{c}\text { Vent. Mecânica } \\
\text { (horas) }\end{array}$ & $\begin{array}{c}\mathrm{PaO}_{2} / \mathrm{FIO}_{2} \\
(\mathrm{mmHg})\end{array}$ & $\begin{array}{c}\text { Cest } \\
\left(\mathrm{cmH}_{2} \mathrm{O}\right)\end{array}$ & $\begin{array}{c}\text { P distensão } \\
\left(\mathrm{cmH}_{2} \mathrm{O}\right)\end{array}$ \\
1 & 12 & 217 & 33,9 & 14 \\
2 & 11 & 179 & 19,5 & 19 \\
3 & 24 & 250 & 33 & 13 \\
4 & 22 & 246 & 40,7 & 13 \\
5 & 7 & 226 & 25 & 18 \\
6 & 48 & 220 & 30 & 21 \\
7 & 7 & 229 & 57,8 & 9 \\
8 & 24 & 78 & 31,8 & 11 \\
9 & 24 & 171 & 25,3 & 15 \\
10 & 6 & 201 & 45 & 10 \\
\hline Mediana & 17 & 219 & 32,4 & 14,5 \\
\hline Abreving
\end{tabular}

Abreviaturas: $\mathrm{PO}_{2} / \mathrm{FIO}_{2}=$ Pressão parcial de oxigênio / Fração inspirada de oxigênio medida com $\mathrm{PEEP}=5 \mathrm{cmH} \mathrm{H}_{2} \mathrm{O}$ Vent. Mecânica $($ horas $)=$ Horas de ventilação mecânica antes da entrada no estudo; Cest = Complacência estática; Pdistensão = Pressão de distensão 
Tabela 3. Concentrações basais (ng/mL) de IL-8 e IL-6 no plasma e mini-Bal:

\begin{tabular}{ccccc}
\hline Paciente & $\begin{array}{c}\mathrm{IL}-8 \text { plasma } \\
(\mathrm{ng} / \mathrm{mL})\end{array}$ & $\begin{array}{c}\mathrm{IL}-8 \text { mini-BAL } \\
(\mathrm{ng} / \mathrm{mL})\end{array}$ & $\begin{array}{c}\mathrm{IL}-6 \text { plasma } \\
(\mathrm{ng} / \mathrm{mL})\end{array}$ & $\begin{array}{c}\mathrm{IL}-6 \text { mini-BAL } \\
(\mathrm{ng} / \mathrm{mL})\end{array}$ \\
3 & 33,18 & 145,62 & 1,85 & 3,74 \\
4 & 28,80 & 137,46 & 7,01 & 19,01 \\
5 & 72,03 & 93,45 & 23,07 & 18,24 \\
6 & 5,89 & 82,41 & 2,50 & 1,96 \\
7 & 13,87 & 78,87 & 8,71 & 33,81 \\
8 & 24,50 & 81,70 & 3,92 & 16,02 \\
9 & 37,65 & 16,01 & 14,02 & 15,78 \\
10 & 7,16 & 99,84 & 9,70 & 12,03 \\
\hline
\end{tabular}

Abreviaturas: IL = Interleucina

Apenas um paciente apresentou $\mathrm{PaO}_{2} / \mathrm{FIO}_{2}>350$ após protocolo ARDS net $24 \mathrm{~h}$ e_foi mantido com esta estratégia. Os demais foram submetidos à estratégia OLC 24 horas (gráfico 1). A mediana das $\mathrm{PaO}_{2} / \mathrm{FIO}_{2}$ com ARDS net 24 horas foi de 200 [186 - 266].

Gráfico 1: Histograma das P/F após 24 horas de ARDSNET

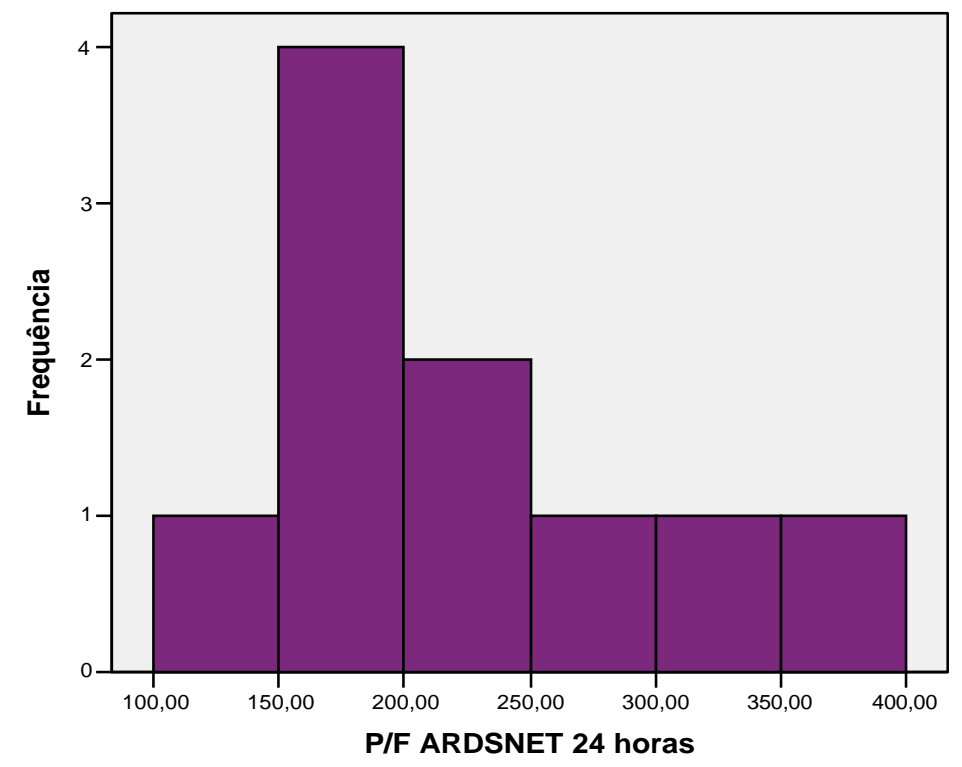

Abeviaturas: $\mathrm{P} / \mathrm{F}=\mathrm{PaO}_{2} / \mathrm{FIO}_{2}$ 


\section{1-Eficácia da estratégia ARDS net 24 horas:}

Quando comparada aos valores basais, ARDS net 24 horas não foi capaz de aumentar a $\mathrm{PaO}_{2} / \mathrm{FIO}_{2}$ (200 [186 - 266] com ARDS net 24 h vs. 219 [177 - 233]; p = 0,386 - Gráfico 2) e a complacência estática (42,2 [23,7 - 48,9] com ARDS net 24 h vs. 32,4 mL/cmH $2 \mathrm{O}$ [25,2 - 41,8]; p=0,139 - Gráfico 3)

promovendo, no entanto, elevação significativa nos níveis de $\mathrm{PaCO}_{2}$ (45 [41 - 50] com ARDS net $24 \mathrm{~h} v s$. $38 \mathrm{mmHg}$ [31 - 44]; p = 0,013 - Gráfico 4).

Gráfico 2: Evolução da relação $\mathrm{PaO}_{2} / \mathrm{FIO}_{2}$ entre valores basais e ARDSNET $24 \mathrm{~h}$

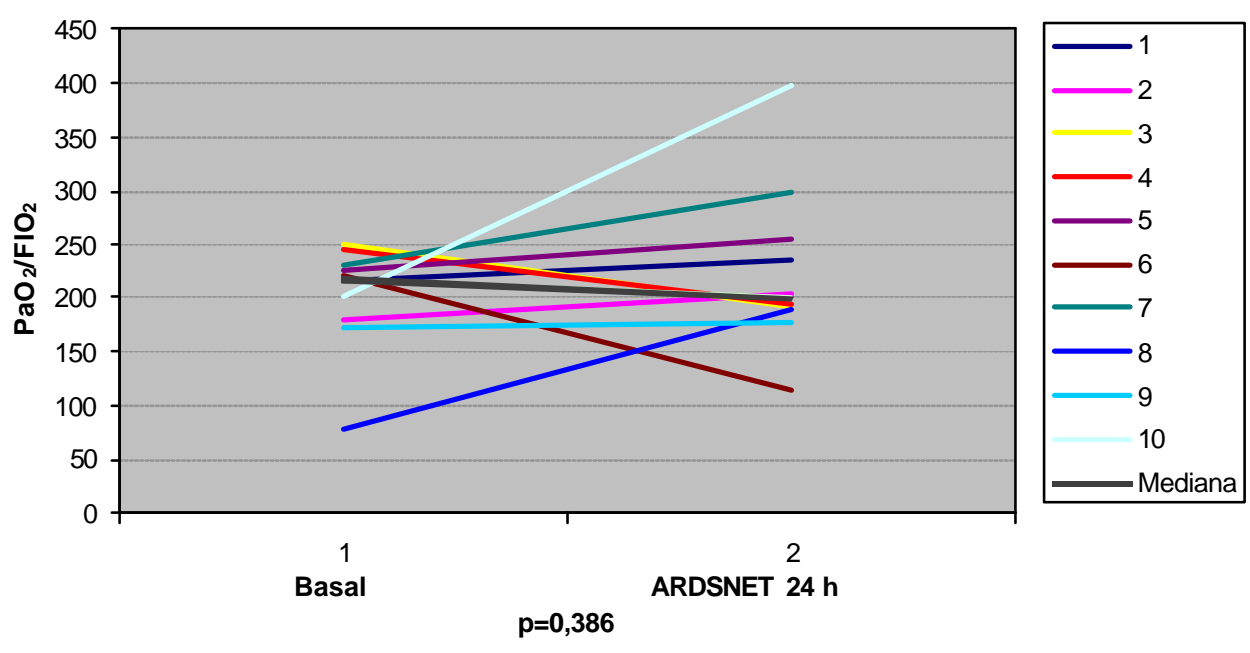


Gráfico 3: Evolução da complacência estática entre valores basais e ARDSNET $24 \mathrm{~h}$

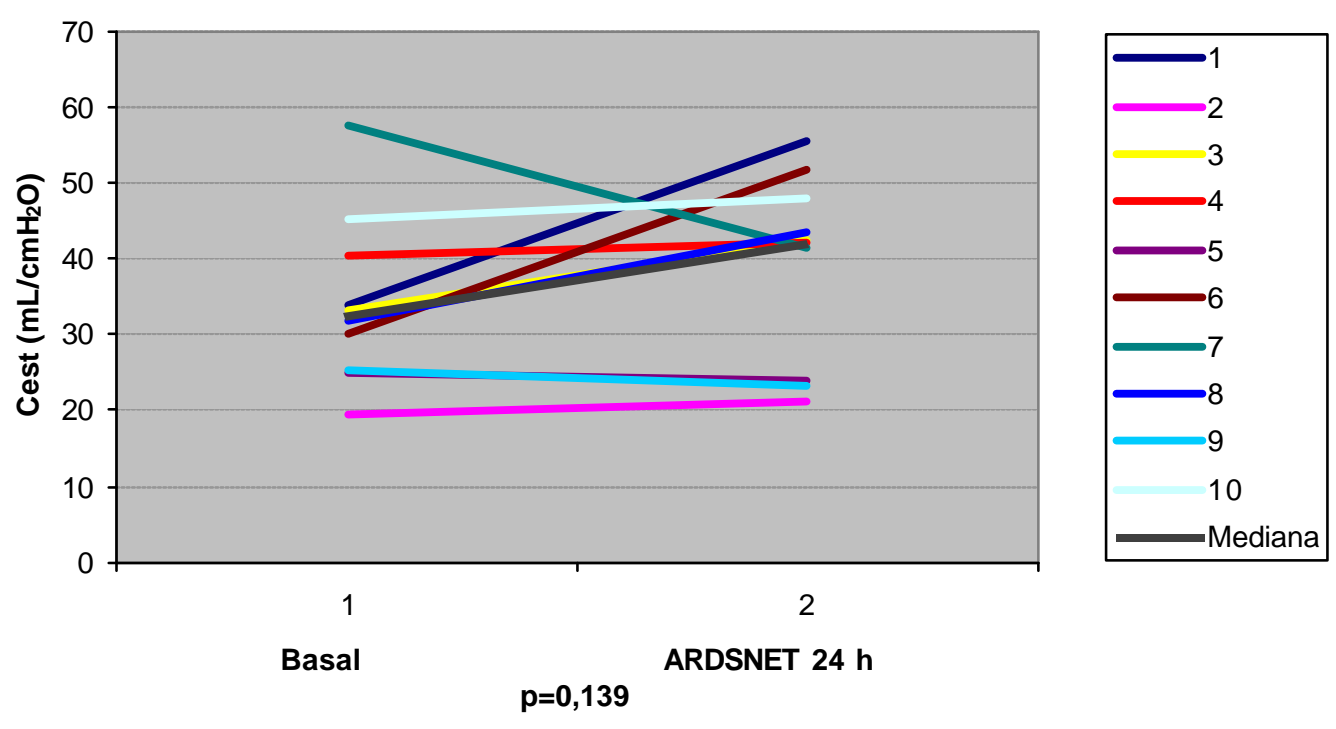

Gráfico 4: Evolução da $\mathrm{PaCO}_{2}$ entre valores basais e ARDSNET $24 \mathrm{~h}$

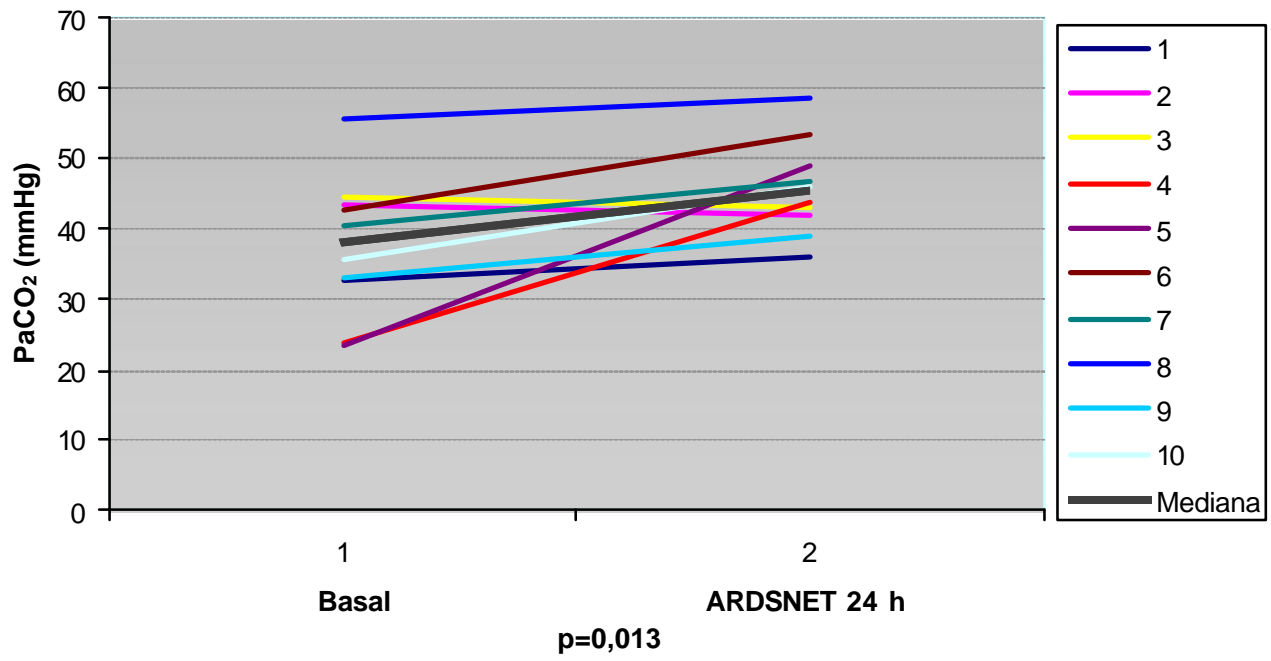


Estratégia ARDSnet 24 horas não alterou de forma significativa os valores da pressão de distensão, em relação aos valores basais (12 [10 - 17] com ARDSnet 24 h vs. 14 [11 - 18]; p=0,345 - Gráfico 5).

Gráfico 5: Evolução da P distensão entre momento basal e ARDSnet $24 \mathrm{~h}$

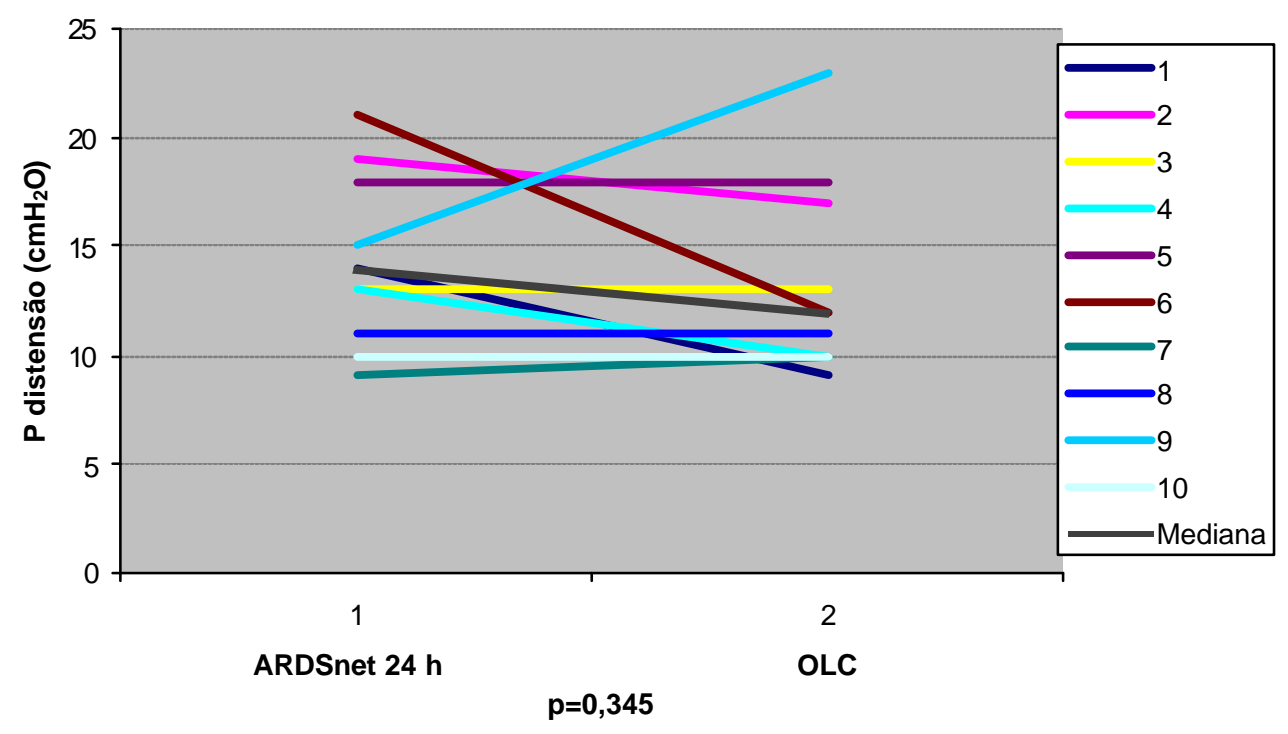


Não houve diferenças significativas nos níveis de IL- 8 e de IL-6 (plasmáticos e de mini-BAL) entre os valores basais e ARDS net 24 horas, conforme demonstrado na tabela 4.

abela 4. Concentrações plasmáticas e pulmonares de IL-8 e IL-6 (ng/mL) no momento basal e com ARDSnet 24horas:

\begin{tabular}{|c|c|c|c|c|c|c|c|}
\hline \multirow[t]{2}{*}{ aciente } & \multicolumn{2}{|c|}{$\begin{array}{c}\text { IL-8 plasmática } \\
(\mathrm{ng} / \mathrm{mL})\end{array}$} & \multicolumn{2}{|c|}{$\begin{array}{c}\text { IL-8 mini-BAL } \\
(\mathrm{ng} / \mathrm{mL})\end{array}$} & $\begin{array}{c}\text { IL-6 plasmática } \\
(\mathrm{ng} / \mathrm{mL})\end{array}$ & \multicolumn{2}{|c|}{$\begin{array}{c}\text { IL-6 mini-BAL } \\
(\mathrm{ng} / \mathrm{mL})\end{array}$} \\
\hline & Basal i & ARDSnet $24 \mathrm{~h}$ & Basal / & ARDSnet $24 \mathrm{~h}$ & Basal / ARDSnet $24 \mathrm{~h}$ & Basal / & ARDSnet $24 \mathrm{~h}$ \\
\hline 3 & 33,18 & $/ \quad 24,94$ & 145,62 & 85,04 & $1,85 / 3,26$ & 3,74 & 8,49 \\
\hline 4 & 28,8 & 11,12 & 137,46 & 132,17 & $7,01 / 4,11$ & 19,01 & 24,14 \\
\hline 5 & 72,03 & 42,18 & 93,45 & 69,25 & $23,07 \quad / 18$ & 18,24 & 14,79 \\
\hline 6 & 5,89 & / 24,89 & 82,41 & / 106,82 & $2,5 / 11,02$ & 1,96 & 25,29 \\
\hline 7 & 13,87 & / 16,83 & 78,87 & 85,75 & 8,71 & 33,81 & 13,83 \\
\hline 8 & 24,5 & 8,3 & 81,7 & / 42,87 & $3,92 \quad /$ & 16,03 & 24,85 \\
\hline 9 & 37,65 & 37,7 & 16,01 & 60,05 & $14,02 \quad /$ & 15,78 & 17,38 \\
\hline 10 & 7,16 & 0,77 & 99,84 & 109,21 & $9,7 / 3,36$ & 12,03 & 20,45 \\
\hline lediana & 26,65 & 20,86 & 87,93 & 85,40 & 7,86 & 15,90 & 18,91 \\
\hline o valor & & 0,263 & & 0,889 & 0,263 & & ,208 \\
\hline
\end{tabular}




\section{2-Análises comparativas das estratégias ARDSnet 24 horas e OLC 24 horas:}

A seguir serão analisados comparativamente os resultados obtidos com estratégia ARDSnet 24 h e com OLC $24 \mathrm{~h}$, nos 9 pacientes sub metidos a esta abordagem.

A-Valores de PEEP:

Os valores de PEEP (gráficos 6 e 7 e tabela 5) foram significativamente superiores durante OLC 24 horas em relação à ARDS net 24 horas (17 [17 - 19] vs. $8 \mathrm{cmH}_{2} \mathrm{O}$ [7,25 - 11] respectivamente; $\left.\mathrm{p}=0,007\right)$. Observar que no gráfico 6 as curvas dos pacientes 2, 3, 5, 7 e a curva da mediana estão sobrepostas.

Gráfico 6: Evolução da PEEP entre ARDSnet 24 h e OLC 24 h

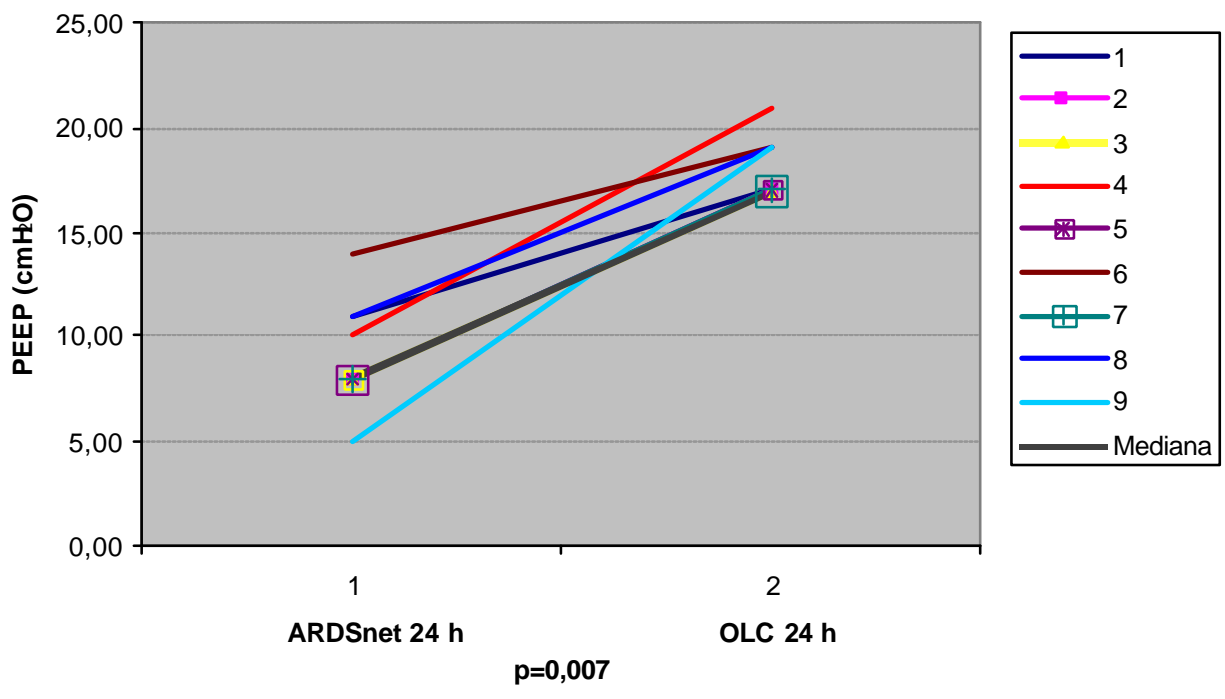


Gráfico 7: Valores de PEEP entre ARDSnet 24 h e OLC 24 h

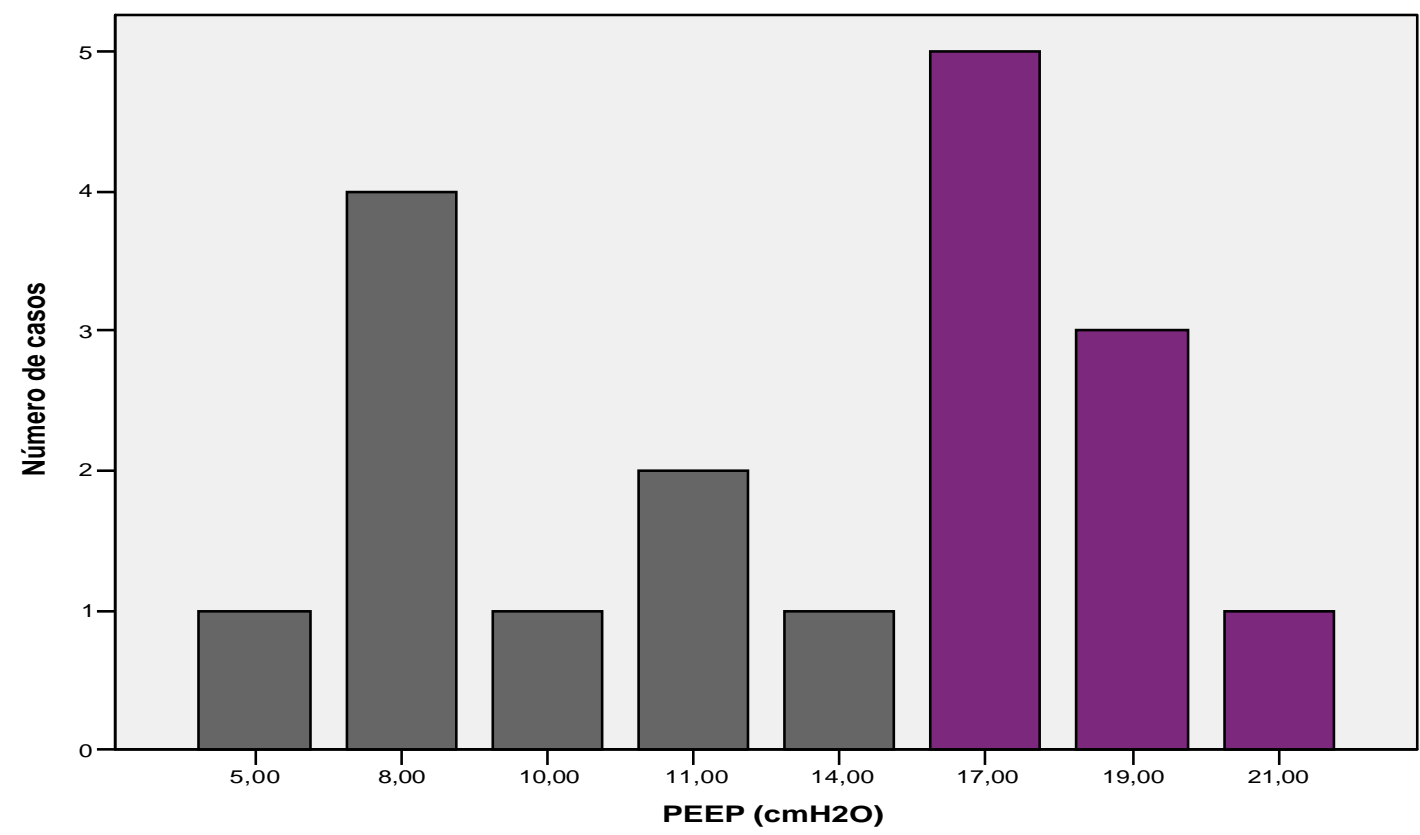

ARDSNET $24 \mathrm{~h}$

OLC $24 \mathrm{~h}$

B.Parâmetros gasométricos e ventilatórios:

As tabelas 5 e 6 resumem as medidas dos parâmetros ventilatórios e gasométricos nas duas estratégias:

Tabela 5. Medidas de parâmetros ventilatórios e de $\mathrm{PaO}_{2} / \mathrm{FIO}_{2}$ com ARDSnet 24 horas e OLC 24 horas:

\begin{tabular}{|c|c|c|c|c|c|c|c|c|c|c|}
\hline \multirow[t]{2}{*}{ Paciente } & \multicolumn{2}{|c|}{$\begin{array}{c}\text { PEEP } \\
\left(\mathrm{cmH}_{2} \mathrm{O}\right)\end{array}$} & \multicolumn{2}{|c|}{$\begin{array}{c}\mathrm{PaO}_{2} / \mathrm{FlO}_{2} \\
(\mathrm{mmHg})\end{array}$} & \multicolumn{2}{|c|}{$\begin{array}{l}\text { Pplatô } \\
\left(\mathrm{cmH}_{2} \mathrm{O}\right)\end{array}$} & \multicolumn{2}{|c|}{$\begin{array}{c}\text { Pdistensão } \\
\left(\mathrm{cmH}_{2} \mathrm{O}\right)\end{array}$} & \multicolumn{2}{|c|}{$\begin{array}{c}\text { Cest. } \\
\left(\mathrm{mL} / \mathrm{cmH}_{2} \mathrm{O}\right)\end{array}$} \\
\hline & ARDSnet & / OLC & ARDSnet / & OLC & ARDSnet / & OLC & ARDSnet & OLC & ARDSnet / & OLC \\
\hline 1 & $11 /$ & 17 & 236 & 364 & $20 \quad /$ & 30 & 91 & 13 & $55,6 \quad /$ & 33 \\
\hline 2 & $8 \quad /$ & 17 & 205 & 243 & $25 /$ & 20 & $17 /$ & 3 & 21,2 / & 120 \\
\hline 3 & $8 \quad /$ & 17 & 193 & 203 & $21 /$ & 20 & $13 /$ & 3 & $42,3 \quad /$ & 133 \\
\hline 4 & $10 /$ & 21 & 195 & 362 & $20 \quad /$ & 28 & 10 / & 7 & 42 & 61,4 \\
\hline 5 & $8 \quad /$ & 17 & 255 & 311 & $26 /$ & 30 & $18 /$ & 13 & $23,9 \quad /$ & 26,9 \\
\hline 6 & $14 /$ & 19 & 114 & 195 & $26 /$ & 30 & $12 /$ & 11 & $51,7 \quad /$ & 46,4 \\
\hline 7 & $8 \quad /$ & 17 & $300 \quad /$ & 380 & $18 /$ & 30 & $10 /$ & 13 & $41,5 \quad /$ & 53 \\
\hline 8 & $11 /$ & 19 & 189 / & 237 & $22 /$ & 33 & 11 & 14 & $43,6 \quad /$ & 32,9 \\
\hline 9 & 51 & 19 & $178 /$ & 270 & $28 \quad /$ & 31 & $23 /$ & 12 & $23 \quad /$ & 31,2 \\
\hline Mediana & $8 \quad 1$ & 17 & $195 /$ & 270 & 221 & 30 & $12 /$ & 12 & $42 \quad /$ & 46,4 \\
\hline $\mathrm{p}$ valor & 0,00 & & 0,008 & & 0,05 & & 0,172 & & 0,26 & \\
\hline
\end{tabular}

Abreviaturas: $\mathrm{PEEP}=$ Pressão ao final da expiração; $\mathrm{PaO}_{2}=$ Pressão parcial de oxigênio arterial; $\mathrm{FIO}_{2}=$ Fração inspirada de oxigênio $;$ Pdistensão = Pressão de distensão, Cest $=$ Complacência estática. 
Tabela 6. Medidas de parâmetros ventilatórios e gasométricos com ARDSnet 24 horas e OLC 24 horas:

\begin{tabular}{|c|c|c|c|c|c|c|c|c|}
\hline \multirow[t]{2}{*}{ Paciente } & \multicolumn{2}{|c|}{$\begin{array}{l}\mathrm{PaCO}_{2} \\
(\mathrm{mmHg})\end{array}$} & \multicolumn{2}{|c|}{$\mathrm{pH}$ arterial } & \multicolumn{2}{|c|}{$\begin{array}{l}\mathrm{VT} / \mathrm{kg} \text { peso ideal } \\
(\mathrm{mL})\end{array}$} & \multicolumn{2}{|c|}{$\begin{array}{l}\text { Vmin } \\
(L / \min )\end{array}$} \\
\hline & ARDSnet / & OLC & ARDSnet / & OLC & ARDSnet / & OLC & ARDSnet / & OLC \\
\hline 1 & 36 & 40 & $7,34 \quad /$ & 7,32 & 91 & 8 & $9,0 \quad /$ & 7,3 \\
\hline 2 & 42 & 54 & $7,37 \quad /$ & 7,26 & 61 & 6 & $8,6 \quad /$ & 5,4 \\
\hline 3 & $43 \quad /$ & 49 & 7,32 / & 7,25 & $8 /$ & 6 & $11 /$ & 6,0 \\
\hline 4 & 44 & 45 & $7,27 \quad /$ & 7,24 & 61 & 6 & $7,6 \quad /$ & 7,7 \\
\hline 5 & 49 & 46 & $7,29 \quad /$ & 7,38 & $8 /$ & 6 & $7,7 \quad /$ & 5,3 \\
\hline 6 & $54 \quad /$ & 63 & $7,26 \quad /$ & 7,22 & $9 /$ & 8 & 11,2 / & 9,2 \\
\hline 7 & 47 & 30 & $7,28 \quad /$ & 7,35 & 81 & 10 & $7,5 \quad /$ & 12,4 \\
\hline 8 & $59 \quad /$ & 57 & $7,41 \quad /$ & 7,27 & $8 \quad /$ & 8 & $7,2 \quad /$ & 8,3 \\
\hline 9 & $39 \quad 1$ & 60 & $7,29 \quad /$ & 7,36 & $10 /$ & 7 & $9,5 \quad /$ & 5,6 \\
\hline Mediana & $44 \quad 1$ & 49 & $7,29 /$ & 7,27 & 71 & 6 & $8,6 \quad /$ & 7,3 \\
\hline p valor & 0,26 & & 0,722 & & 0,208 & & 0,173 & \\
\hline
\end{tabular}

Abre viaturas: $\mathrm{PaCO}_{2}$ = Pressão parcial de dióxido de carbono arterial; VT = Volume corrente; Vmin = Ventilação por minuto.

Após 24 horas de estratégia OLC a melhora obtida na oxigenação permaneceu estatisticamente significativa, quando comparada à ARDS net 24 horas ( $\mathrm{p}=0,008$ - Tabela 5, Gráfico 8), sem diferenças significativas nos valores de Pdist, Pplatô (tabela 5 e gráficos 9 e 10, respectivamente), $\mathrm{PaCO}_{2}, \mathrm{pH}$ e ventilação - minuto (tabela 6 e gráficos 11 a 13, respectivamente). Os valores máximos de Pdist e de Pplatô observados com OLC 24 horas foram, respectivamente, 14 e $33 \mathrm{cmH}_{2} \mathrm{O}$ (tabela 5). Nenhum paciente submetido à OLC 24 horas necesitou de terapias de resgate para acidose respiratória ou hipoxemia refratária (anexo I). 
Gráfico 8: Evolução da relação $\mathrm{PaO}_{2} / \mathrm{FIO}_{2}$ entre ARDSnet 24 h e OLC 24 h

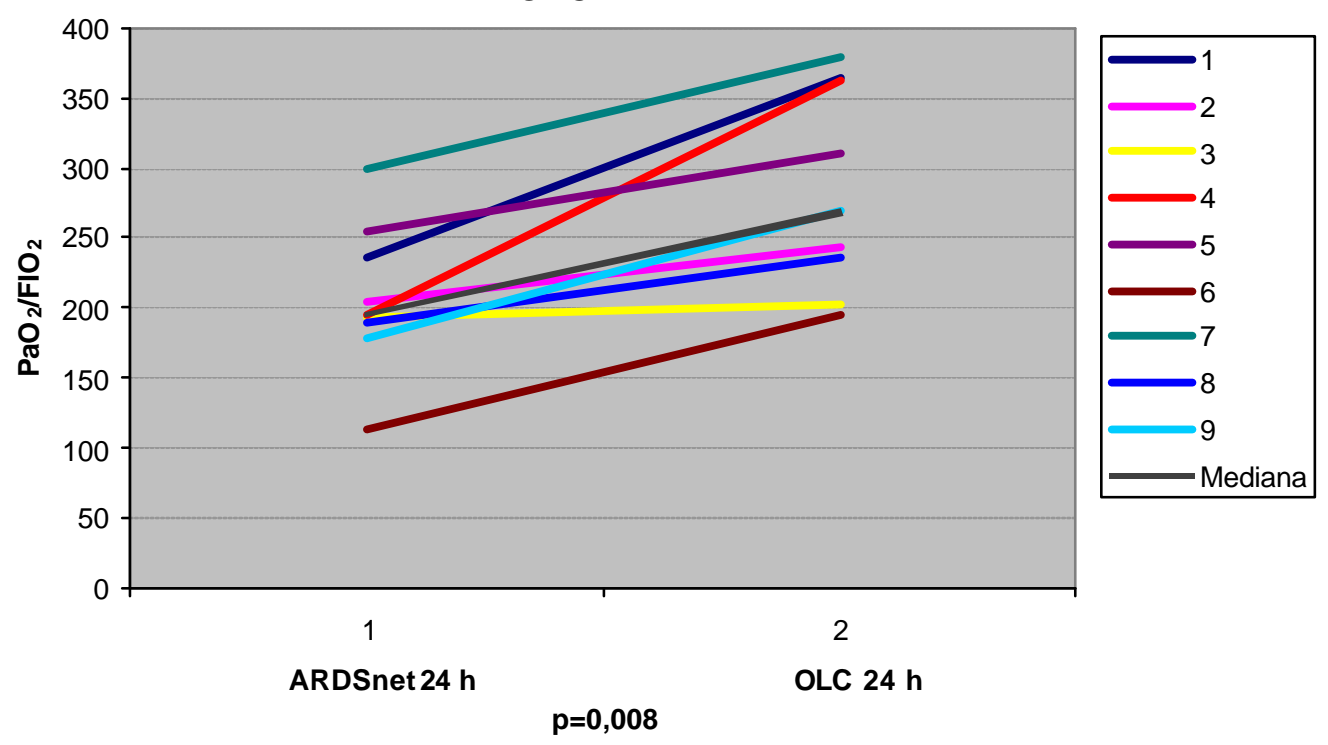

Gráfico 9: Evolução da P distensão entre ARDSnet 24 h e OLC 24 h
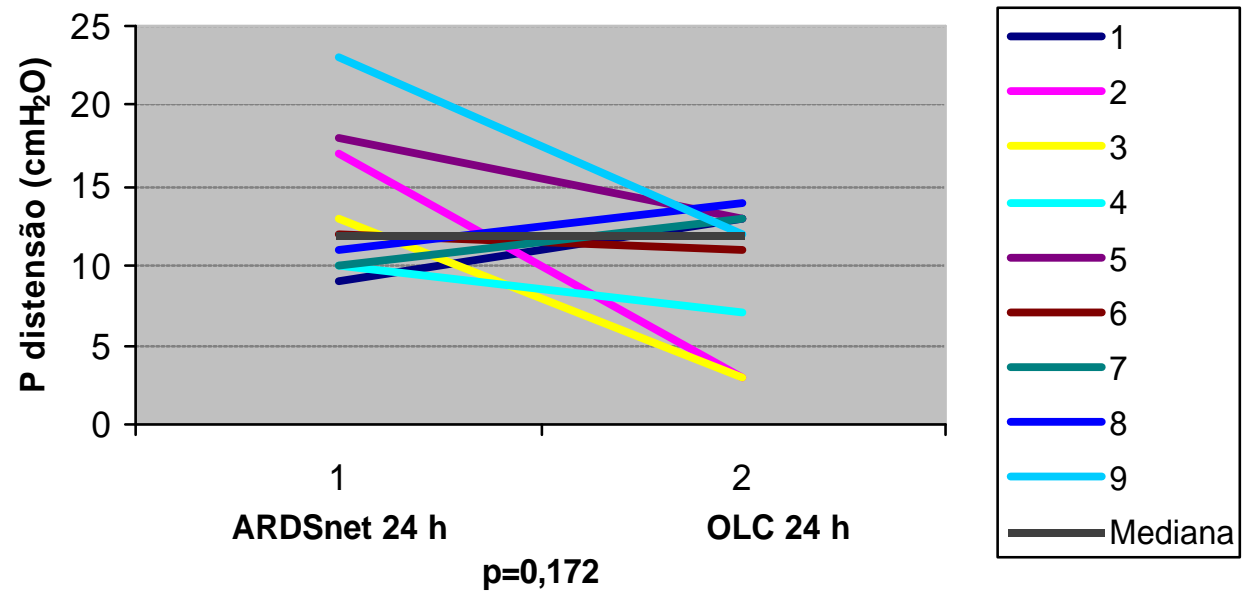
Gráfico 10: Evolução da P platô entre ARDSnet 24 h e OLC 24 h

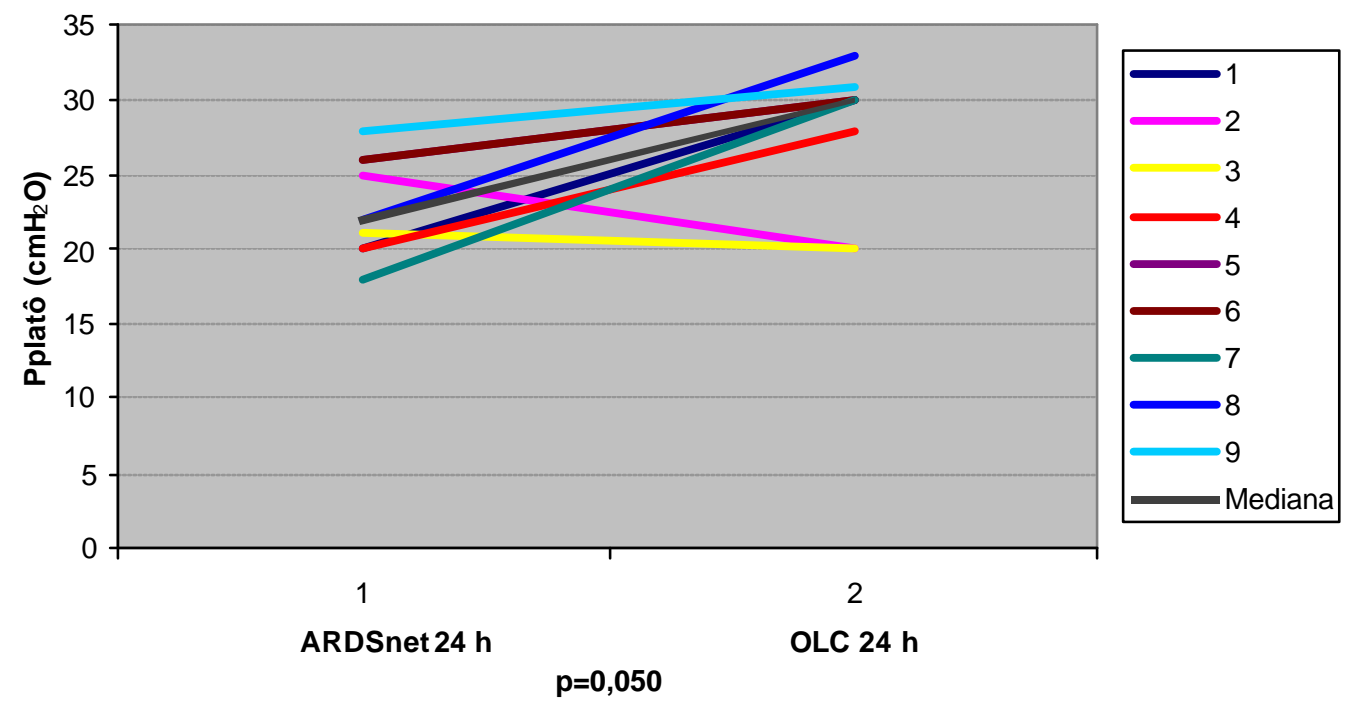

Gráfico 11: Evolução da $\mathrm{PaCO}_{2}$ entre ARDSnet 24 h e OLC 24 h

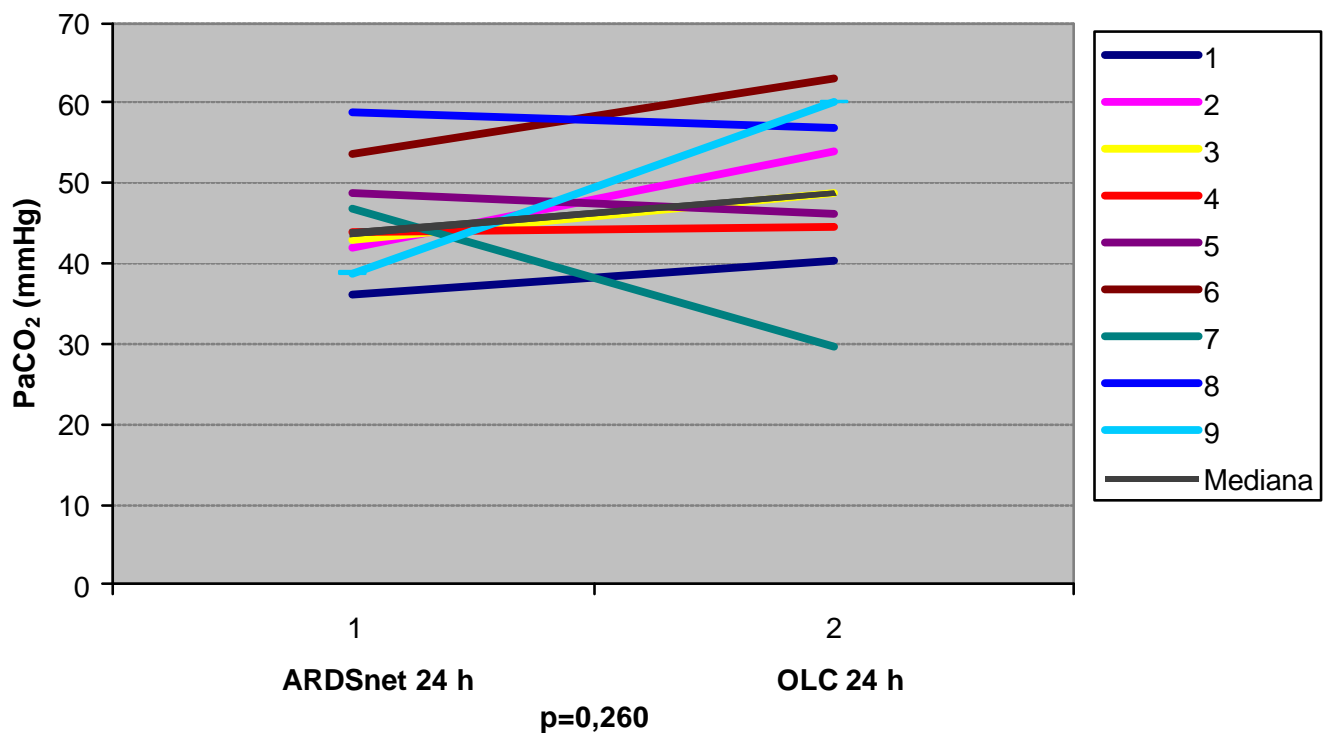


Gráfico 12: Evolução do pH arterial entre ARDSnet 24 h e OLC 24 h

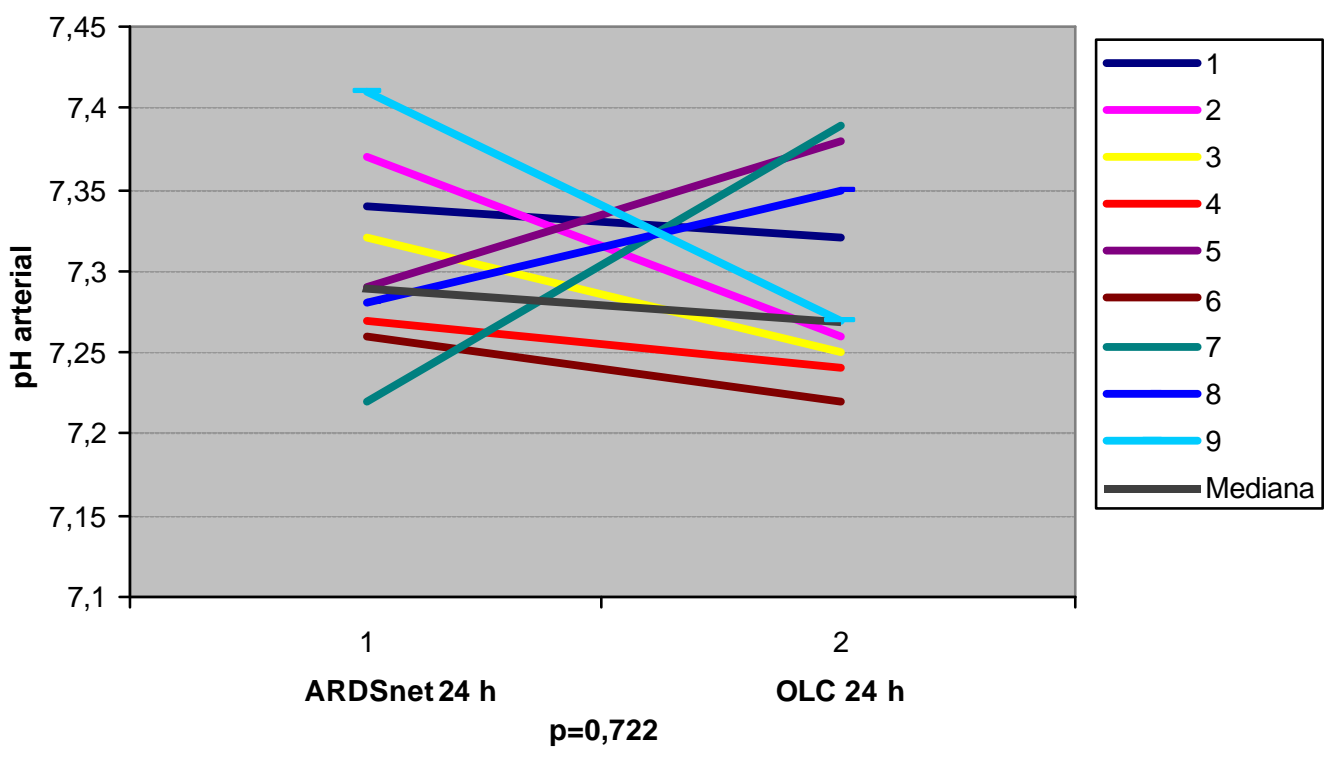

Gráfico 13: Evolução da ventilação - minuto entre ARDSnet 24 h e OLC 24 h

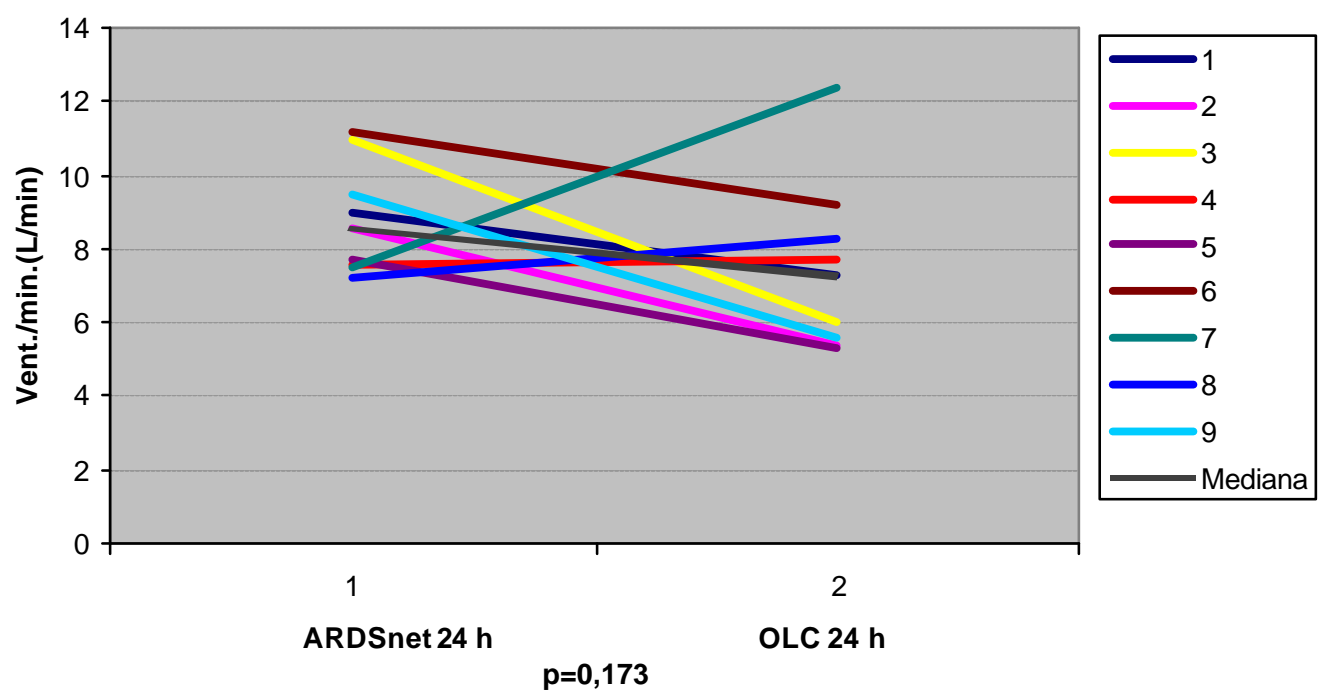


Não houve diferença estatisticamente significativa nos valores de VT/peso ideal entre as duas estratégias ( $\mathrm{p}=0,208$ - tabela 6). As medidas de complacência estática também não diferiram de forma estatisticamente significativa ( $\mathrm{p}=0,260$ - tabela 5, gráfico 14).

Gráfico 14: Evolução da complacência estática entre ARDSnet 24 h e OLC 24 h
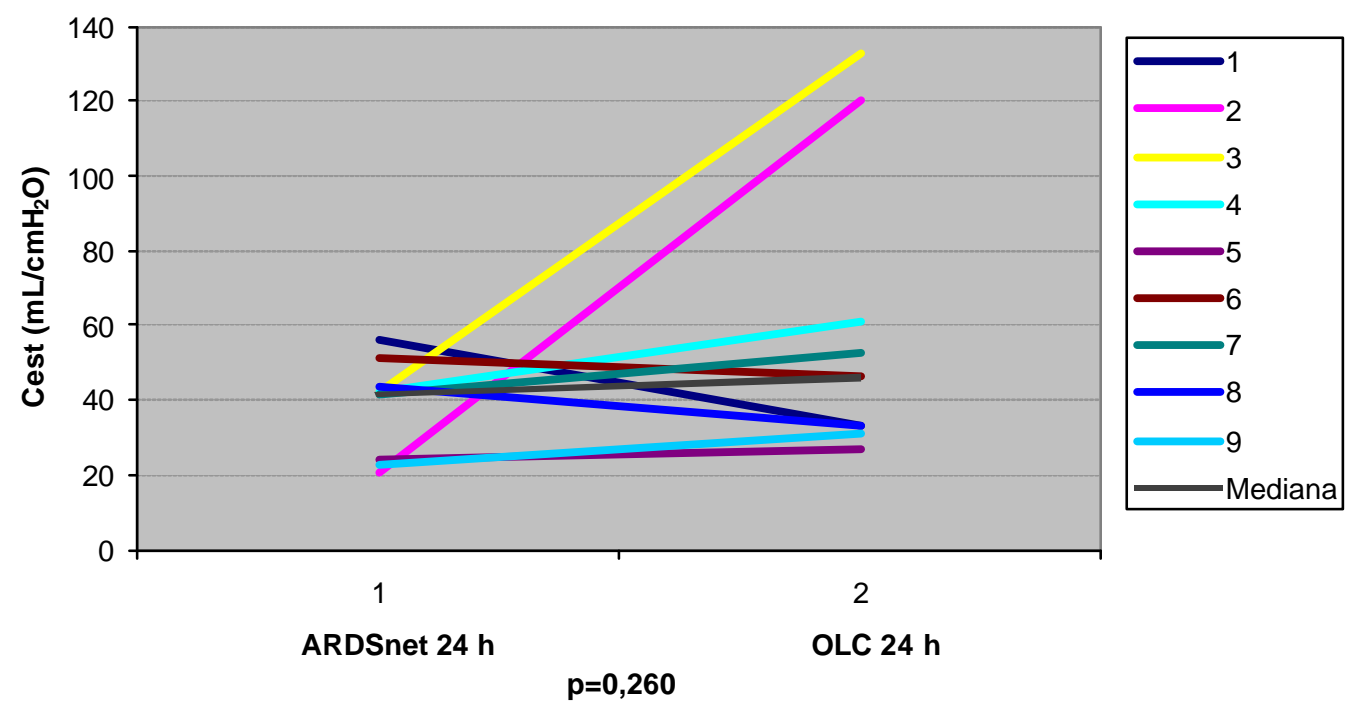
C. Análises tomográficas:

As tabelas 7 e 8 demonstram os resultados das análises quantitativas das imagens tomográficas, baseadas em volume pulmonar total (VPT) e em massa pulmonar total (MPT), respectivamente, com ARDSnet 24 horas e com OLC (nos 9 pacientes submetidos à OLC) e com ARDSnet 48 horas (no paciente 10, que respondeu à esta estratégia).

Tabela 7. Análises quantitativas volumétricas das imagens tomográficas com ARDS net 24 horas e OLC 24 horas (nos 9 pacientes submetidos à OLC) e com ARDSnet 48 h (no paciente 10, com resposta à ARDSnet $24 \mathrm{~h})$

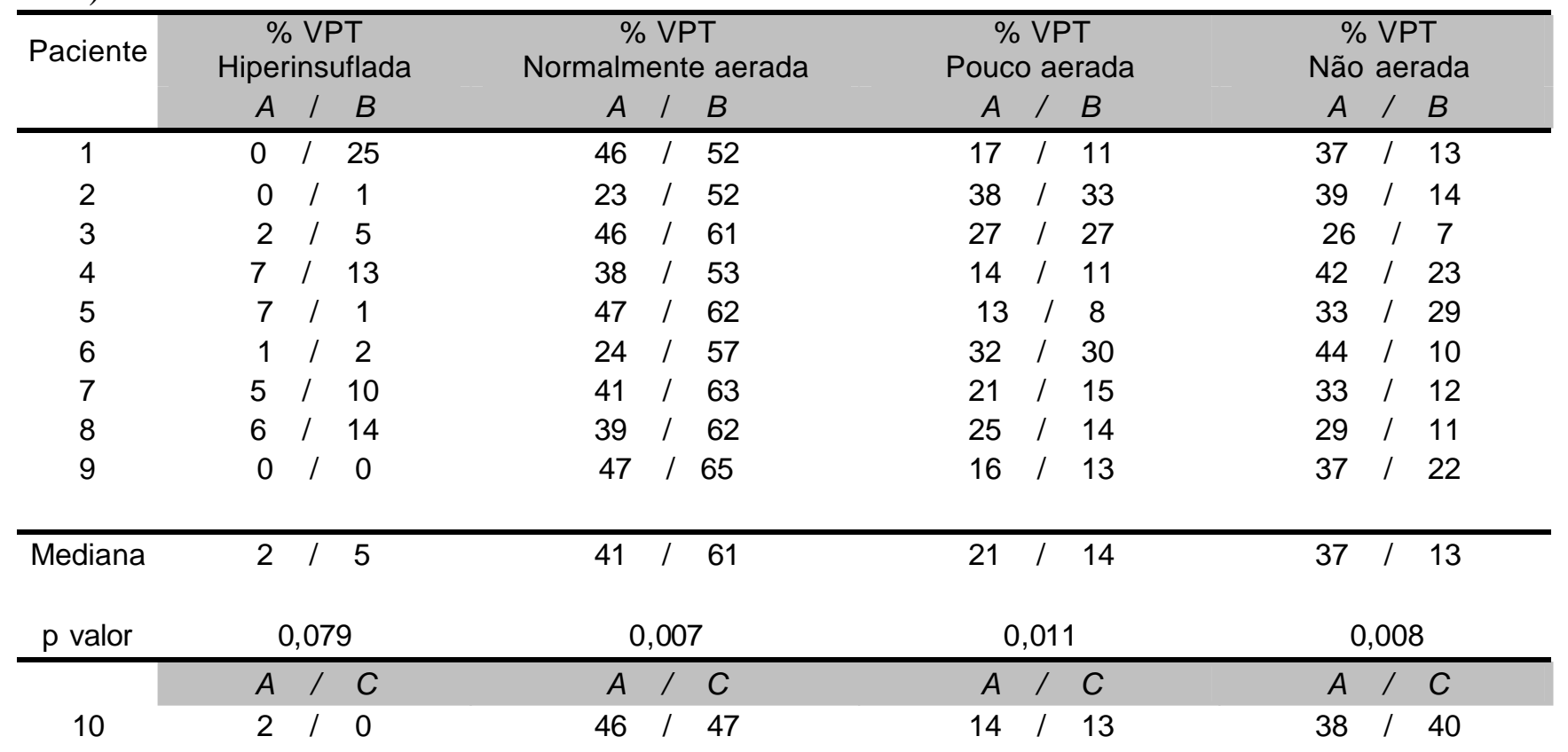

Abreviaturas: \% VPT = Percentagem do volume pulmo nar total; A = Medidas após ARDSnet 24 h; B = Medidas após OLC 24 h; $\mathrm{C}=$ Medidas após ARDSnet 48h (paciente 10). 
Tabela 8. Análises quantitativas das imagens tomográficas com relação à massa pulmonar total com ARDS net 24 horas e OLC 24 horas (nos 9 pacientes submetidos à OLC) e com ARDSnet 48 h (no paciente 10 , com resposta à ARDSnet $24 \mathrm{~h}$ )

\begin{tabular}{|c|c|c|c|c|c|c|c|c|c|c|}
\hline \multirow[t]{2}{*}{ Paciente } & \multicolumn{2}{|c|}{$\begin{array}{c}\% \text { MPT } \\
\text { Hiperinsuflada }\end{array}$} & \multicolumn{2}{|c|}{$\begin{array}{c}\% \text { MPT } \\
\text { Normalmente aerada }\end{array}$} & \multicolumn{3}{|c|}{$\begin{array}{c}\% \text { MPT } \\
\text { Pouco aerada }\end{array}$} & \multicolumn{3}{|c|}{$\begin{array}{c}\text { \% MPT } \\
\text { Não aerada }\end{array}$} \\
\hline & & $/ B$ & $A$ & $/ B$ & A & I & $B$ & A & / & $B$ \\
\hline$\overline{1}$ & 0 & 14 & 21 & $/ 36$ & 19 & 1 & 23 & 60 & 1 & 38 \\
\hline 2 & 0 & 10 & 10 & / 31 & 37 & / & 42 & 53 & / & 26 \\
\hline 3 & 0 & / 1 & 23 & / 41 & 33 & / & 43 & 44 & / & 16 \\
\hline 4 & 1 & 12 & 16 & / 28 & 17 & I & 17 & 67 & I & 53 \\
\hline 5 & 1 & 10 & 22 & / 30 & 18 & / & 11 & 60 & / & 59 \\
\hline 6 & 0 & 10 & 10 & / 38 & 31 & / & 41 & 58 & / & 20 \\
\hline 7 & 0 & 12 & 19 & / 43 & 25 & / & 26 & 55 & / & 30 \\
\hline 8 & 1 & / 2 & 20 & / 44 & 30 & / & 25 & 49 & / & 28 \\
\hline 9 & 0 & 10 & 25 & / 38 & 17 & / & 18 & 58 & / & 44 \\
\hline Mediana & 0 & $/ 1$ & 20 & $/ 38$ & 25 & 1 & 25 & 58 & 1 & 30 \\
\hline \multirow[t]{2}{*}{$p$ valor } & \multicolumn{2}{|c|}{0,084} & \multicolumn{2}{|c|}{0,008} & \multicolumn{3}{|c|}{0,292} & \multicolumn{3}{|c|}{0,008} \\
\hline & $A$ & / C & $A$ & / C & $A$ & I & $C$ & $A$ & I & $C$ \\
\hline 10 & 0 & 10 & 22 & / 23 & 16 & / & 14 & 61 & / & 63 \\
\hline
\end{tabular}

OLC 24 horas determinou redução significativa na percentagem de VPT não aerado $(13 \%$ [10,5 - 22,5] vs. 37\% [31 - 40,5] com ARDS net 24 horas; $p=0,008$ - gráfico 15) sem aumento significativo na percentagem de VPT hiperinsuflado $(5 \%[1-13,5]$ vs. 2\% [0 - 6,5] com ARDS net 24 horas; $\mathrm{p}=0,079$ - gráfico 16). A análise baseada em massa pulmonar total evidenciou resultados semelhantes à análise volumétrica: a percentagem de MPT não aerada foi significativamente menor com OLC (30\% [23 - 48,5] vs. 58\% [51- 60] com ARDSnet; $\mathrm{p}=0,008$ - gráfico 17), sem aumento significativo na percentagem de MPT hiperinsuflada (1\% [0 - 2]com OLC vs. $0 \%$ [0 - 1]com ARDSnet; $\mathrm{p}=0,084$ - gráfico 18). 
Gráfico 15: Variação do percentual de volume pulmonar total (VPT) não aerado entre ARDSnet 24 h e OLC 24 h

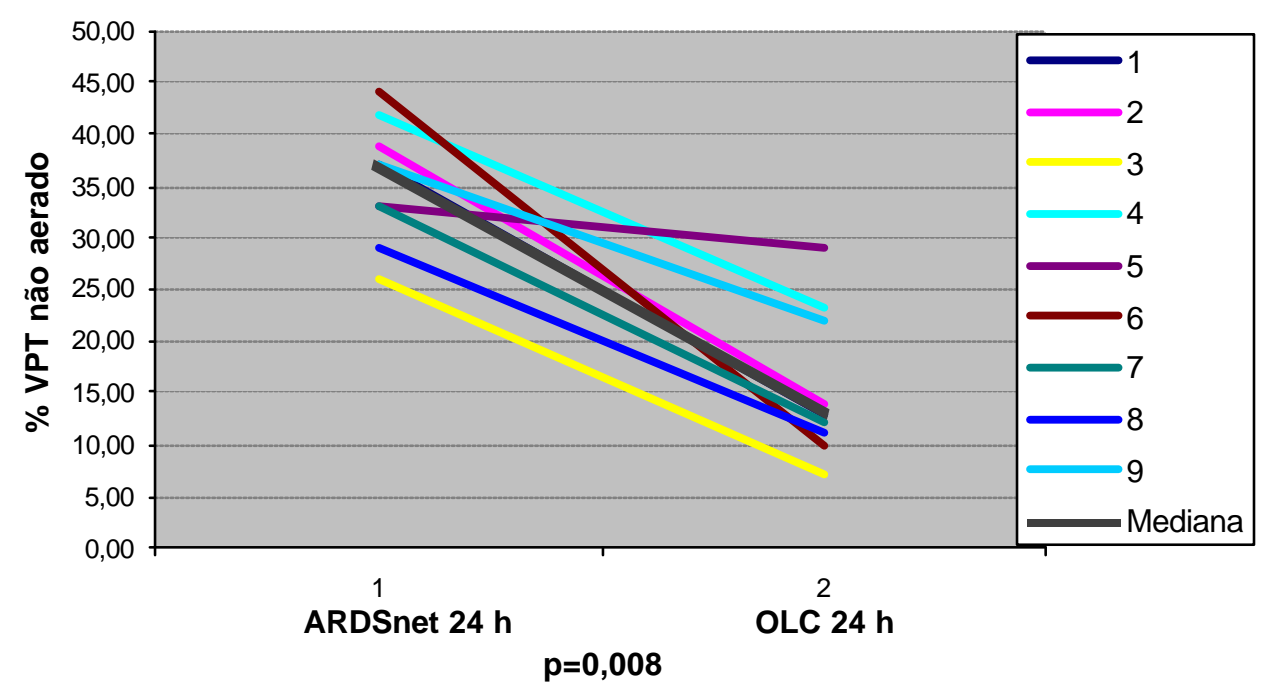

Gráfico 16: Variação do percentual de volume pulmonar total (VPT) hiperinsuflado entre ARDSnet 24 h e OLC 24 h

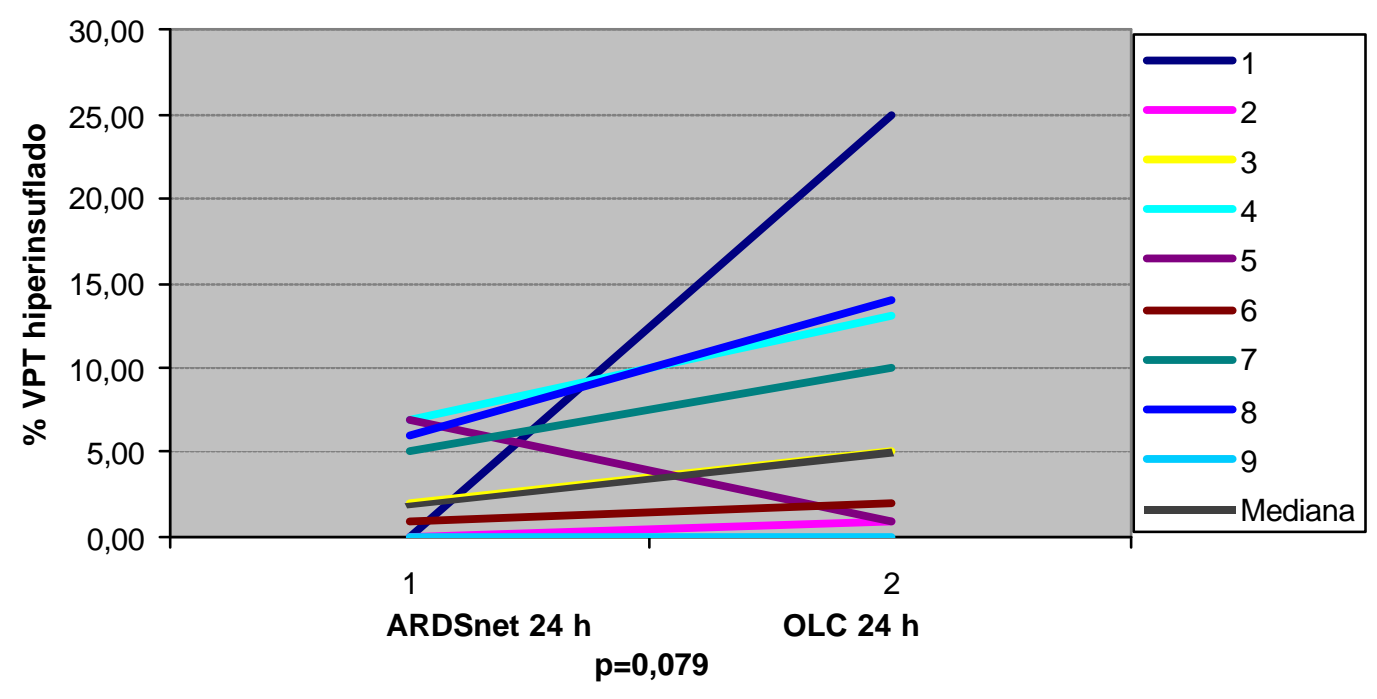


Gráfico 17: Variação do percentual de massa pulmonar total (MPT) não aerada entre ARDSnet 24 h e OLC 24 h
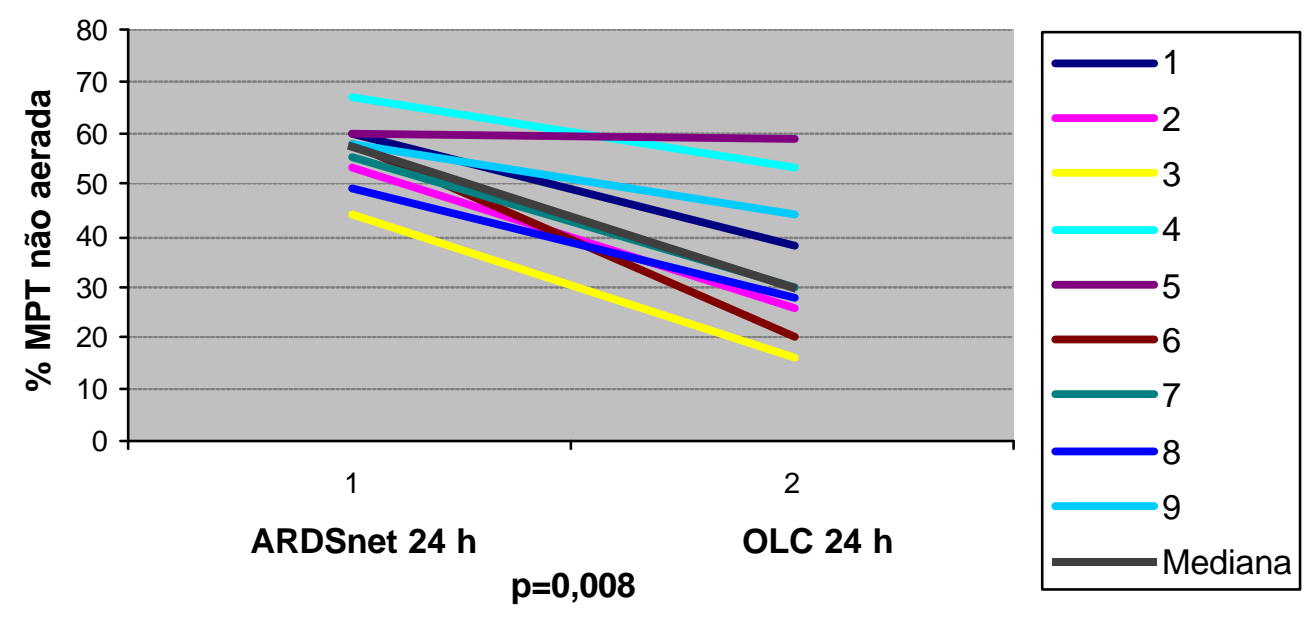

Gráfico 18: Variação do percentual de massa pulmonar total (MPT) hiperinsuflada entre ARDSnet 24 h e OLC 24 h

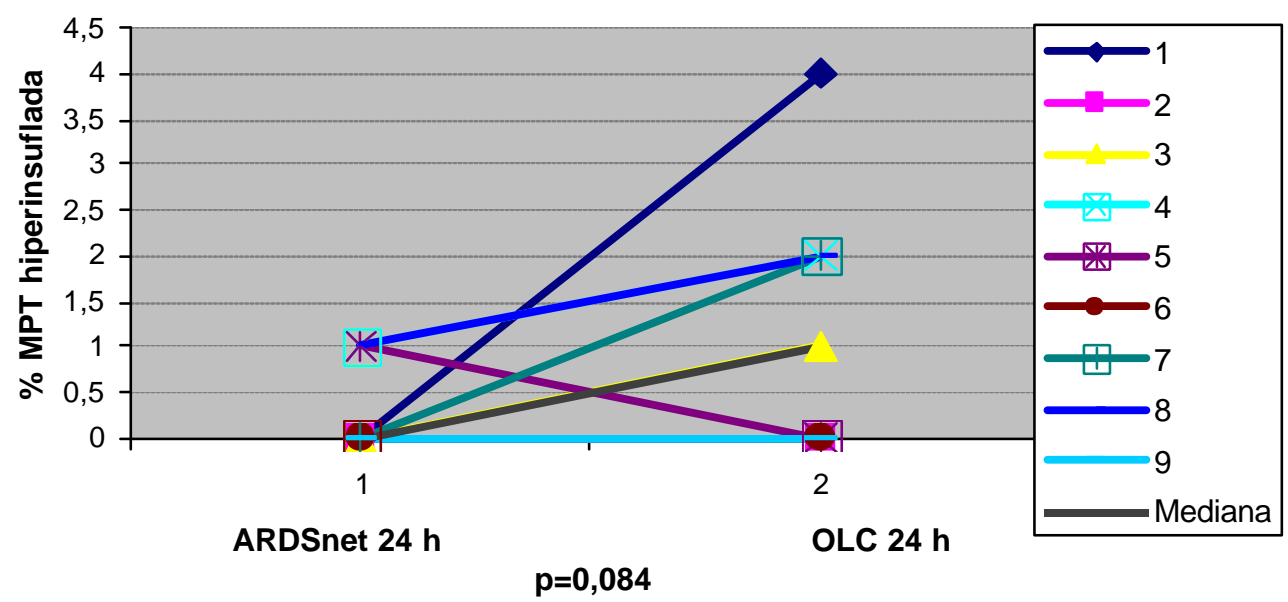


D. Hemodinâmica e balanço hídrico:

Não houve diferença estatisticamente significativa entre as estratégias no que concerne média dos valores/dia de PAM ( $\mathrm{p}=0,374$ - gráfico 19) e taxa de infusão de noradrenalina ( $\mathrm{p}=0,866$ - gráfico 20).

Gráfico 19: Evolução da média dos valores diários das PAMs entre

ARDSnet 24 h e OLC 24 h

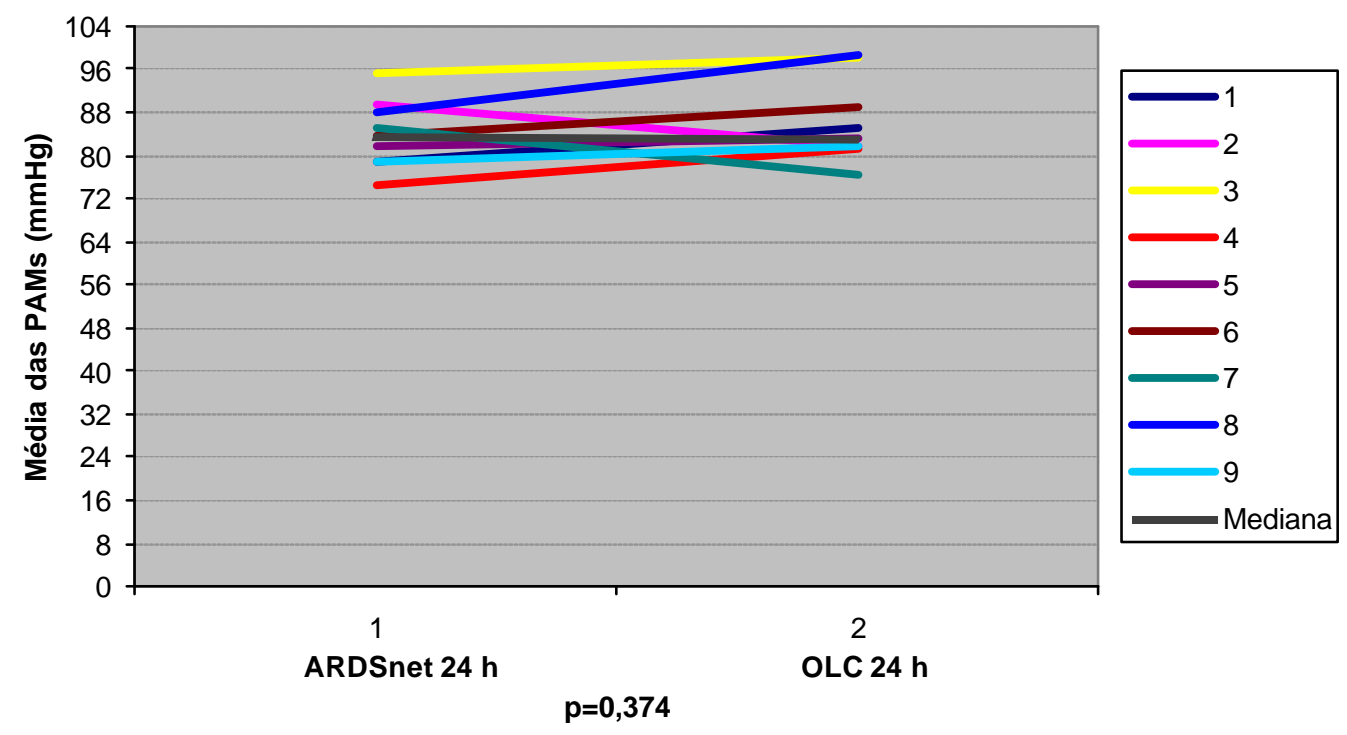


Gráfico 20: Evolução da infusão de noradrenalina entre ARDSNET 24 h

e

OLC 24 h

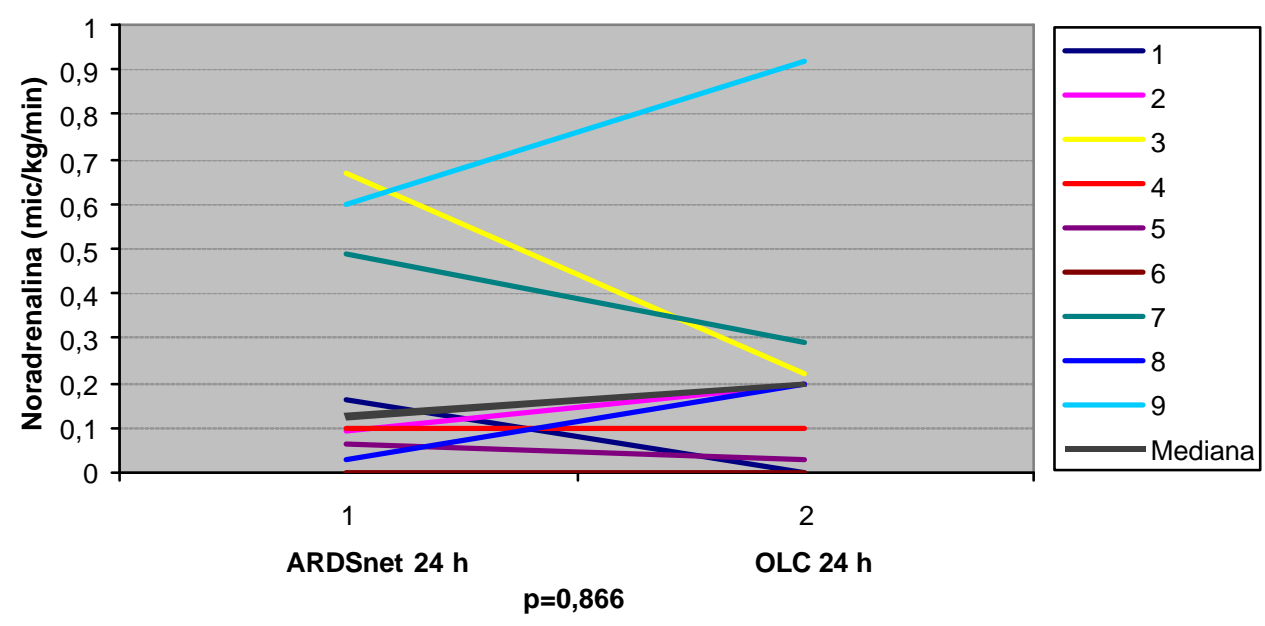

Houve tendência de menores balanços hídricos com OLC 24 horas em relação à ARDS net 24 horas, porém sem significância estatística ( $\mathrm{p}=0,05$-Gráfico 21).

Gráfico 21: Evolução do balanço hídrico de 24 horas entre ARDSnet 24 h e OLC 24 h

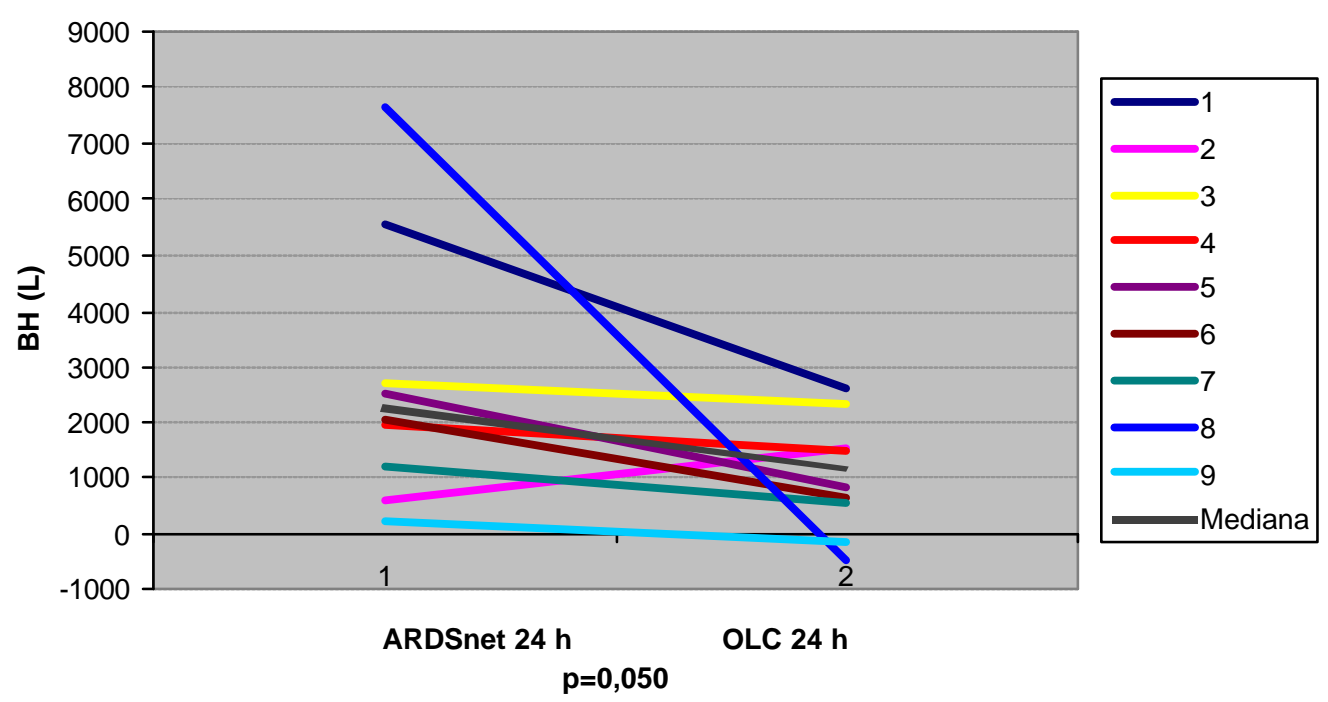


E. Mediadores inflamatórios:

Nos 7 pacientes submetidos à OLC 24 horas, que tiveram níveis de IL- 8 e IL-6 medidos no plasma e no mini-BAL, observou-se redução significativa apenas nos níveis plasmáticos de IL-6 após OLC 24 horas em relação à ARDS net 24 horas $(3,32$ [2,16 - 9,46] vs. 4,11 ng/mL [3,26 - 11,02], respectivamente; p=0,018 - Tabela 9, gráfico 22). As outras concentrações não foram significativamente diferentes entre as duas estratégias (tabela 9, gráficos 23 a 25).

Tabela 9. Concentrações de IL-8 e IL-6 no plasma e mini-Bal (ng/mL) com ARDSnet 24 horas e OLC 24 horas:

\begin{tabular}{|c|c|c|c|c|}
\hline Paciente & $\begin{array}{c}\text { IL-8 plasmática } \\
\text { (ng/mLI) } \\
\text { ARDSnet } 24 \mathrm{~h} / \text { OLC } 24 \mathrm{~h}\end{array}$ & $\begin{array}{c}\text { IL-8 mini-BAL } \\
(\mathrm{ng} / \mathrm{mLI}) \\
\text { ARDSnet } 24 \mathrm{~h} / \text { OLC } 24 \mathrm{~h}\end{array}$ & $\begin{array}{c}\text { IL-6 plasmática } \\
\text { (ng/mLI) } \\
\text { ARDSnet } 24 \mathrm{~h} / \text { OLC } 24 \mathrm{~h}\end{array}$ & $\begin{array}{c}\mathrm{IL}-6 \mathrm{mini}-\mathrm{BAL} \\
(\mathrm{ng} / \mathrm{mLI}) \\
\text { ARDSnet } 24 \mathrm{~h} / \text { OLC } 24\end{array}$ \\
\hline 3 & $24,94 / 13,63$ & $85,04 / 131,41$ & $3,26 / 1,95$ & $8,49 / 30,26$ \\
\hline 4 & $11,12 / 8,71$ & $132,17 / 115,11$ & $4,11 / 2,22$ & $24,14 / 9,58$ \\
\hline 5 & $42,18 / 63,18$ & $69,25 / 83,56$ & $18 / 16$ & $14,79 / 6,14$ \\
\hline 6 & 24,89 / 20,22 & $106,82 / 96,84$ & $11,02 / 3,32$ & $25,29 / 23,47$ \\
\hline 7 & $16,83 / 28,33$ & $85,75 / 75,80$ & $3,70 / 3,35$ & $13,83 / 9,51$ \\
\hline 8 & $8,3 / 7,19$ & $42,87 / 43,60$ & $3,10 / 2,16$ & 24,85 / 8,45 \\
\hline 9 & 37,7 / 48,42 & $60,05 / 52,11$ & $10,02 / 9,46$ & $17,38 / 21,62$ \\
\hline Mediana & $24,89 / 20,22$ & $85,04 / 83,56$ & $4,11 / 3,32$ & $17,38 / 9,58$ \\
\hline$p$ valor & 0,612 & 0,866 & 0,018 & 0,398 \\
\hline
\end{tabular}


Gráfico 22: Evolução dos níveis plasmáticos de IL- 6 entre ARDSnet 24 h e OLC 24 h

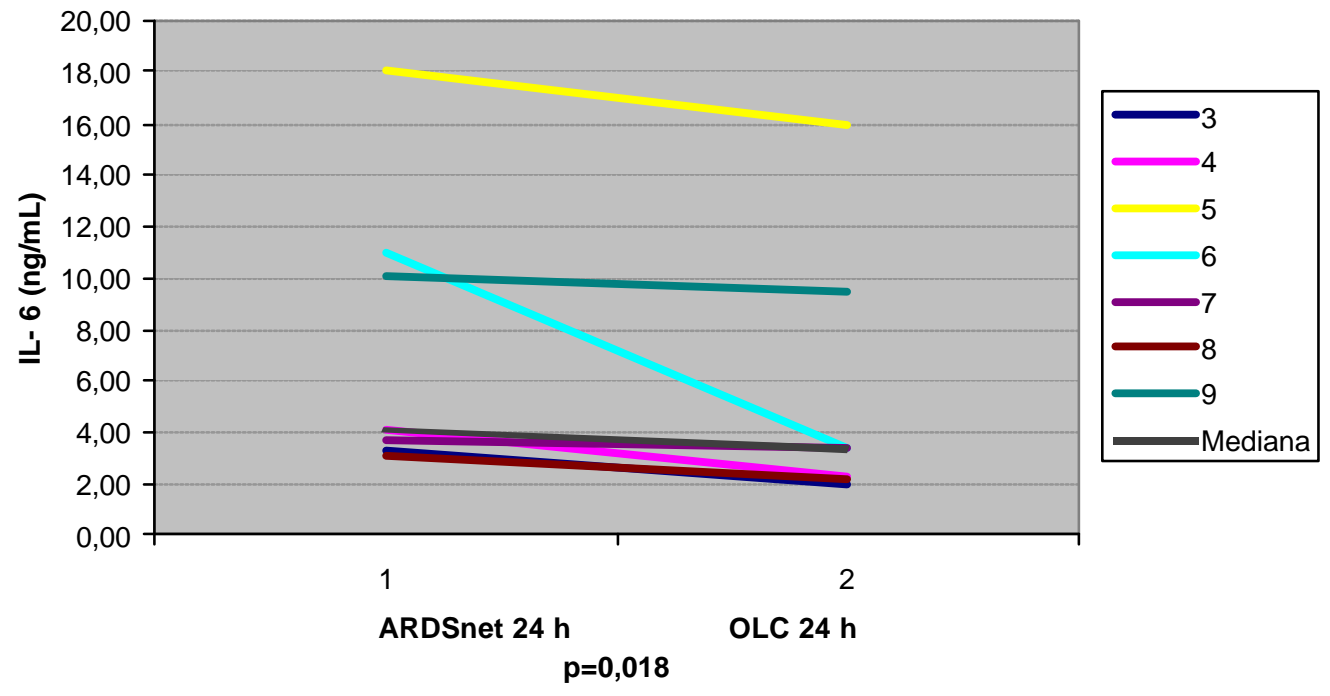

Gráfico 23: Evolução dos níveis de IL- 6 no mini-BAL entre ARDSnet 24 h e OLC 24 h

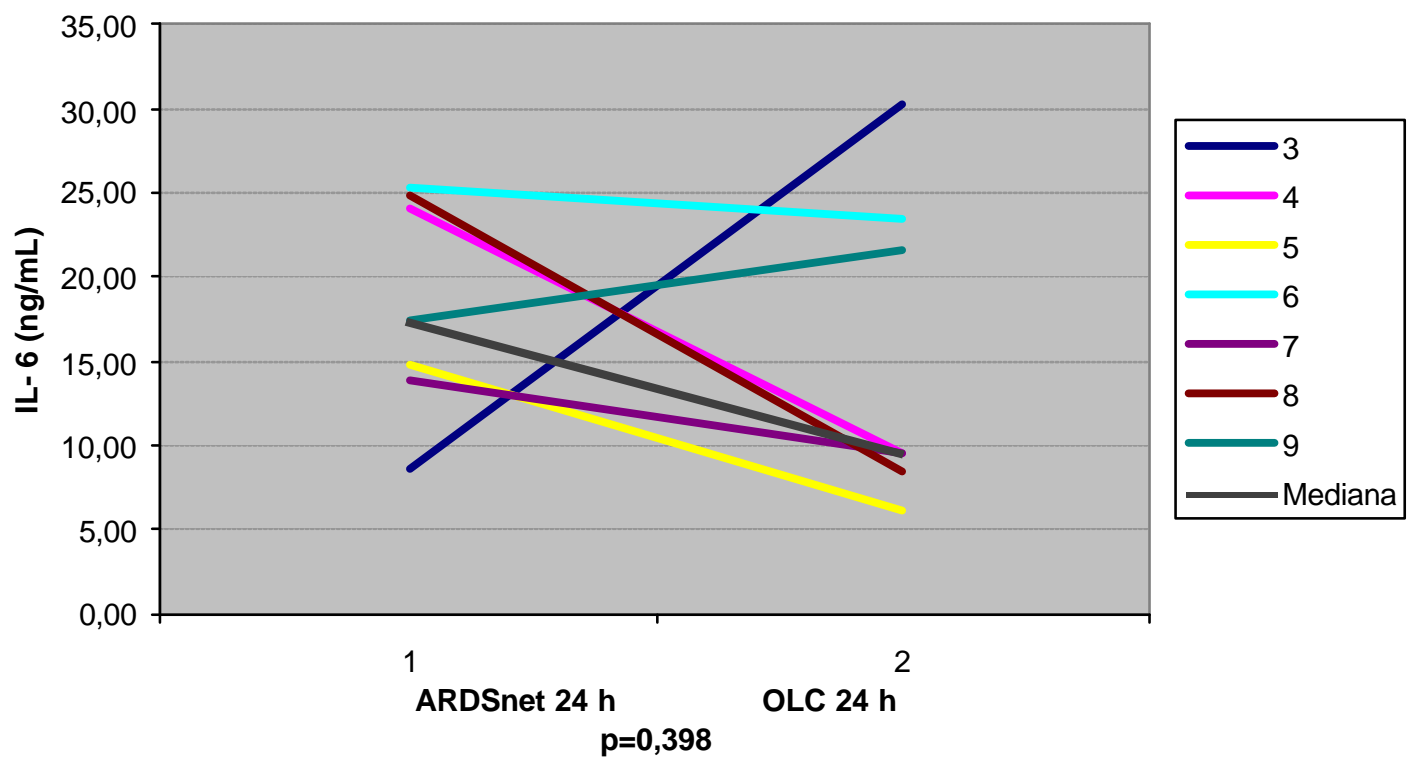


Gráfico 24: Evolução dos níveis de IL- 8 no mini-BAL entre ARDSnet 24 h e OLC 24 h

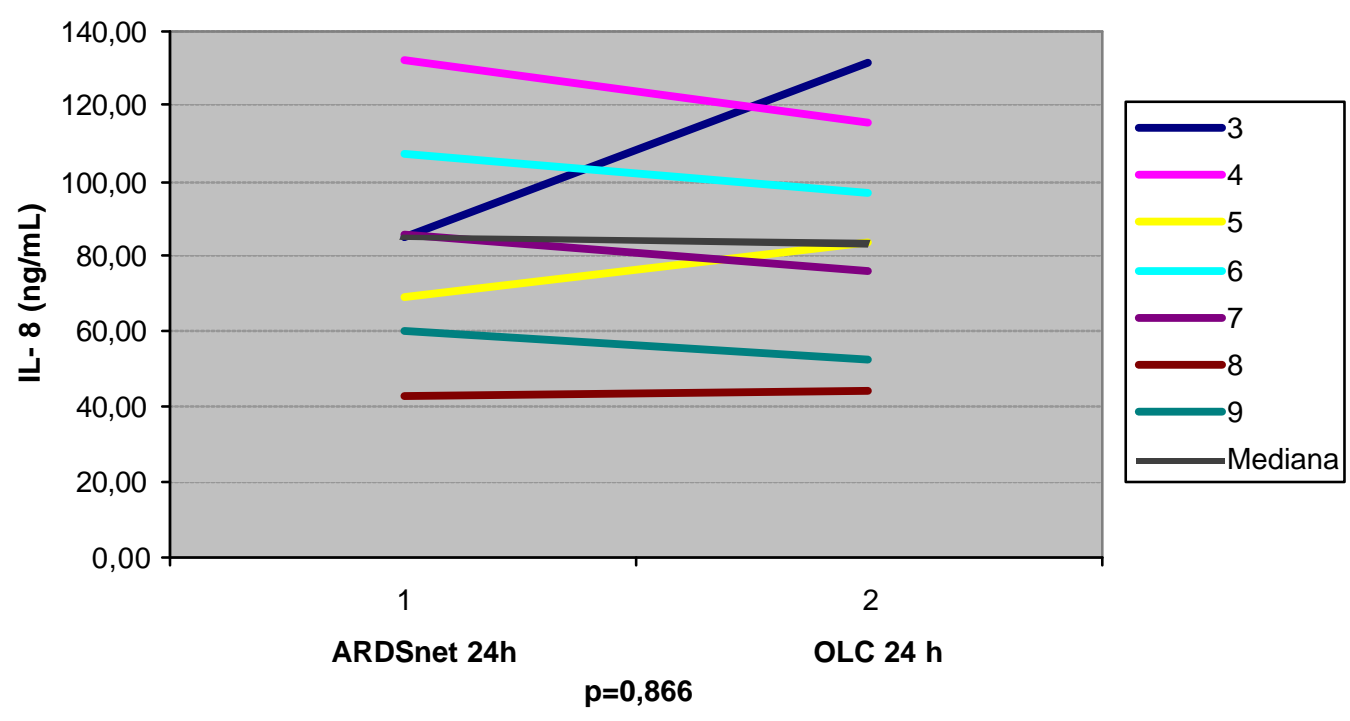

Gráfico 25: Evolução dos níveis plasmáticos de IL- 8 entre ARDSnet 24 h e OLC 24h

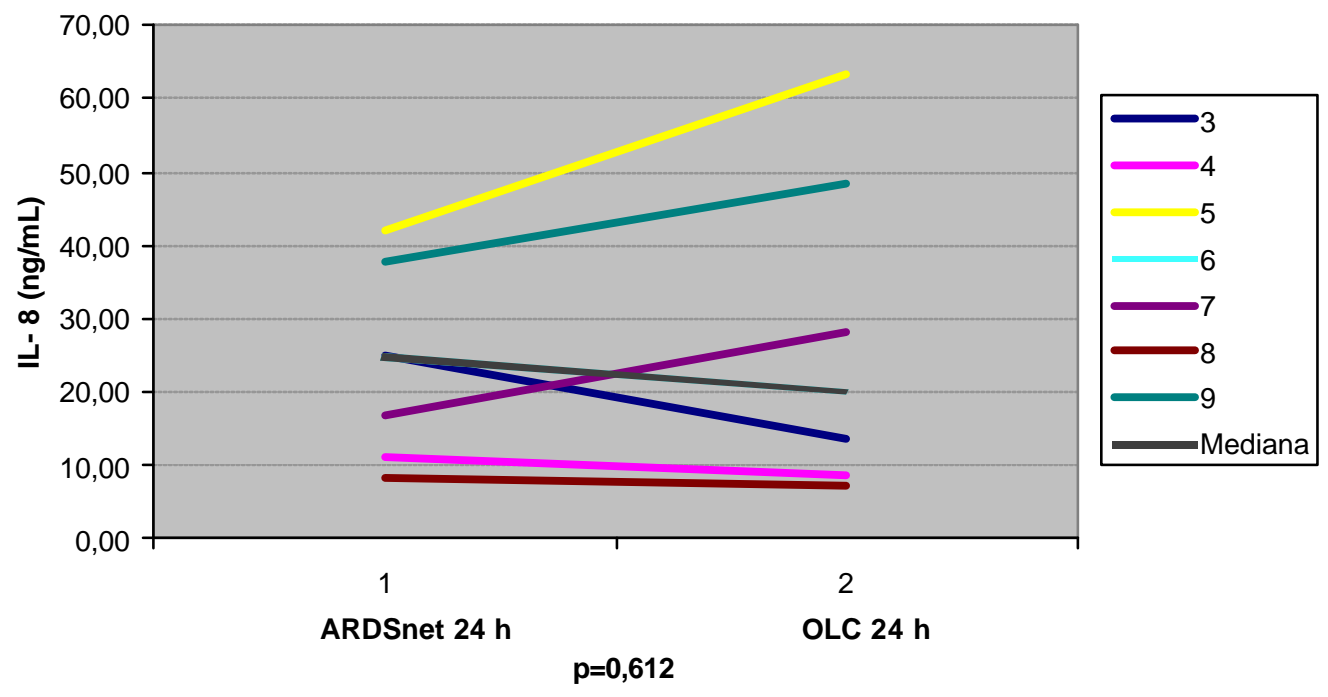




\section{3-Padrões tomográficos de resposta às estratégias ventilatórias estudadas:}

Três diferentes padrões tomográficos de resposta à ARDS net e OLC foram observados. A seguir, estes padrões serão exemplificados através de cortes tomográficos, reconstruções tridimensionais e histogramas, obtidos nas diferentes fases do estudo.

Os cortes tomográficos são demonstrados no nível da carina e próximo à base.

As reconstruções tridimensionais são demonstradas nas visões diagonais ântero-posterior (imagem à esquerda) e póstero-anterior (imagem à direita), onde: vermelho representa as regiões hiperinsufladas, azul as normalmente aeradas, branco as pobremente aeradas e preto as não aeradas.

Os histogramas da distribuição de frequiências das unidades Hounsfield são demonstrados segundo os eixos céfalo-caudal (imagens superiores) e ventro-dorsal (imagens inferiores). Nestes histogramas, a linha espessa representa a média dos valores das unidades Hounsfield e as linhas verticais representam a dispersão dos valores entre os percentis 25 e 75 . 


\section{Boa resposta a OLC (Paciente 6):}

Nos cortes tomográficos observa-se melhora importante das áreas de colapso alveolar após OLC 24

h, com relação à ARDSnet, principalmente nas regiões posteriores dos pulmões (figura 4).

\section{ARDSnet $24 \mathrm{~h} ? \quad \mathrm{PEEP}=14 \mathrm{cmH}_{2} \mathrm{O}$}
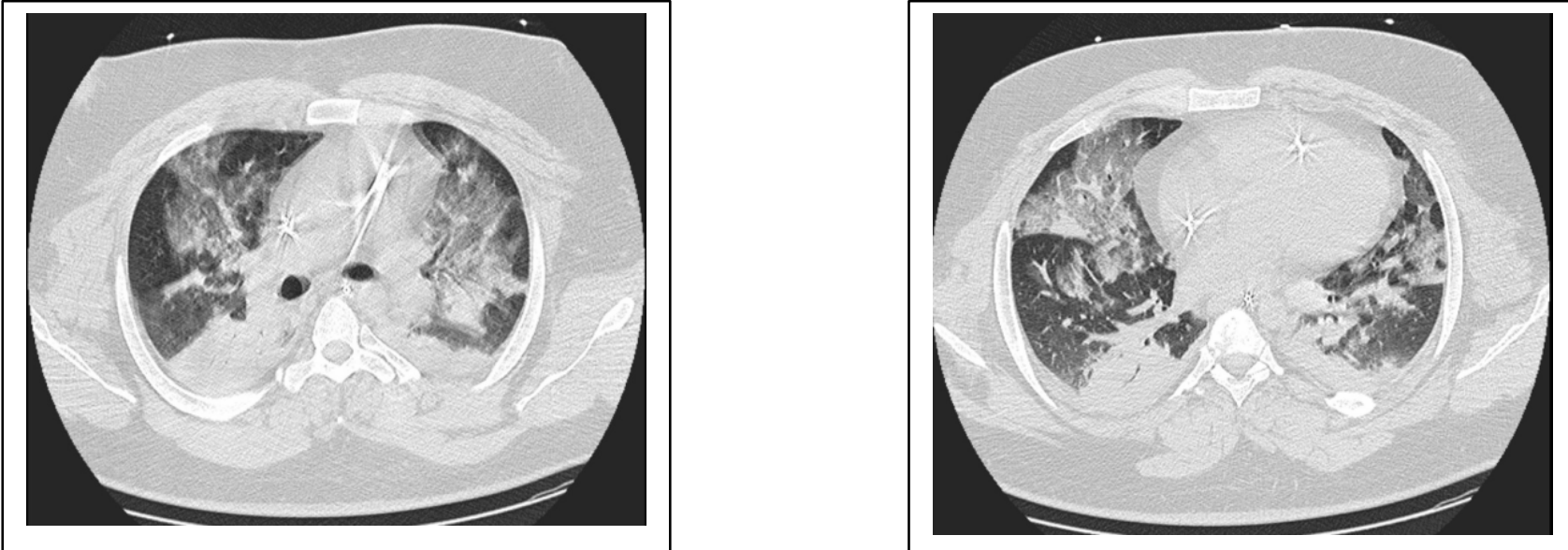

OLC $24 \mathrm{~h} ? \quad \mathrm{PEEP}=19 \mathrm{cmH}_{2} \mathrm{O}$
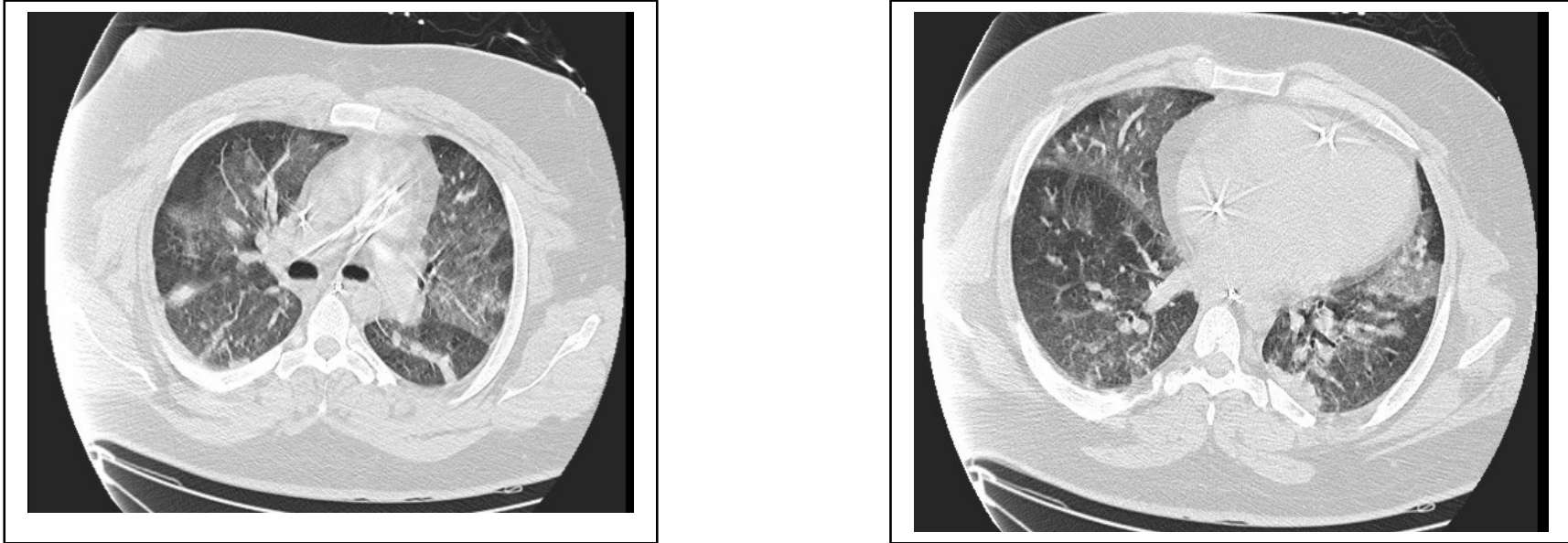

Figura 4: Cortes tomográficos na altura da carina e próximo à base, com ARDSnet 24 h (imagens superiores) e com OLC 24 h (imagens inferiores), de um paciente com boa resposta à OLC. 
As reconstruções tridimensionais demonstram que, após OLC 24 h, as regiões não aeradas diminuem de forma significativa, com aumento nas áreas normalmente aeradas, sem grande incremento das regiões hiperinsufladas (figura 5).

ARDSnet $24 \mathrm{~h} ? \quad \mathrm{PEEP}=14 \mathrm{cmH}_{2} \mathrm{O}$

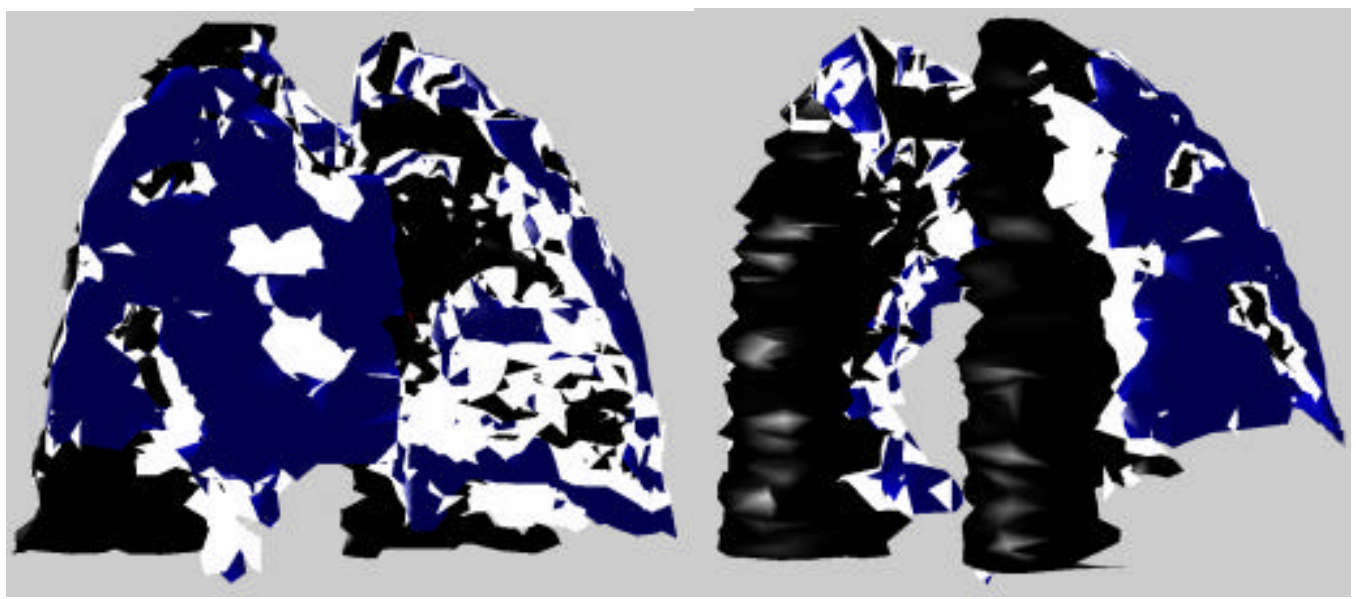

OLC $24 \mathrm{~h} ? \quad \mathrm{PEEP}=19 \mathrm{cmH}_{2} \mathrm{O}$

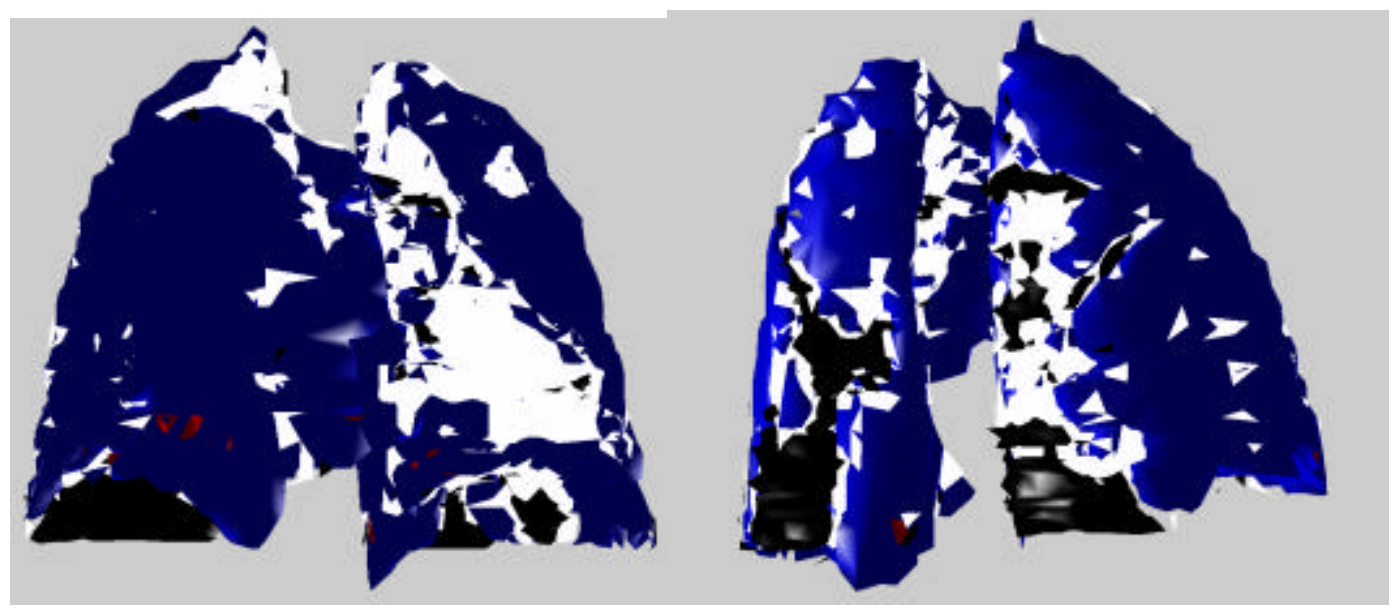

Figura 5: Reconstruções tridimensionais nas visões diagonais ântero-posterior (imagem à esquerda) e póstero-anterior (imagem à direita), onde vermelho representa as regiões hiperinsufladas, azul as normalmente aeradas, branco as pobremente aeradas e preto as não aeradas. As imagens superiores foram obtidas com ARDSnet $24 \mathrm{~h}$ e as inferiores com OLC $24 \mathrm{~h}$, de um paciente com boa resposta à OLC. 
Nos histogramas observa-se que após ARDSnet 24 h existe uma grande dispersão dos valores, em relação à média, demonstrando a não homogeneidade pulmonar. Há também intenso colapso alveolar, principalmente próximo à base pulmonar. Após OLC, ocorre redução na dispersão dos valores e a curva da média desloca-se, em sua quase totalidade, para a área representativa de regiões normalmente aeradas (figuras 6 e 7).
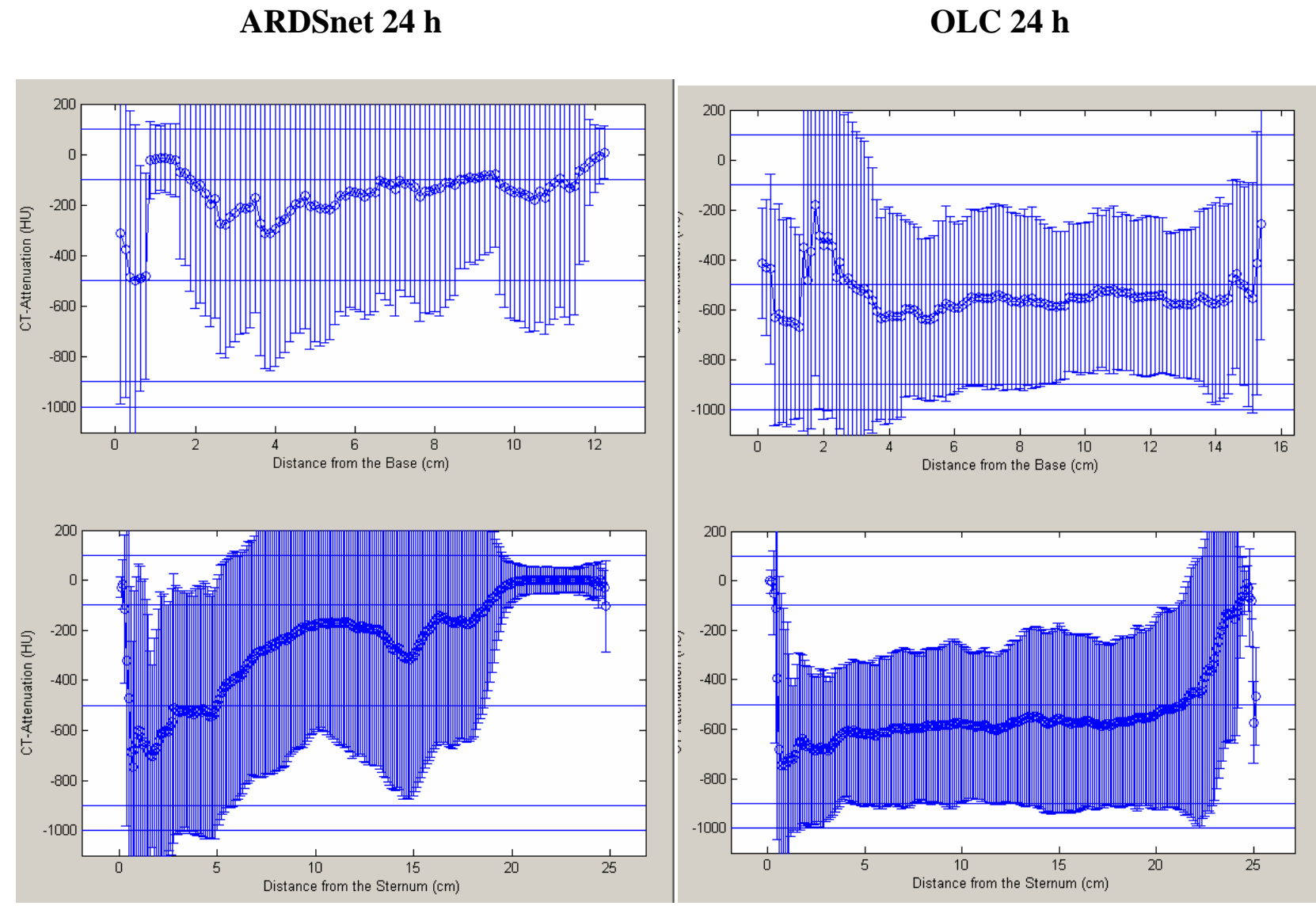

Figura 6: Histogramas da distribuição de freqüências das unidades Hounsfield após ARDSnet 24 h (coluna esquerda) e após OLC 24 h (coluna direita) obtidos de um paciente com boa resposta à OLC. A linha espessa representa a média dos valores das unidades Hounsfield e as linhas verticais representam a dispersão dos valores entre os percentis 25 e 75 . 
ARDSnet 24 h

OLC 24 h
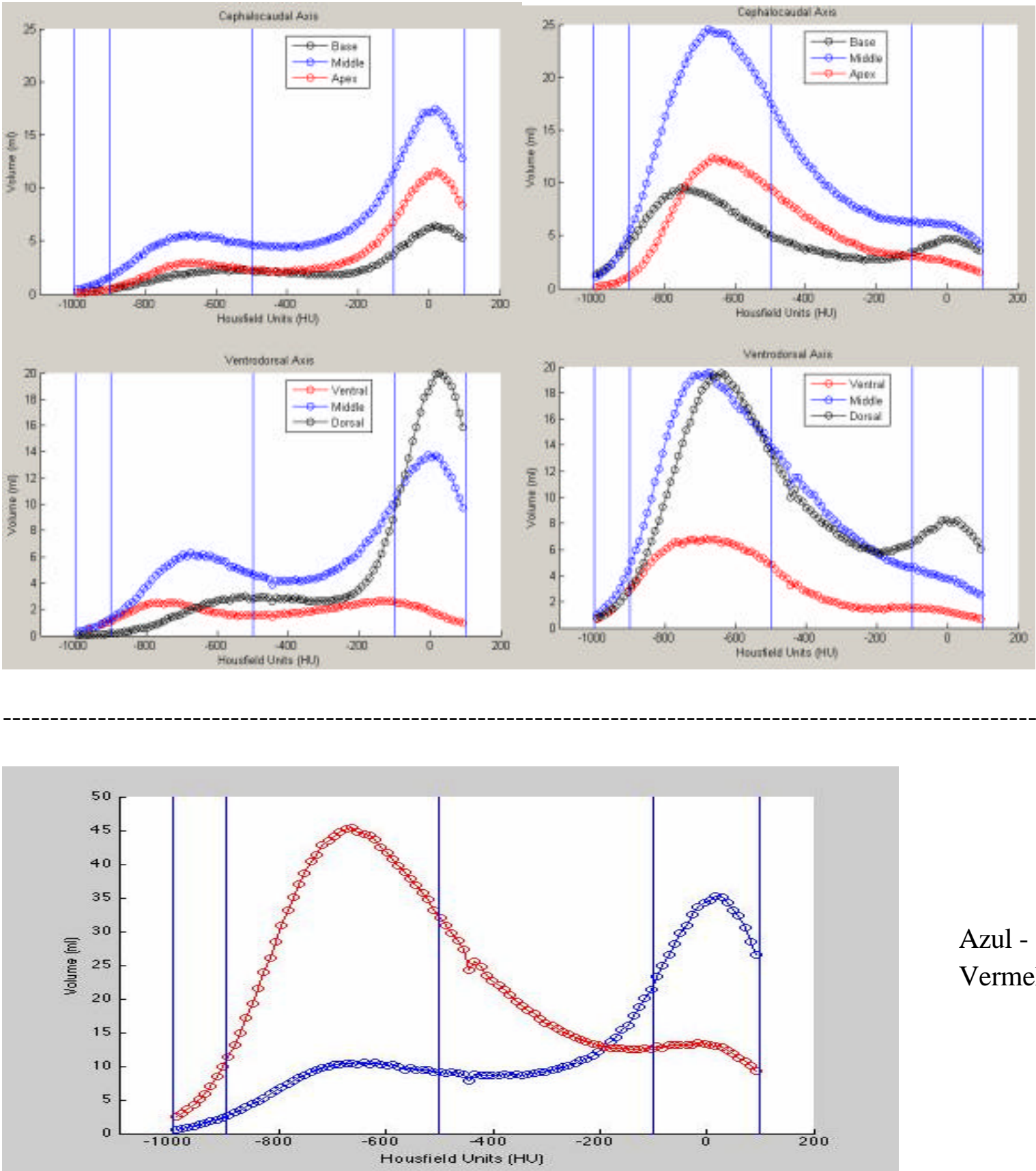

Azul - ARDSnet 24h

Vermelho - OLC 24h

Figura 7: Histogramas das zonas de West (imagens superiores) com ARDSnet $24 \mathrm{~h}$ (coluna esquerda) e com OLC (coluna direita) e histograma de todo o pulmão (imagem inferior) obtidos de um paciente com boa resposta ã OLC. 


\section{Hiperinsuflacão com OLC (paciente 7):}

As imagens tomográficas revelam que, após OLC 24 h, ocorreu recrutamento da área de consolidação no lobo superior direito, evidenciando-se no entanto, área de destruição pulmonar (figura 8). Na mesma região, surgiu pneumotórax, melhor visualizado nos cortes mais cefálicos (como será discutido posteriormente).

ARDSnet $24 \mathrm{~h} ? \quad$ PEEP $=8 \mathrm{cmH}_{2} \mathrm{O}$
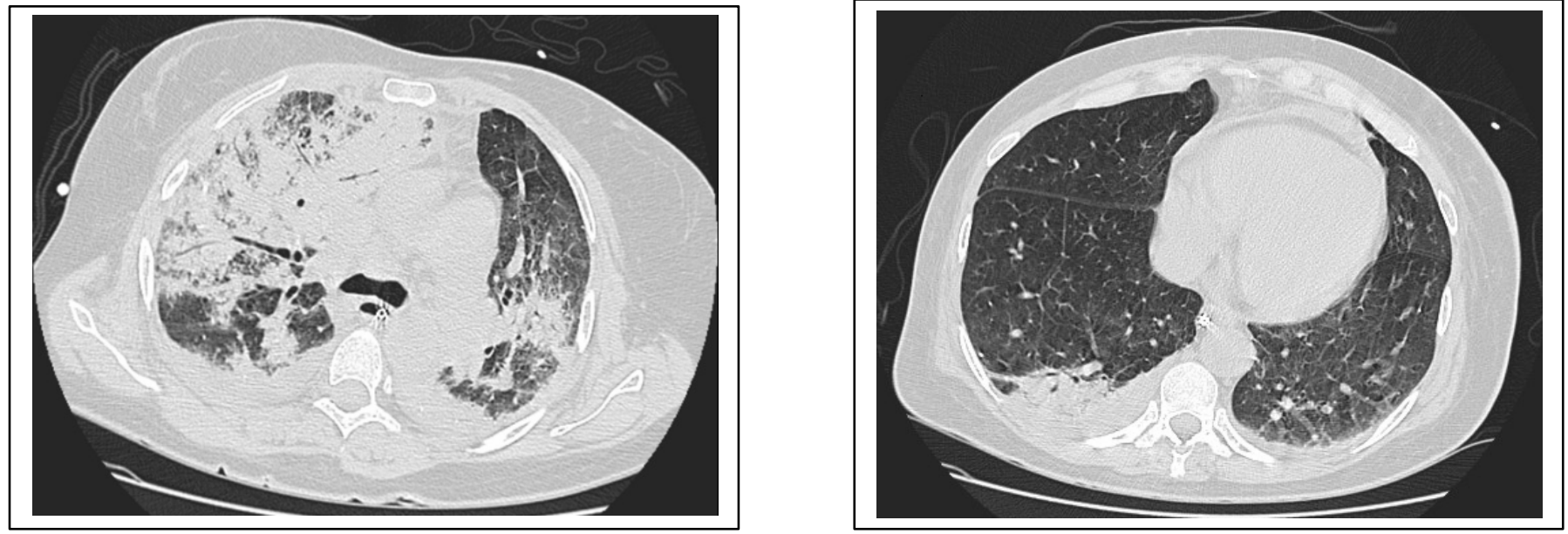

OLC $24 \mathrm{~h} ? \quad \mathrm{PEEP}=17 \mathrm{cmH}_{2} \mathrm{O}$
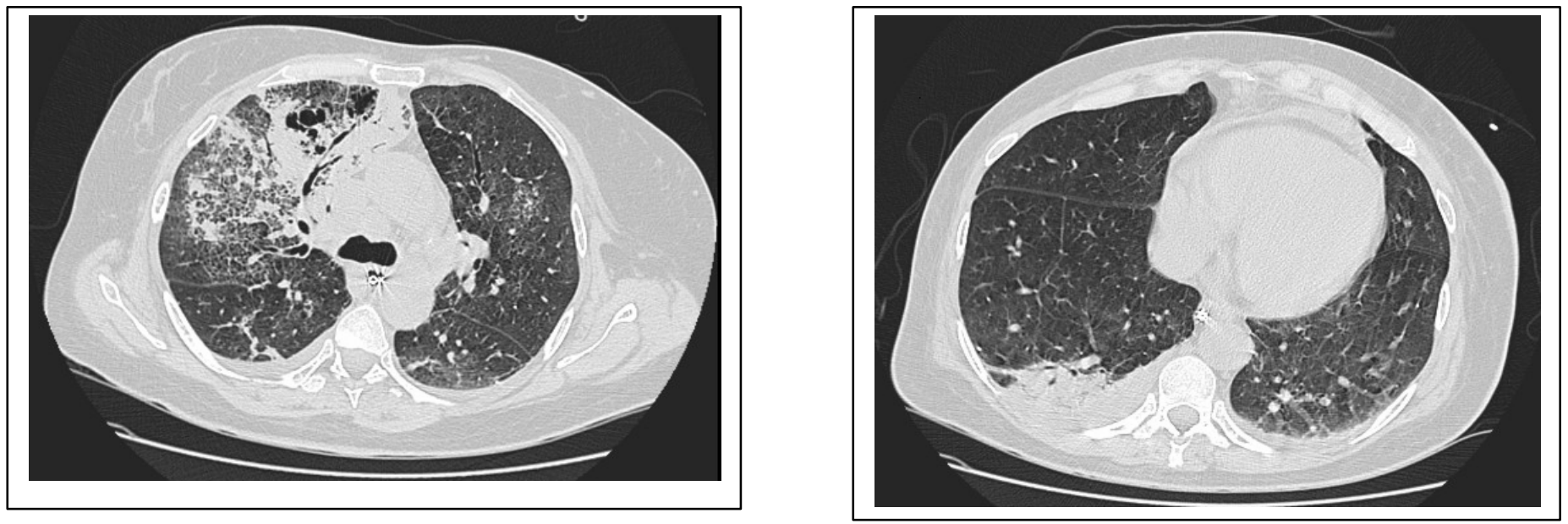

Figura 8: Cortes tomográficos na altura da carina e próximo à base, com ARDSnet 24 h (imagens superiores) e com OLC 24 h (imagens inferiores), de um paciente com hiperinsuflação com OLC. 
As reconstruções tridimensionais demonstram que OLC 24 horas determinou redução nas áreas de colapso alveolar (principalmente nas porções posteriores), com aumento nas áreas de hiperinsuflação (figura 9).

ARDSnet $24 \mathrm{~h} ? \quad \mathrm{PEEP}=8 \mathrm{cmH}_{2} \mathrm{O}$

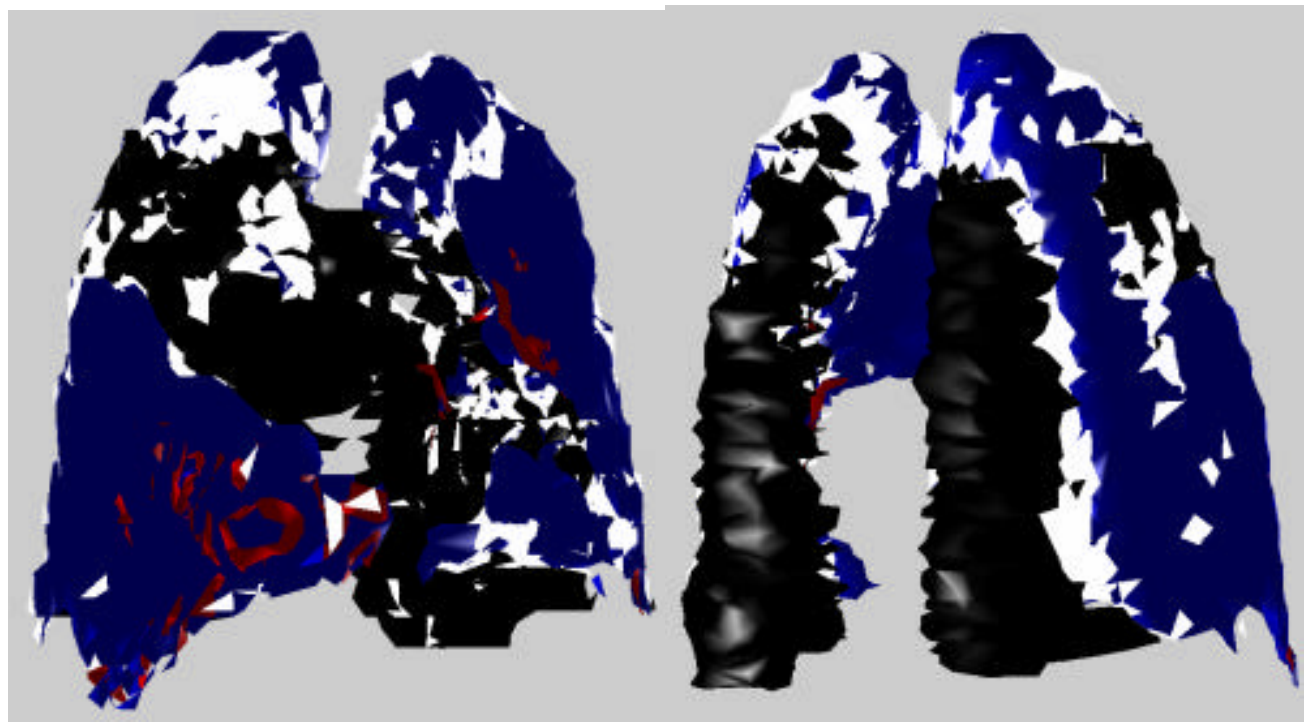

OLC $24 \mathrm{~h} ? \quad \mathrm{PEEP}=17 \mathrm{cmH}_{2} \mathrm{O}$

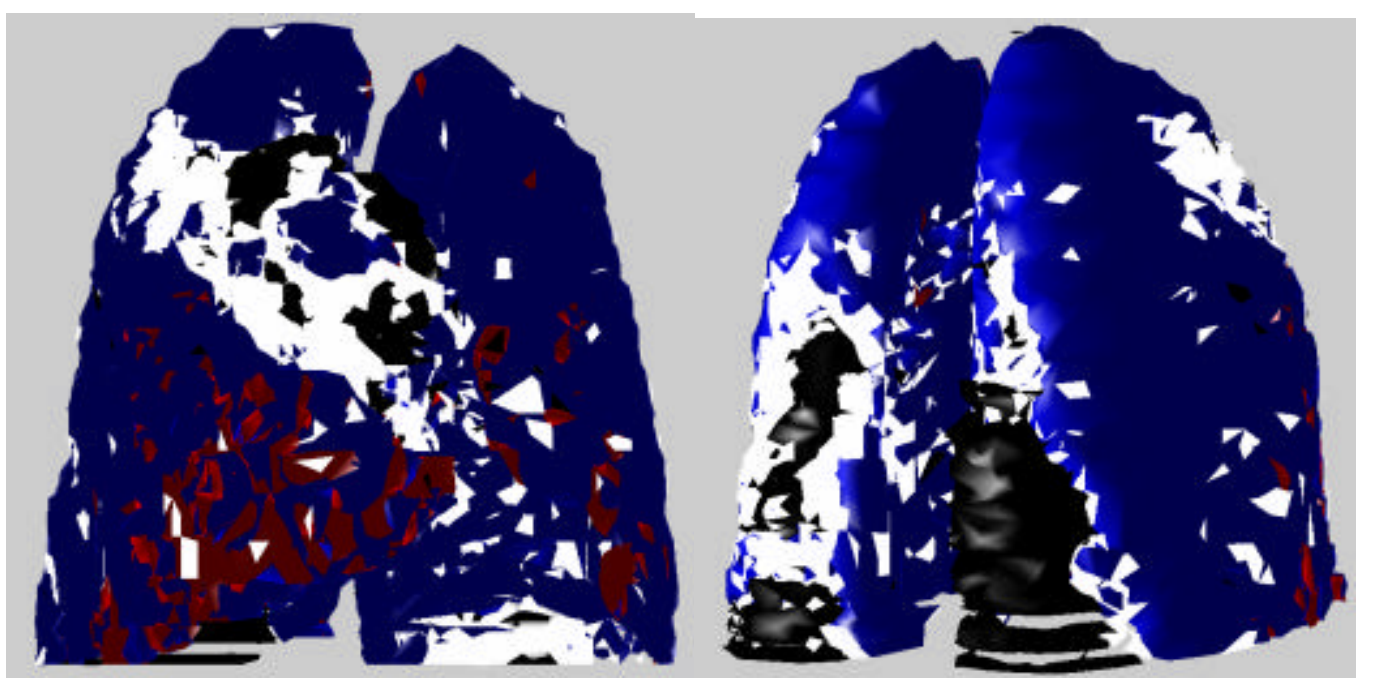

Figura 9: Reconstruções tridimensionais nas visões diagonais ântero-posterior (imagem à esquerda) e póstero-anterior (imagem à direita), onde: vermelho representa as regiões hiperinsufladas, azul as normalmente aeradas, branco as pobremente aeradas e preto as não aeradas. As imagens superiores foram obtidas com ARDSnet $24 \mathrm{~h}$ e as inferiores com OLC $24 \mathrm{~h}$, de um paciente com hiperinsuflação com OLC. 
Os histogramas após ARDSnet 24 h demonstram grande dispersão na distribuição de freqüências das unidades Hounsfield, com concentração das áreas de colapso nas porções posteriores dos pulmões. OLC 24 h promove maior homogeinização pulmonar, com redução nas áreas de colapso alveolar, porém com aumento nas áreas de hiperinsuflação, particularmente nas porções mediais dos pulmões (figuras 10 e 11).

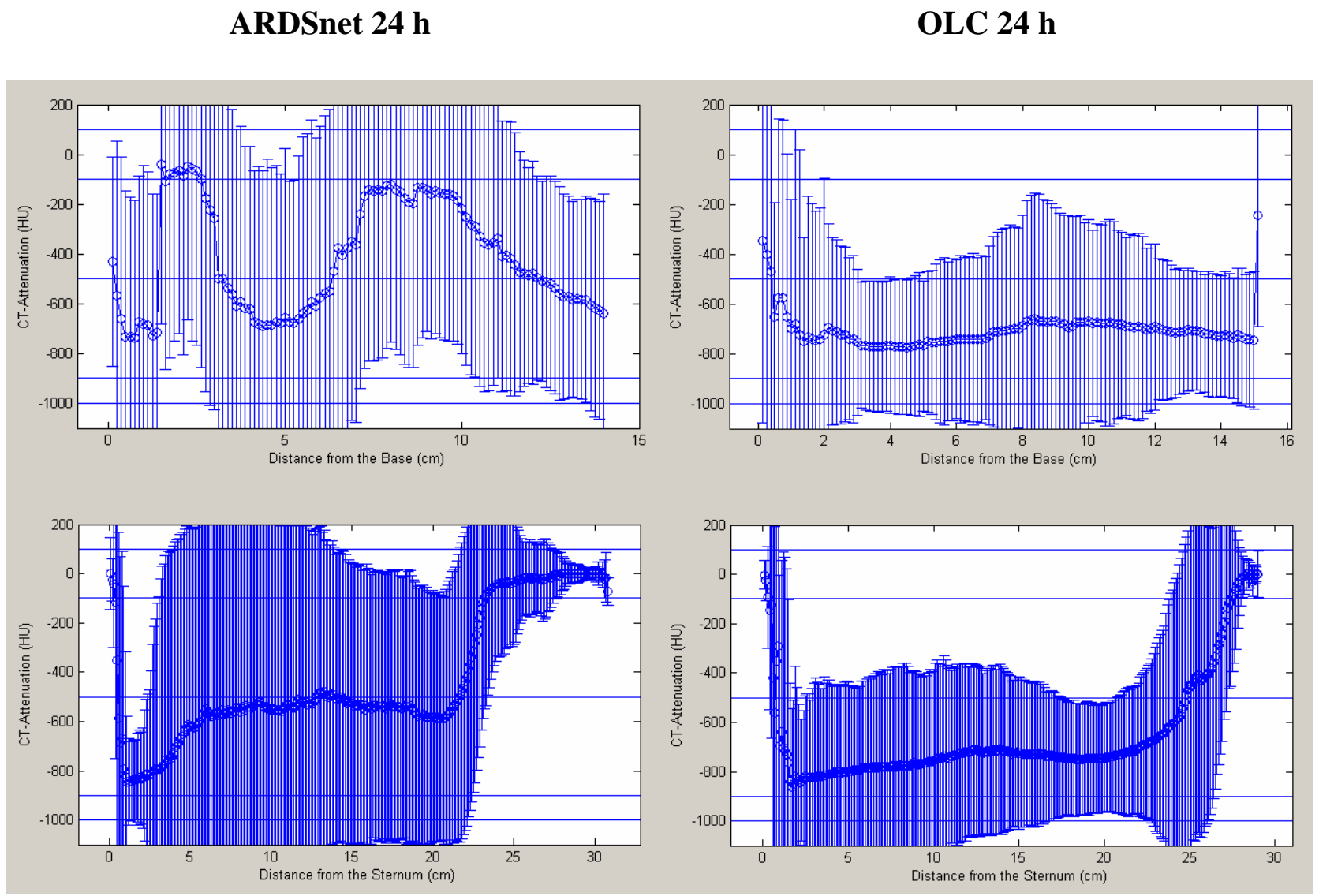

Figura 10: Histogramas da distribuição de freqüências das unidades Hounsfield após ARDSnet 24 h (coluna esquerda) e após OLC (coluna direita) obtidos de um paciente com hiperinsuflação com OLC. A linha espessa representa a média dos valores das unidades Hounsfield e as linhas verticais representam a dispersão dos valores entre os percentis 25 e 75. 
ARDSnet 24 h

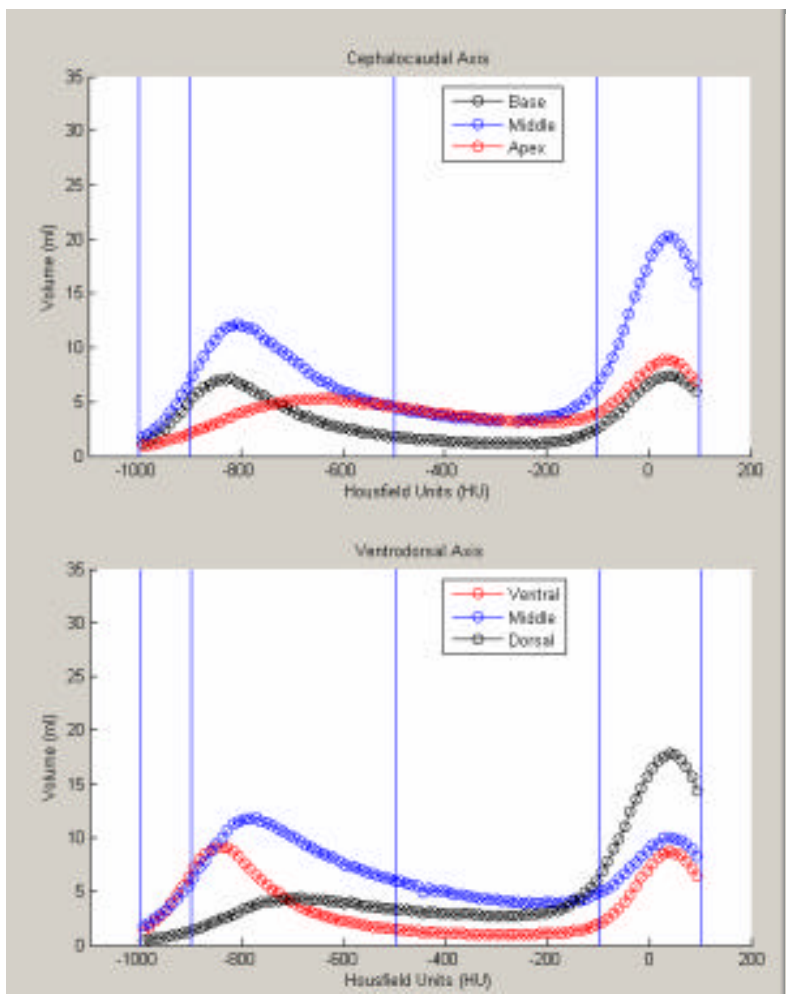

OLC 24 h
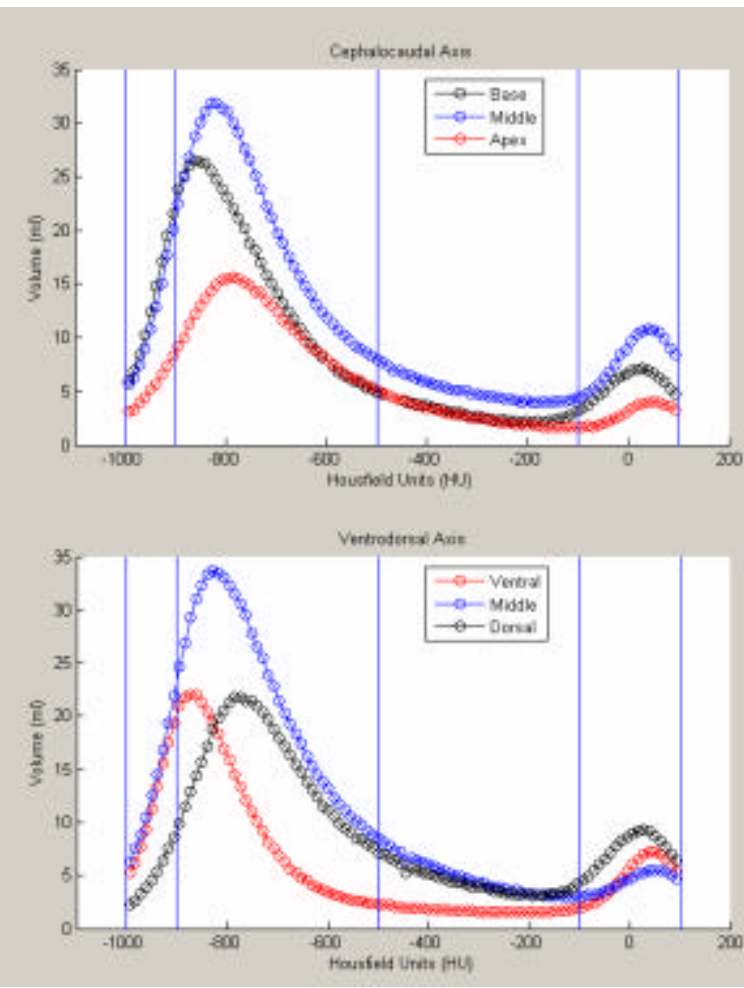

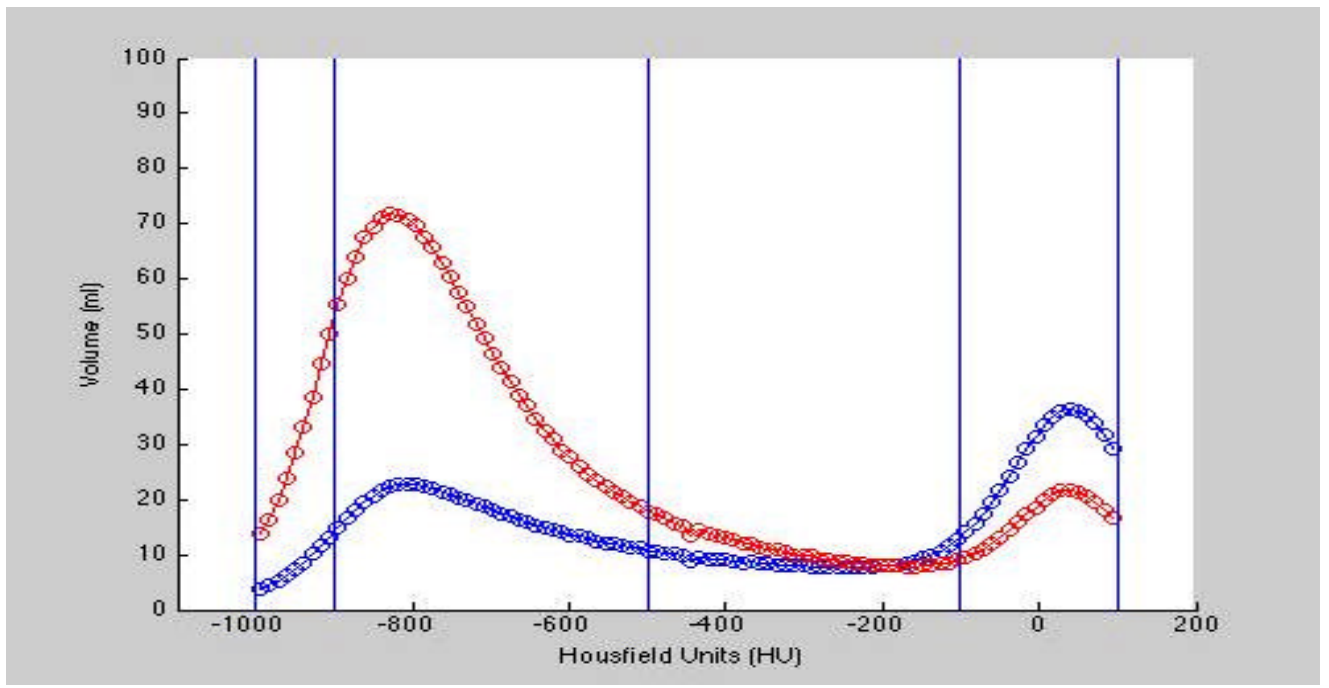

Azul - ARDSnet 24h

Vermelho - OLC 24h

Figura 11: Histogramas das zonas de West (imagens superiores) com ARDSnet 24 h (coluna esquerda) e com OLC (coluna direita) e histograma de todo o pulmão (imagem inferior) obtidos de um paciente com hiperinsuflação com OLC. 


\section{Estratégia ARDSnet $24 \mathrm{~h}$ determinou $\mathrm{PaO}_{2} / \mathrm{FIO}_{2}>350$ (Paciente 10):}

As imagens tomográficas evidenciam que, após ARDSnet 48 h houve persistência de intenso colapso alveolar, principalmente nas regiões posteriores dos pulmões, apesar da redução das áreas de colapso alveolar existentes após 24 h de ARDSnet (figura 12).

ARDSnet $24 \mathrm{~h}\left(\mathrm{PEEP}=5 \mathrm{cmH}_{2} \mathrm{O}\right)$
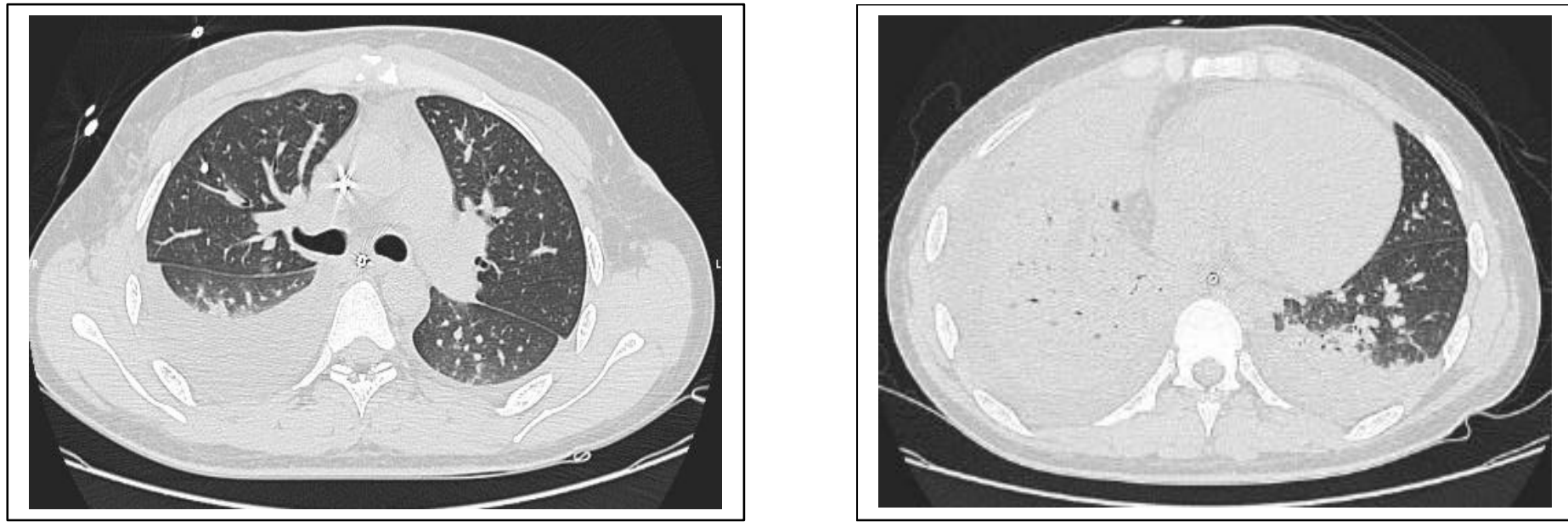

ARDSnet $48 \mathrm{~h}$ ? $\quad$ PEEP $=5 \mathrm{cmH}_{2} \mathrm{O}$
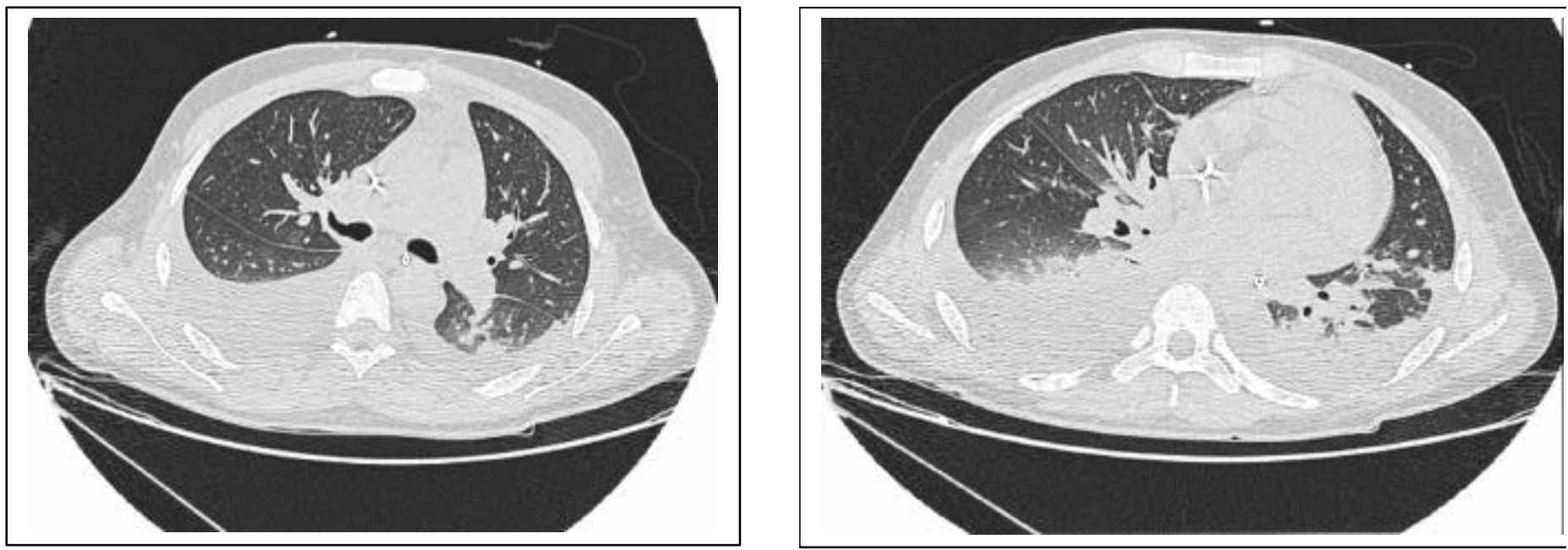

Figura 12: Cortes tomográficos na altura da carina e próximo à base, com ARDSnet 24 h (imagens superiores) e com ARDSnet $48 \mathrm{~h}$ (imagens inferiores), de um paciente com boa resposta à ARDSnet $24 \mathrm{~h}$. 
As imagens das reconstruções tridimensionais após 24 e 48 h de ARDSnet são semelhantes, evidenciando intensas áreas de colapso alveolar (figura 13).

\section{ARDSnet $24 \mathrm{~h} ? \mathrm{PEEP}=5 \mathrm{cmH}_{2} \mathrm{O}$}

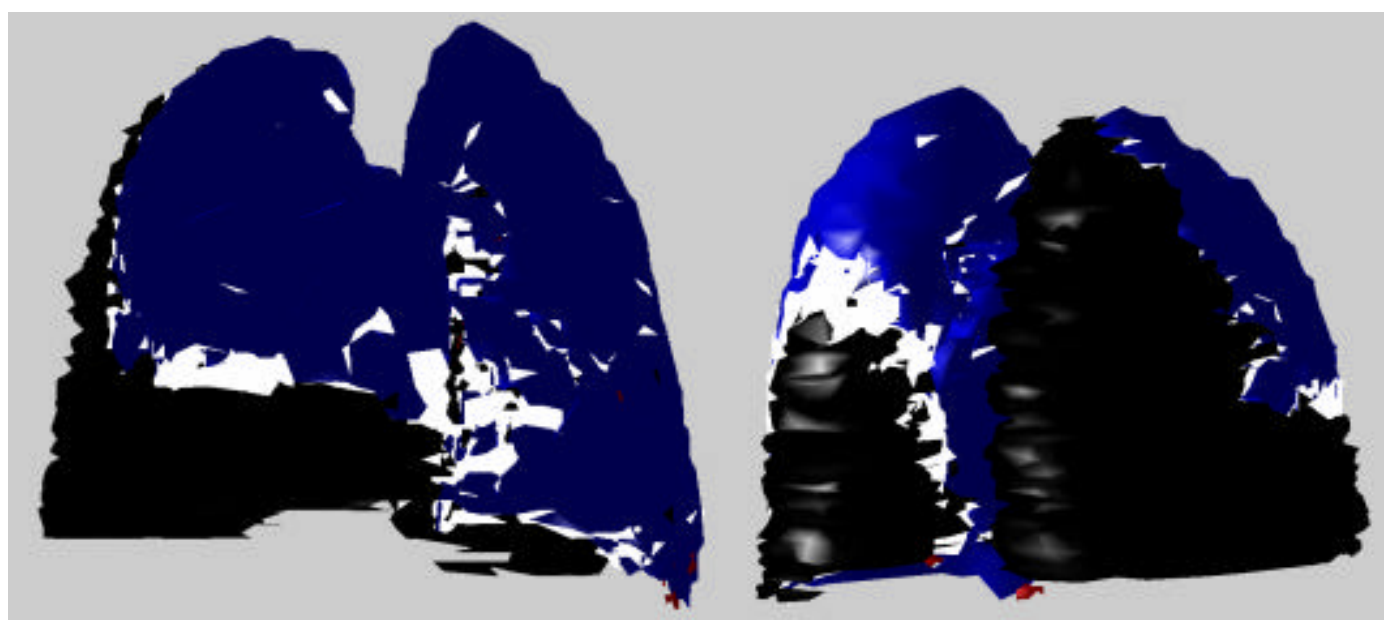

ARDSnet $48 \mathrm{~h} ? \quad \mathrm{PEEP}=5 \mathrm{cmH}_{2} \mathrm{O}$

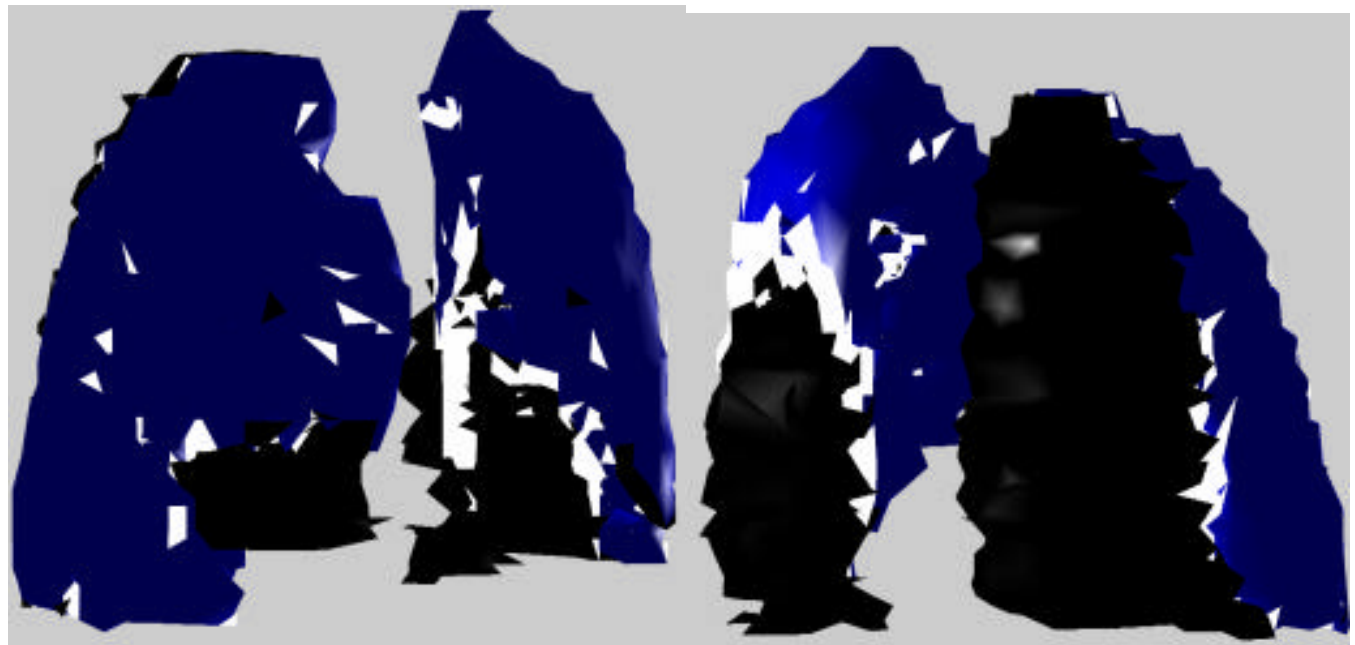

Figura 13: Reconstruções tridimensionais nas visões diagonais ântero-posterior (imagem à esquerda) e póstero-anterior (imagem à direita), onde: vermelho representa as regiões hiperinsufladas, azul as normalmente aeradas, branco as pobremente aeradas e preto as não aeradas. As imagens superiores foram obtidas com ARDSnet $24 \mathrm{~h}$ e as inferiores com ARDSnet $48 \mathrm{~h}$, de um paciente com boa respostas à ARDSnet $24 \mathrm{~h}$. 
Os histogramas após 24 e 48 h de ARDSnet são semelhantes, evidenciando intensa dispersão na distribuição de frequiências das unidades Hounsfield (figura 14). Os histogramas das zonas de West demonstram curvas bimodais, com o maior pico na região de colapso alveolar, que predomina nas regiões posteriores e basais dos pulmões (figura 15).

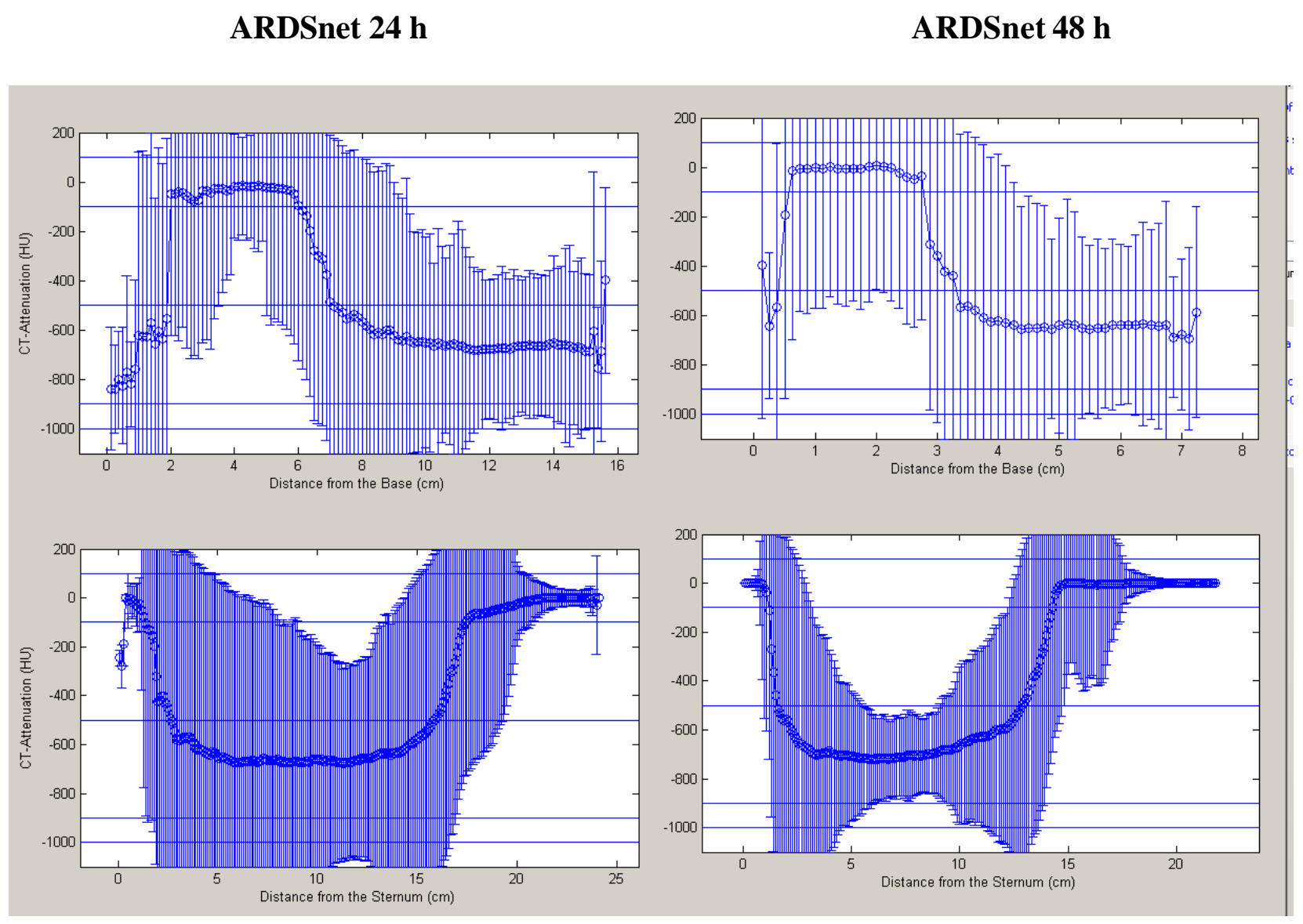

Figura 14: Histogramas da distribuição de freqüências das unidades Hounsfield após ARDSnet 24 h (coluna esquerda) e após ARDSnet $48 \mathrm{~h}$ (coluna direita), de um paciente com boa resposta à ARDSnet $24 \mathrm{~h}$. A linha espessa representa a média dos valores das unidades Hounsfield e as linhas verticais representam a dispersão dos valores entre os percentis 25 e 75 . 
ARDSnet 24 h

ARDSnet 48 h
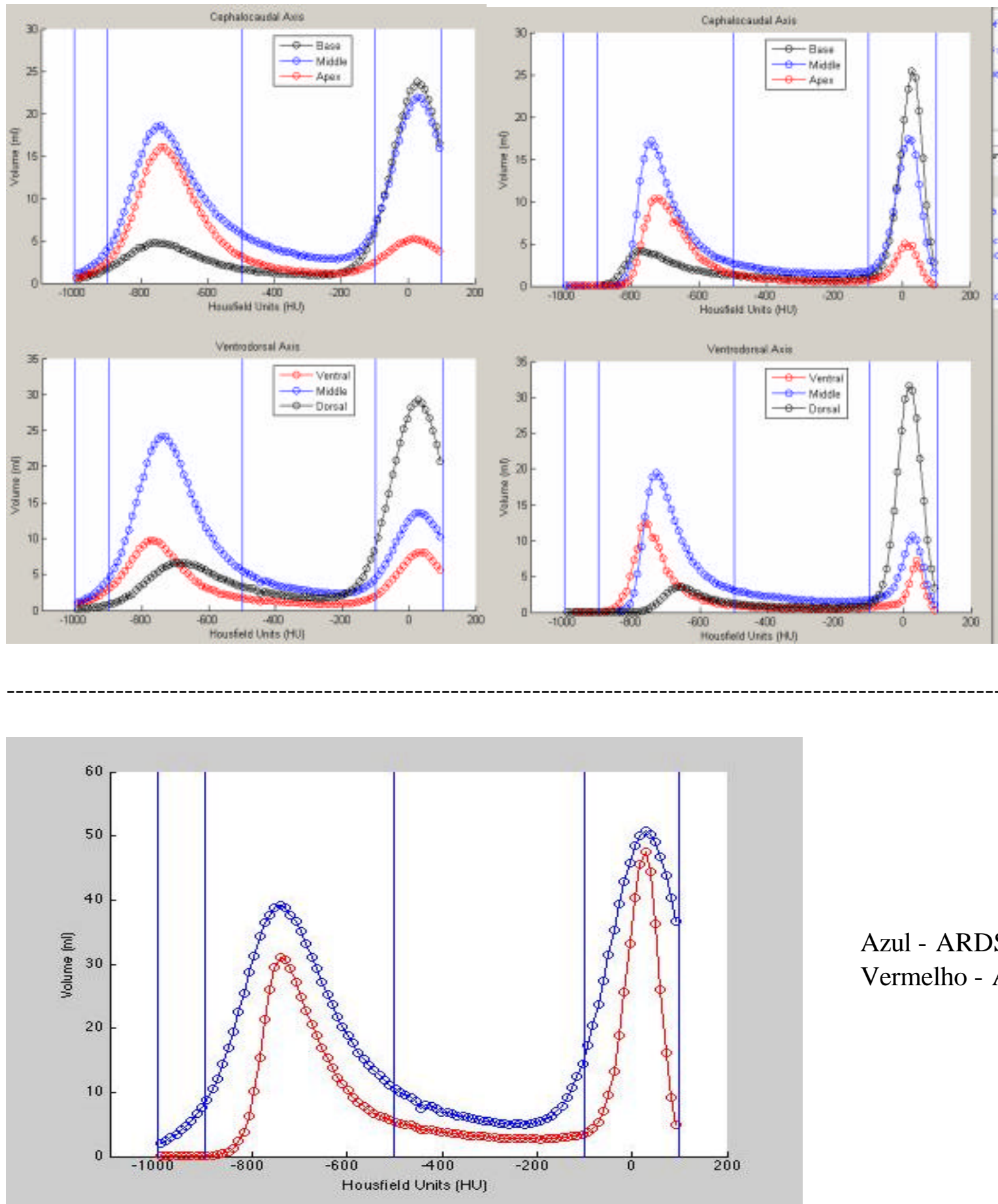

Azul - ARDSnet $24 \mathrm{~h}$

Vermelho - ARDSnet $48 \mathrm{~h}$

Figura 15: Histogramas das zonas de West (imagens superiores) com ARDSnet $24 \mathrm{~h}$ (coluna esquerda) e com ARDSnet $48 \mathrm{~h}$ (coluna direita) e histograma de todo o pulmão (imagem inferior), obtidos de um paciente comboa resposta à ARDSnet $24 \mathrm{~h}$. 


\section{4-Manobras de recrutamento:}

O número de manobras de recrutamento realizadas por paciente durante a titulação da PEEP está demonstrado no gráfico 26.

\section{Gráfico 26: Número de manobras de recrutamento realizadas por paciente durante titulação de PEEP:}

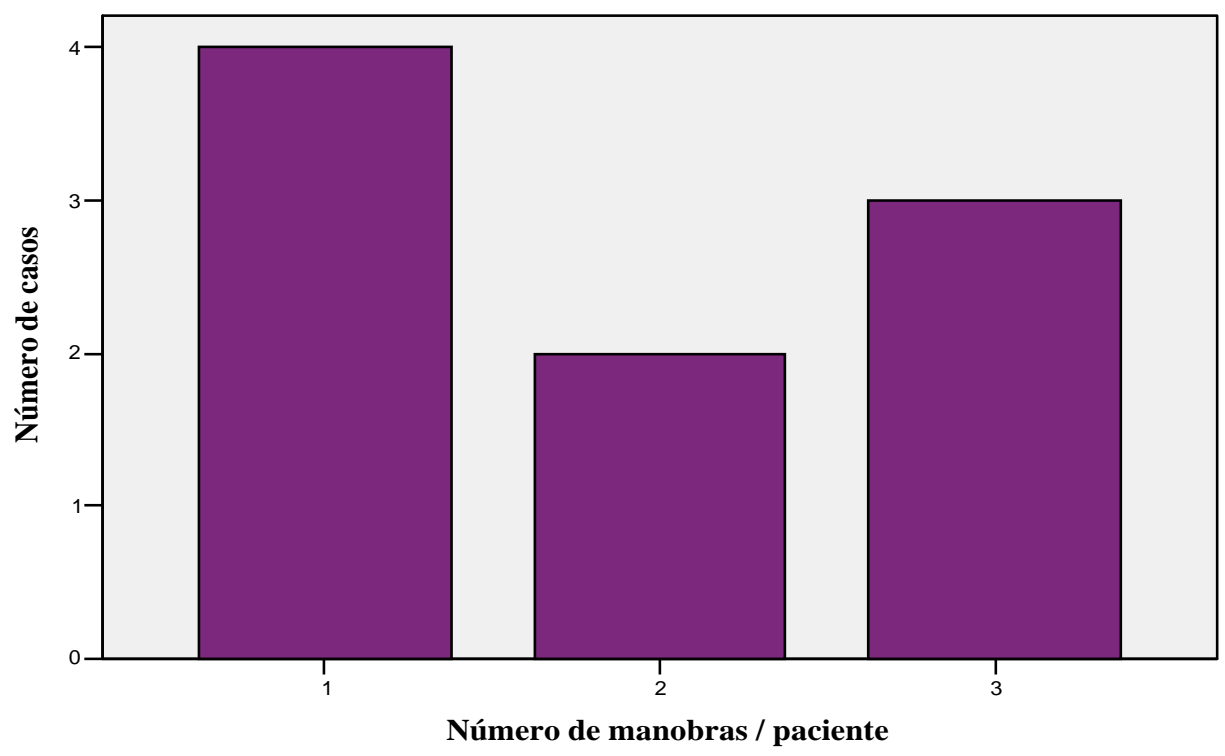

Em um paciente (paciente 7) identificourse pneumotórax na TC de tórax realizada 24 horas após o recrutamento (como será detalhado posteriormente). Nos demais pacientes não se observou pneumotórax, pneumomediastino ou enfisema subcutâneo nas TC de tórax realizadas 24 horas após o recrutamento. Nenhum paciente necessitou de interrupção da manobra por instabilidade hemodinâmica. 


\section{5-Manutenção dos benefícios do recrutamento após 24 horas de OLC:}

A relação $\mathrm{PaO}_{2} / \mathrm{FIO}_{2}$ não se alterou de forma significativa entre gasometrias coletadas após 20 minutos de recrutamento e ventilação com PEEP alvo e as coletadas após 24 horas de $\mathrm{OLC}\left(\mathrm{PaO}_{2} / \mathrm{FIO}_{2}=\right.$ 352,6 [237,1 - 388,85] vs. 270 [219,75 - 363] após 24 horas de OLC; p = 0,314 - gráfíco 27).

Gráfico 27: Evolução da relação $\mathrm{PaO}_{2} / \mathrm{FIO}_{2}$ entre 20 minutos pósrecrutamento e OLC $24 \mathrm{~h}$

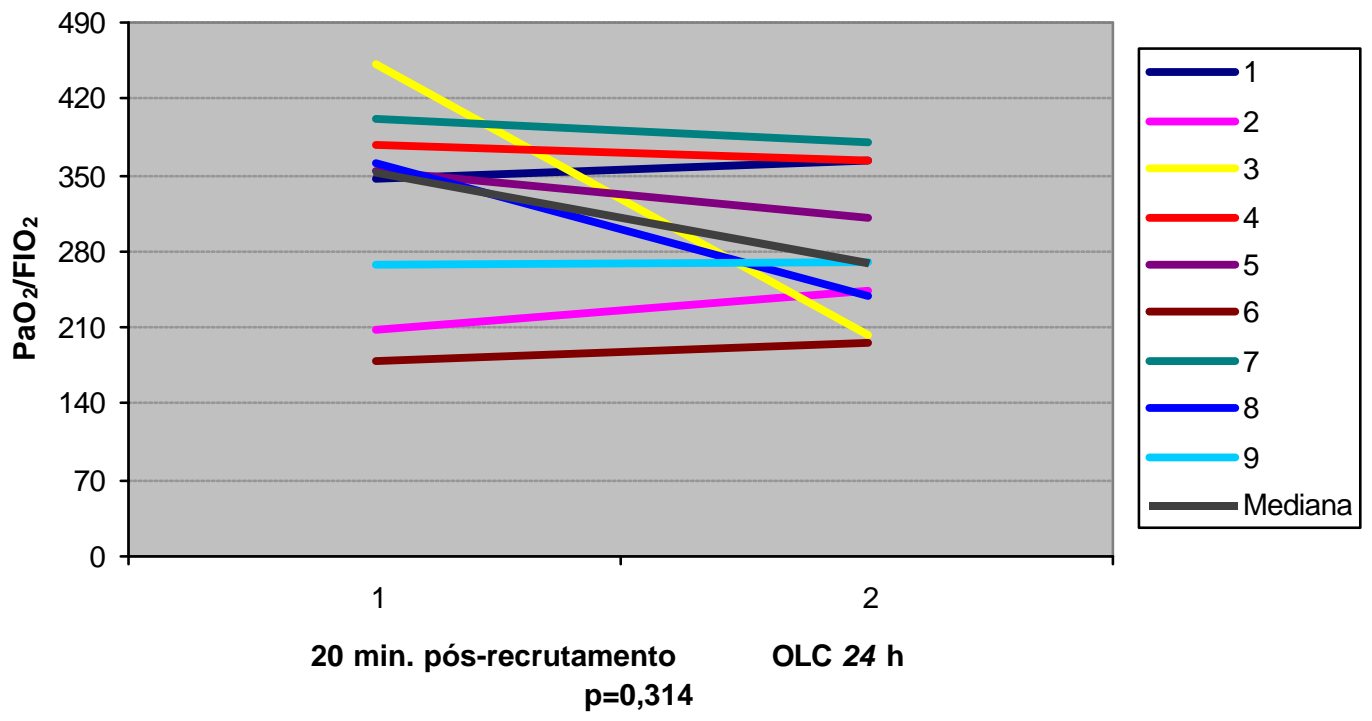

5.6-Avaliação comparativa dos níveis de citocinas no plasma e Mini-BAL nas diferentes fases do estudo:

As concentrações de IL-8 no mini-BAL foram significativamente superiores às plasmáticas, em todas as fases do estudo. Os níveis pulmonares de IL-6 também mostraram tendência a valores superiores em relação aos plasmáticos, com diferença estatisticamente significativa após ARDSnet 24 h (Tabela 10). 
Tabela 10. Concentrações de IL-6 e IL-8 no plasma e mini-BAL nas diferentes fases do estudo:

\begin{tabular}{cccc}
\hline & Basal $(\mathrm{ng} / \mathrm{mL})$ & ARDSnet $24 \mathrm{~h}(\mathrm{ng} / \mathrm{mL})$ & OLC $24 \mathrm{~h}(\mathrm{ng} / \mathrm{mL})$ \\
\hline IL-6 PL / MB & $7,9 / 15,9$ & $3,9 / 18,9$ & $3,3 / 10,6$ \\
p valor & 0,09 & 0,017 & 0,069 \\
\hline IL-8 PL / MB & $26,7 / 87,9$ & $20,9 / 85,4$ & $16,9 / 90,2$ \\
p valor & 0,025 & 0,012 & 0,012 \\
\hline
\end{tabular}

Abreviaturas: $\mathrm{PL}=\mathrm{Plasma} ; \mathrm{MB}=$ mini $-\mathrm{BAL}$

5.7-Seguimento dos pacientes:

A tabela 11 descreve a evolução ventilatória dos pacientes do estudo. Pneumotórax foi identificado em dois pacientes (paciente 7 e paciente 8). No paciente 7 a TC de tórax feita após 24 horas do recrutamento demonstrou esta complicação (figura 16) No paciente 8 a TC de tórax realizada 24 horas após o recrutamento não evidenciou pneumotórax (figura 17), que só foi diagnosticado (através de radiografia de tórax) após troca de tubo orotraqueal por guia, que aconteceu 48 horas após o recrutamento.

Tabela 11. Evolução ventilatória:

\begin{tabular}{ccccc}
\hline Paciente & $\begin{array}{c}\text { Tempo VM } \\
\text { (dias) }\end{array}$ & $\begin{array}{c}\text { TQT } \\
(\mathrm{S} / \mathrm{N})\end{array}$ & $\begin{array}{c}\text { Pneumotórax } \\
(\mathrm{S} / \mathrm{N})\end{array}$ & $\begin{array}{c}\text { Liberação de VM } \\
(\mathrm{S} / \mathrm{N})\end{array}$ \\
\hline 1 & 7 & $\mathrm{~N}$ & $\mathrm{~N}$ & $\mathrm{~S}$ \\
2 & 8 & $\mathrm{~N}$ & $\mathrm{~N}$ & $\mathrm{~S}$ \\
3 & $15^{*}$ & $\mathrm{~N}$ & $\mathrm{~N}$ & $\mathrm{~N}$ \\
4 & 27 & $\mathrm{~S}$ & $\mathrm{~N}$ & $\mathrm{~S}$ \\
5 & 8 & $\mathrm{~N}$ & $\mathrm{~N}$ & $\mathrm{~S}$ \\
6 & 29 & $\mathrm{~S}$ & $\mathrm{~N}$ & $\mathrm{~S}$ \\
7 & $100^{*}$ & $\mathrm{~S}$ & $\mathrm{~S}$ & $\mathrm{~N}$ \\
8 & $17^{*}$ & $\mathrm{~S}$ & $\mathrm{~S}$ & $\mathrm{~N}$ \\
9 & 8 & $\mathrm{~N}$ & $\mathrm{~N}$ & $\mathrm{~S}$ \\
10 & 4 & $\mathrm{~N}$ & $\mathrm{~N}$ & $\mathrm{~S}$ \\
\hline Mediana & 11,5 & & & \\
\hline
\end{tabular}

Abreviaturas e simbologias: VM = Ventilação mecânica; TQT = Traqueostomia; S = Sim; N = Não; * Tempo de ventilação mecânica calculado até a data do óbito. 


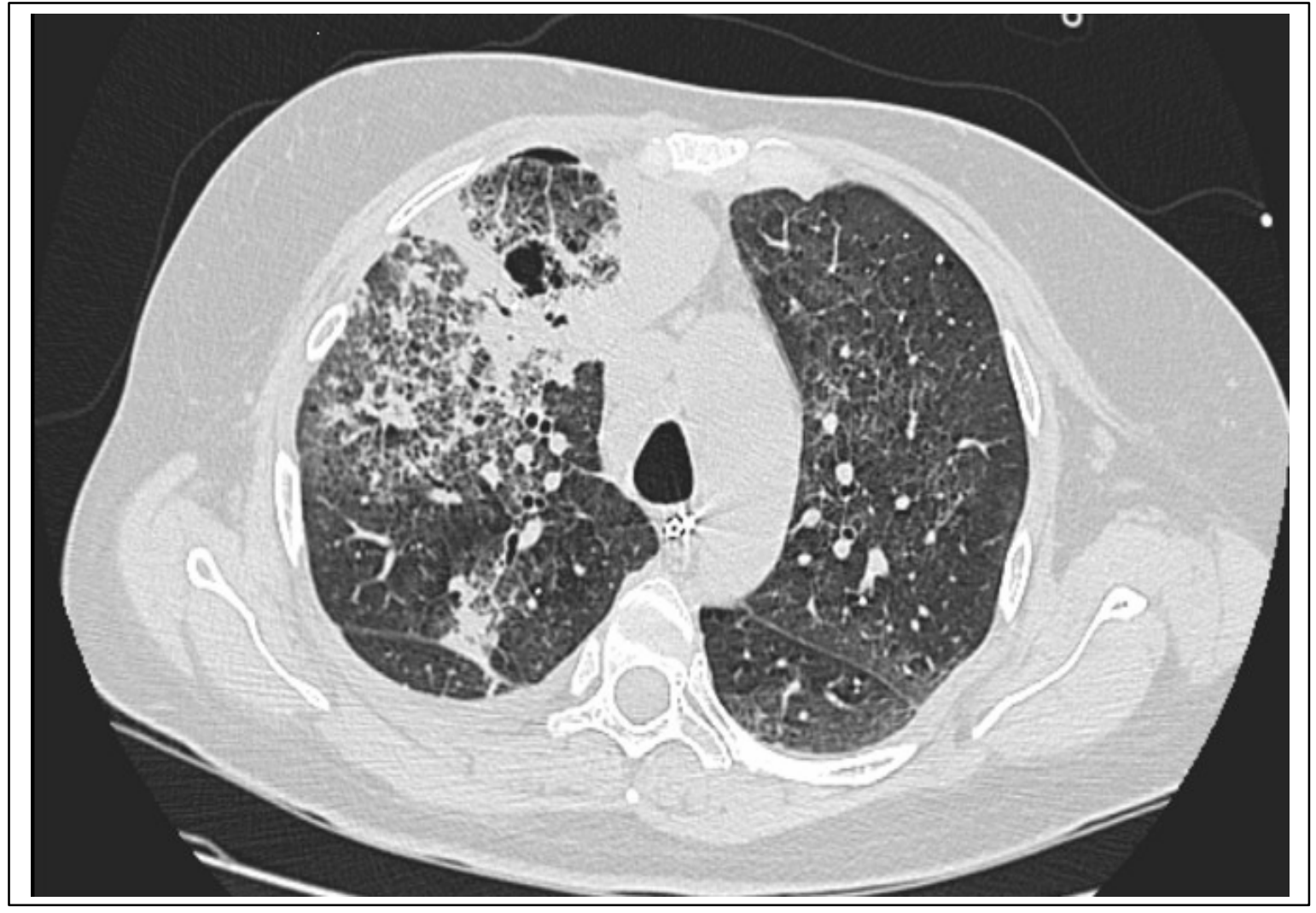

Figura 16. Corte tomográfico obtido do paciente 7 após 24 h de $\mathrm{OLC}\left(\mathrm{PEEP}=17 \mathrm{cmH}_{2} \mathrm{O}\right)$, evidenciando pneumotórax à direita. 

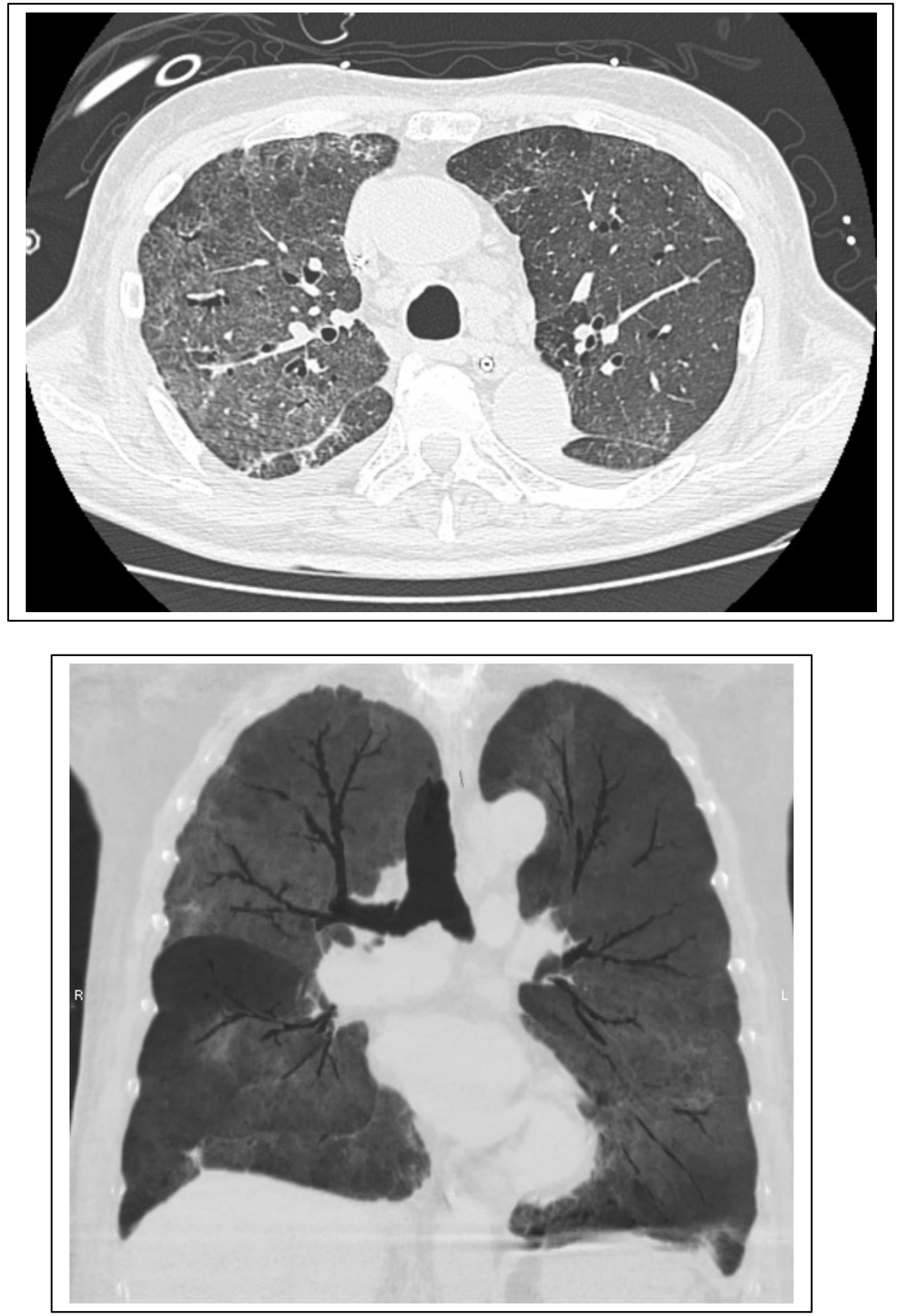

Figura 17. Tomografia computadorizada do paciente 8 após $24 \mathrm{~h}$ de OLC $\left(\mathrm{PEEP}=19 \mathrm{cmH}_{2} \mathrm{O}\right)$ demonstrando ausência de pneumotórax. Imagem superior $=$ Corte axial. Imagem inferior $=$ Corte coronal com reconstrução MINIP $($ minimum intensity projection). 
No $14^{\circ}$ dia após o início do estudo, a mediana da $\mathrm{PaO}_{2} / \mathrm{FIO}_{2}$ foi de 242,3 [214,5 - 434,3].

Os escores SOFA estão demonstrados na tabela 12.

Tabela 12. Escores SOFA:

\begin{tabular}{|c|c|c|c|c|c|c|c|}
\hline Paciente & $\begin{array}{c}\text { Dia da } \\
\text { internação } \\
\text { no CTI }\end{array}$ & $\begin{array}{c}\text { Dia de } \\
\text { entrada } \\
\text { no protocolo }\end{array}$ & ARDSnet $24 \mathrm{~h}$ & OLC $24 \mathrm{~h}$ & $\begin{array}{c}\text { D1 pós- } \\
\text { término } \\
\text { do protocolo }\end{array}$ & $\begin{array}{l}\mathrm{D}_{2} \text { pós-término } \\
\text { do protocolo }\end{array}$ & $\begin{array}{l}\text { D7 pós-término } \\
\text { do protocolo }\end{array}$ \\
\hline 1 & 5 & 7 & 3 & 3 & 0 & 0 & 0 \\
\hline 2 & 3 & 7 & 5 & 6 & 6 & 3 & 4 \\
\hline 3 & 7 & 8 & 9 & 6 & 6 & 5 & 10 \\
\hline 4 & 4 & 8 & 5 & 7 & 2 & 4 & 11 \\
\hline 5 & 3 & 7 & 7 & 7 & 6 & 4 & 3 \\
\hline 6 & 6 & 5 & 4 & 5 & 4 & 4 & 2 \\
\hline 7 & 6 & 7 & 5 & 5 & 1 & 0 & 11 \\
\hline 8 & 4 & 5 & 8 & 7 & 2 & 5 & 6 \\
\hline 9 & 9 & 11 & 11 & 10 & 11 & 6 & 9 \\
\hline 10 & 8 & 8 & 6 & 5 & 2 & 3 & 0 \\
\hline
\end{tabular}

Abreviaturas: SOFA = Sequential Organ Failure Assessment

Os desfechos clínicos estão descritos na tabela 13. A taxa de mortalidade foi de $40 \%$ e todos os óbitos aconteceram no CTI.

Tabela 13. Desfechos clínicos:

\begin{tabular}{cccccc}
\hline Paciente & $\begin{array}{c}\text { Óbito } \\
\text { no CTI }\end{array}$ & $\begin{array}{c}\text { Óbito } \\
\text { intra-hosp. }\end{array}$ & Dia do óbito & $\begin{array}{c}\text { ?T CTI } \\
\text { (dias) }\end{array}$ & $\begin{array}{c}\text { ?T hospital } \\
\text { (dias) }\end{array}$ \\
\hline 1 & $\mathrm{~N}$ & $\mathrm{~N}$ & $\mathrm{~N} / \mathrm{A}$ & 10 & 18 \\
2 & $\mathrm{~N}$ & $\mathrm{~N}$ & $\mathrm{~N} / \mathrm{A}$ & 36 & 53 \\
3 & $\mathrm{~S}$ & $\mathrm{~S}$ & 14 & 16 & 16 \\
4 & $\mathrm{~N}$ & $\mathrm{~N}$ & $\mathrm{~N} / \mathrm{A}$ & 28 & 75 \\
5 & $\mathrm{~N}$ & $\mathrm{~N}$ & $\mathrm{~N} / \mathrm{A}$ & 19 & 195 \\
6 & $\mathrm{~N}$ & $\mathrm{~N}$ & $\mathrm{~N} / \mathrm{A}$ & 40 & 59 \\
7 & $\mathrm{~S}$ & $\mathrm{~S}$ & 104 & 107 & 107 \\
8 & $\mathrm{~S}$ & $\mathrm{~S}$ & 15 & 31 & 31 \\
9 & $\mathrm{~S}$ & $\mathrm{~S}$ & 11 & 14 & 14 \\
10 & $\mathrm{~N}$ & $\mathrm{~N}$ & $\mathrm{~N} / \mathrm{A}$ & 4 & 10 \\
\hline Mediana & & & & 23,5 & 42 \\
\hline
\end{tabular}

Abreviaturas: ?T CTI = Tempo de internação no CTI; ?T hospital = Tempo de internação hospitalar; N/A = Não se aplica; Dia do óbito = Intervalo de tempo entre o fim do protocolo e o óbito. 


\section{6-Discussão:}

Nesse estudo que avaliou uma estratégia ventilatória seqüencial em pacientes com LPA / SARA, protocolo ARDSnet aplicado por 24 horas não promoveu melhora significativa na oxigenação, assim como não determinou redução nas áreas de maior colapso alveolar visualizadas em TC de tórax. Por outro lado, estratégia OLC foi capaz de induzir melhora na oxigenação e reduzir colapso alveolar após 24 horas de implementação, promovendo também redução nos níveis plasmáticos de IL-6. OLC não determinou aumento significativo nas áreas hiperinsufladas, determinando valores de Pdist inferiores a $20 \mathrm{cmH}_{2} \mathrm{O}$ e Pplatô inferiores a $35 \mathrm{cmH}_{2} \mathrm{O}$. Efeitos hemodinâmicos adversos não foram observados durante OLC, não havendo maior necessidade de fluidos intravenosos ou aminas vasoativas, quando comparada à estratégia ARDSnet.

Diversos estudos avaliando estratégias protetoras de ventilação mecânica foram realizados nos últimos anos. ${ }^{(26)(27)(46)}$ É consenso que ventilação com limitação de VT e de Pplatô determina melhor prognóstico. O papel das medidas que reduzem atelectrauma (valores elevados de PEEP e / ou manobras recrutativas), ainda é controverso.

Dois importantes estudos ${ }^{(27)(46)}$ demonstraram melhor prognóstico associado à adoção de estratégias protetoras com baixos VT e Pplatô, combinados com medidas redutoras de volutrauma. Nos dois, a titulação de PEEP foi baseada na curva PxV e, em um destes, utilizou-se também, manobras de recrutamento. ${ }^{(27)}$ No entanto, um terceiro estudo ${ }^{(43)}$ randomizado com elevado número de pacientes que comparou duas formas de utilização de PEEP em pacientes ventilados com limitação de VT e Pplatô, não demonstrou diferença significativa de prognóstico em favor de altas PEEP. A principal diferença entre estes três estudos foi a forma de titulação da PEEP, levantando-se a possibilidade de que ajuste da PEEP de acordo com parâmetros fisiológicos seja mais eficaz do que segundo oxigenação. Recentemente, uma grande coorte de pacientes com LPA / SDRA ${ }^{(48)}$ testando a superioridade de ventilação protetora baseada em níveis elevados de PEEP, 
ajustados segundo parâmetros fisiológicos (utilizando valores máximos de PEEP associados com Pplatô < $30 \mathrm{cmH}_{2} \mathrm{O}$ ) não demonstrou redução de mortalidade. No ent anto, em relação aos desfechos secundários, o grupo com PEEP mais elevada apresentou redução significativa no tempo de ventilação mecânica.

O presente estudo tem como principal diferença em relação aos previamente existentes (que randomizaram os pacientes em dois grupos de ventilação), a comparação de duas estratégias ventilatórias realizadas seqüencialmente. Nas primeiras 24 horas aplicou-se o protocolo ARDSnet, que é aceito por muitos autores como a forma padrão de ventilação em pacientes com LPA / SDRA. Nas 24 horas seguintes, nos pacientes que não alcançaram o alvo estabelecido de $\mathrm{PaO}_{2} / \mathrm{FIO}_{2}$, a ventilação foi baseada no conceito de pulmão aberto. ${ }^{(34)}$ Determinamos $\mathrm{PaO}_{2} / \mathrm{FIO}_{2}$ como objetivo a ser alcançado tanto após 24 horas de ARDSnet como após recrutamento e titulação de PEEP, tendo como base estudo tomográfico recente ${ }^{(70)}$ que demonstrou haver menos de $5 \%$ de massa de tecido pulmonar colapsado quando $\mathrm{PaO}_{2} / \mathrm{FIO}_{2}$ atinge valores superiores a 350 .

Durante ventilação segundo protocolo ARDSnet respeitamos o valor inicial de $6 \mathrm{~mL} / \mathrm{kg}$ para ajuste do VT. Após 24 horas desta estratégia, alguns pacientes encontravam-se com VT superiores a este limite (máximo valor observado de $10 \mathrm{~mL} / \mathrm{kg}$ ). Como optamos por utilizar modos ventilatórios limitados à pressão (PRVC ou PCV), o valor do VT não pôde ser rigidamente controlado, ficando sujeito a variações determinadas por mudanças na complacência do sistema respiratório. Nota-se que em alguns pacientes onde o VT excedeu $6 \mathrm{~mL} / \mathrm{kg}$, houve aumento nos valores de complacência após 24 horas de ARDSnet, quando comparados aos valores basais. Como em nenhum caso a Pplatô excedeu o limite de $30 \mathrm{cmH}_{2} \mathrm{O}$, não acreditamos que este fato tenha influenciado nossos resultados.

Optamos por uma estratégia baseada no OLC $^{(34)}$ que determinasse o máximo de homogeneização pulmonar, mas que também fosse de simples realização já que os dois estudos ${ }^{(27)(46)}$ que demonstraram redução de mortalidade com esta forma de ventilação utilizaram curvas PxV para cálculo de PEEP ideal, o 
que é de difícil execução e interpretação na prática clínica. Os níveis de PEEP testados durante titulação foram baseados na média dos valores de PEEP encontrados pela curva PxV no estudo de Amato e cols ${ }^{(27)}$ (limite inferior de 17) e na titulação decremental de PEEP realizada após recrutamento no estudo de Borges e cols ${ }^{(70)}$ (limite superior de 21).

Mesmo o limite inferior de PEEP utilizado por nós durante OLC foi excessivo para alguns pacientes. Os pacientes de números 1, 4 e 7 foram os que mais hiperinsuflaram. O paciente 1 tinha comprometimento pulmonar prévio por Artrite Reumatóide e isso pode ter predisposto à hiperinsuflação com OLC. A análise da cinética de ILs dos pacientes 4 e 7 (no paciente 1 a mensuração de ILs não foi realizada) demonstra que, apesar da hiperinsuflação determinada por OLC, todas as ILs mensuradas tiveram tendência de queda (exceto por IL-8 plasmática no paciente 7). É importante lembrar, no entanto, a clara associação de pneumotórax com a estratégia OLC em um destes pacientes (paciente 7). A aplicação de níveis prédefinidos de PEEP sem uma estratégia de titulação progressiva (como a utilizada no OLA ${ }^{(27)}$ ou através de curvas PEEP / complacência decrescentes) estão associadas à hiperinsuflação. ${ }^{(69)}$ Terragni e cols ${ }^{(68)}$ demonstraram que análises quantitativas de TC realizadas após ajuste de parâmetros ventilatórios segundo protocolo ARDSnet identificaram um grupo de pacientes mais suceptível à hiperinsuflação ao final da inspiração. Neste grupo mais suceptível, a média dos valores de PEEP ajustados segundo o protocolo ARDSDnet $^{(26)}$ foi de $12,6 \mathrm{cmH}_{2} \mathrm{O}$, houve maior percentagem de tecido pulmonar não aerado em comparação a um grupo mais protegido e valores de Pplatô superiores a $28 \mathrm{cmH}_{2} \mathrm{O}$ determinaram hiperinsuflação ao final da inspiração. No nosso estudo, a mediana dos valores de Pplatô após OLC foi de $30 \mathrm{cmH}_{2} \mathrm{O}$, sendo o valor máximo encontrado de $33 \mathrm{cmH}_{2} \mathrm{O}$. Não é possível comparar em valores absolutos a percentagem de tecido não aerado nos dois estudos, pois as técnicas utilizadas para a realização das imagens tomográficas foram diferentes. No entanto, podemos traçar um paralelo entre os dois estudos: Terragni e cols ${ }^{(68)}$ determinaram que quanto maior é a quantidade de tecido colapsado, maior a 
possibilidade de hiperinsuflação ao final da inspiração. Como em no sso estudo observamos que houve redução significativa de regiões colapsadas com OLC quando comparamos com ARDSnet, é possível que OLC tenha conferido algum grau de proteção com relação a hiperinsuflação ao final da inspiração. Apesar de alguns pacientes em nosso estudo terem evoluído com aumento de hiperinsuflação com OLC, a diferença na percentagem de VPT hiperinsuflado não foi estatisticamente significativa em relação ao protocolo ARDSnet. Não fizemos análise de imagens tomográficas ao final da inspiração, onde a homogeneização do pulmão parece ter um papel primordial na prevenção de hiperinsuflação. ${ }^{(39)}$ (74) Pdist elevada é um marcador de risco para hiperinsuflação ao final da inspiração e já foi associada à piora prognóstica ${ }^{(27)}$. No presente estudo, nenhum paciente apresentou Pdist superior a $20 \mathrm{cmH}_{2} \mathrm{O}$ após 24 horas de OLC.

O papel de variáveis fisiológicas na determinação do potencial de recrutamento é questionável. Variações na relação $\mathrm{PaO}_{2} / \mathrm{FIO}_{2}$ e na mecânica pulmonar induzidas por elevação nos níveis de PEEP foram independentemente associadas a recrutamento alveolar por Grasso e cols. ${ }^{(45)}$ Diferentemente, em outro estudo $^{(69)}$ mecânica ventilatória não foi boa preditora de recrutamento alveolar. No presente estudo, apesar das reduções nas áreas colapsadas e pouco aeradas induzidas pela OLC 24 horas, não houve melhora estatisticamente significativa na complacência do sistema respiratório. Não observamos diferença estatisticamente significativa nos níveis de $\mathrm{PaCO}_{2}$, que também podem ser utilizados como marcadores de hiperinsuflação, ${ }^{(45)}$ entre OLC e ARDSnet.

A utilização de manobras de recrutamento não é unanimidade na literatura. ${ }^{(75-76)}$ Recentemente, o estudo LOV ${ }^{(47)}$ não demonstrou redução de mortalidade com a aplicação de uma OLC que utilizou manobras de recrutamento, quando comparada ao protocolo ARDSnet. No entanto, a manobra de recrutamento utilizada determinava uma $\mathrm{P}=40 \mathrm{cmH}_{2} \mathrm{O}$ em vias aéreas e PEEP foi ajustada com base na tabela ARDSnet adaptada para determinar níveis mais elevados de PEEP. Há evidências ${ }^{(70)}$ de que Pplatô superiores a $40 \mathrm{cmH}_{2} \mathrm{O}$ são necessárias, muitas vezes, para obter-se recrutamento máximo em alguns 
pacientes. Assim, a manobra de recrutamento utilizada no estudo LOV ${ }^{(47)}$ pode não ter induzido homogenização pulmonar em uma parcela dos pacientes. Mesmo assim, esta estratégia associou-se a menores incidências de hipoxemia refratária e de morte por hipoxemia refratária e determinou redução na necessidade de aplicação de terapias de resgate. Em nossa estratégia OLC optamos pela realização de manobras de recrutamento que determinassem uma Pplatô final próxima de $60 \mathrm{cmH}_{2} \mathrm{O}$, nível associado ao máximo de recrutamento na maioria dos participantes do estudo de Borges e cols. ${ }^{(70)}$ Diferentemente de outros relatos ${ }^{(47-48)}$, a estratégia OLC por nós adotada não requereu balanço hídrico mais positivo ou maior infusão de aminas vasoativas. Nenhuma manobra de recrutamento foi associada à instabilidade hemodinâmica.

Os estudos existentes com análises quantitativas das imagens tomográficas avaliaram TC realizadas em um curto período de tempo após a aplicação de uma determinada estratégia ventilatória. Em nosso estudo optamos por realizar as TC após 24 horas de cada estratégia, por considerarmos que as conseqüências que perduram são as mais importante como determinantes de prognóstico. Observamos manutenção dos benefícios oximétricos alcançados com a OLC adotada, 24 horas após sua aplicação.

Quando comparadas com estratégias indutoras de estiramento alveolar excessivo, formas protetoras de ventilação induziram menor liberação de citocinas plasmáticas e pulmonares. ${ }^{(24)(9)}$ No presente estudo observamos que OLC 24 horas promoveu redução significativa apenas nos níveis plasmáticos de IL-6 quando comparada à ARDSnet 24 h. As concentrações de IL-6 no mini-Bal e de IL-8 (no plasma e mini$B A L)$ não variaram de forma significativa entre as duas estratégias. Com relação aos valores basais, ARDSnet 24 horas não alterou significativamente os níveis plasmáticos e pulmonares de IL-6 e IL-8. No estudo de Ranieri e cols. ${ }^{(9)}$ a única citocina plasmática que evoluiu com concentrações significativamente menores durante estratégia protetora foi IL-6, o que está de acordo com nossos achados. Redução 
significativa nos níveis plasmáticos de IL-6 após três dias de estratégia protetora também foi identificado no estudo ARDSnet.

As concentrações de IL-6 e IL-8 no mini-BAL em nosso estudo não tiveram um comportamento evolutivo definido, ao contrário do estudo de Ranieri e cols. ${ }^{(9)}$ Neste, identificourse queda progressiva nos níveis pulmonares de IL-1ß, TNF-a, IL-8 e IL-6 com estratégia protetora, porém o material respiratório foi coletado de uma forma mais sistemática, optando-se sempre por material do pulmão sem infiltrado identificado ou pelo lobo médio (ou inferior direito) nos casos com infiltrado pulmonar difuso.No presente estudo, a coleta de mini-BAL foi feita às cegas através da introdução de um trach-care, o que provavelmente interferiu nos resultados. Mesmo assim, as concentrações de IL-6 e IL-8 medidas no mini-BAL foram mais altas do que as do plasma, semelhante ao observado em outros experimentos. ${ }^{(15)}$ Diferentes comportamentos entre as concentrações de citocinas plasmáticas e pulmonares já foram observados asnteriormente. Stuber e cols. ${ }^{(24)}$ ao avaliarem as diferenças nas concentrações de citocinas promovidas pela mudança transitória de uma estratégia protetora para uma estratégia mais deletéria, observaram que após seis horas de retorno à estratégia protetora as citocinas plasmáticas (que haviam subido durante a estratégia lesiva) retornaram aos valores basais, enquanto os níveis pulmonares continuaram subindo. ${ }^{(24)}$

A maioria dos casos de LPA/ SDRA do nosso estudo foi de origem pulmonar. Estudos experimentais ${ }^{(77)}$ sugerem que manobras de recrutamento e PEEP elevadas têm efeito mais benéfico (em termos de oxigenação e mecânica respiratória) na LPA/ SDRA de origem extrapulmonar, em relação à pulmonar. Alguns estudos clínicos corroboram esses achados ${ }^{(78)(30)}$ enquanto em outros ${ }^{(45)(66)}$ essa diferenças não foi encontrada. Grasso e cols. ${ }^{(76)}$ demonstraram que o potencial para recrutamento alveolar é influenciado primordialmente pelas propriedades elásticas da parede torácica e do pulmão, independente da etiologia da LPA / SDRA; assim, pulmões com injúria precoce têm maior potencial de recrutamento. No presente estudo todos os casos foram de LPA / SDRA precoce, o que com certeza contribuiu para a boa 
resposta ao OLC. É importante citar que mesmo sendo aplicada 24 horas após estratégia ARDSDnet, OLC mostrou-se eficaz em reduzir áreas pulmonares colapsadas e pouco aeradas.

A taxa de mortalidade de $40 \%$ encontrada no atual estudo foi semelhante à observada em outros estudos com estratégias protetoras. ${ }^{(27)(47-48)} \mathrm{Na}$ maioria dos experimentos a incidência de pneumotórax com estratégias baseadas no OLC não diferiram da observada com outras formas de ventilação. ${ }^{(46-48)}$ -Diagnosticamos dois pneumotórax durante o presente estudo. Em um dos casos, houve clara associação entre a estratégia OLC e o surgimento do pneumotórax. No segundo caso não ha via pneumotórax na TC realizada após 24 horas de OLC, que só foi evidenciado 48 horas após a manobra. Poucas horas antes deste diagnóstico havia sido realizada troca de tubo orotraqueal, o que tornou-se um fator confundidor na determinação da causa desta complicação.

Nosso estudo tem algumas limitações. O número reduzido de pacientes pode ter obscurecido eventuais diferenças entre as duas estratégias. O desenho seqüencial, apesar de oferecer uma proposta diferente de conduta nos pacientes com LPA / SDRA, gera dificuldades para interpretação da cinética das citocinas. A redução nos níveis plasmáticos de IL-6 pode ter sido consequência da mudança na estratégia ventilatória ou apenas decorrente de melhora clínica dos pacientes. Em favor da primeira hipótese está o SOFA evolutivo, que é uma medida comprovadamente eficaz na quantificação de falências orgânicas. ${ }^{\text {(79-80) }}$ A mediana dos valores dos escores SOFA obtida no início do estudo foi semelhante à determinada após 24 horas de OLC (7 [6 - 8] versus 6 [5 - 7], respectivamente; $p=0,12)$, assim como a mediana dos valores calculados após ARDSnet 24 horas e após OLC 24 horas $(5$ [4,5 - 8,5] versus 6 [5 - 7], respectivamente; $\mathrm{p}=$ 0,91), o que sugere gravidades semelhantes nestas fases do estudo. No entanto, para a confirmação dos efeitos da estratégia OLC nos níveis plasmáticos de IL-6, é necessário a realização de uma segunda etapa do presente estudo, na qual os pacientes seriam ventilandos apenas segundo ARDSnet e citocinas seriam medidas nos mesmos momentos (24 e $48 \mathrm{~h})$. 
Em resumo, estratégia ventilatória baseada no OLC, com fácil aplicabilidade na prática clínica, adotada para pacientes sem resposta a 24 horas de ventilação segundo protocolo ARDSnet, foi capaz de promover melhora na oxigenação e redução nas áreas de colapso alveolar, sem indução de hiperinsuflação significativa e sem efeitos hemodinâmicos adversos. Determinou, também, redução nos níveis plasmáticos de IL-6.

Este foi o primeiro estudo a avaliar OLC como terapia de resgate em pacientes não respondedores à ARDSnet, sugerindo uma nova forma de abordagem para pacientes com LPA / SARA. Novos estudos, com um maior número de pacientes, são necessários para determinar a segurança da OLC empregada, assim como para definir o perfil dos pacientes que melhor respondem a cada uma dessas estratégias ventilatórias. 


\section{Conclusão:}

Estratégia ARDSnet aplicada por $24 \mathrm{~h}$ não foi capaz de reduzir as áreas de colapso alveolar e corrigir a hipoxemia.

Estratégia OLC aplicada nas $24 \mathrm{~h}$ seqüenciais foi efetiva em homogeneizar os pulmões, revertendo as áreas de colapso, sem gerar hiperinsuflação, reduzindo também os níveis plasmáticos de IL-6.

Os pacientes com LPA / SDRA apresentaram níveis elevados de citocinas, com predomínio das concentrações pulmonares sobre as plasmáticas. 


\section{8-Referências bibliográficas:}

1. Rubenfeld G, Caldwell E, Peabody E, et al. Incidence and Outcomes of Acute Lung Injury. N England J Med 2005; 353:1685-93.

2. Angus DC, Musthafa AA, Clermont G, et al. Quality-adjusted survival in the first year after the Acute Respiratory Distress Syndrome. Am J Respir Crit Care Med 2001; 163:1389-94.

3. Vincent JL, Sakr Y, Ranieri VM. Epidemiology and outcome of acute respiratory failure in intensive care unit patients. Crit Care Med 2003; 31[Suppl]: S296-9.

4. Gattinoni L, Caironi P, Carlesso E. How to ventilate patients with Acute Lung Injury and Acute Respiratory Distress Syndrome. Curr Opin Crit Care 2005; 11:69-76.

5. Slutsky AS, Imai Y. Ventilator-induced lung injury, cytokines, PEEP, and mortality: implications for practice and for clinical trials. Intensive Care Med 2003; 29:1218-21.

6. Bernard GR, Artigas A, Brigham KL, et al. The American-European Consensus Conference on ARDS. Definitions, mechanisms, relevant outcomes and clinical trial coordination. Am J Respir Crit Care Med 1994; 149:818-24.

7. Villar J, Pérez-Méndes L, Kacmarek RM. Current definitions of Acute Respiratory Distress Syndrome do not reflect their true severity and outcome. Intensive Care Med 1999; 25:930-5.

8. Villar J, L Pérez-Méndes, Lopez J et al. An early PEEP/FIO 2 trial identifies different degrees of lung injury in patients with Acute Respiratory Distress Syndrome. Am J Respir Crit Care Med 2007; 176:795804.

9. Ranieri VM, Suter PM, Tortorella C, et al. Effect of mechanical ventilation on inflamatory mediators in patients with Acute Respiratory Distress Syndrome. JAMA 1999; 281:54-61.

10. Shimabukuro DW, Sawa T, Gropper MA. Injury and repair in lung and airways. Crit Care Med 2003; 31[Suppl]:S524-9.

11. Gattinoni L, Pesenti A. The concept of “baby lung”). Intensive Care Med 2005; 31:776-84.

12. Gattinoni L, Caironi P, Pelosi P et al. What has computed tomography taught us about the Acute Respiratory Distress Syndrome? Am J Respir Crit Care Med 2001; 164:1701-11.

13. Gattinoni L, Carlesso E, Valenza F, et al. Acute Respiratory Distress Syndrome, the critical care paradigm: what we learned and what we forgot. Curr Opin Crit Care 2004; 10:272-8.

14. Pugin J, Dunn I, Jolliet P et al. Activation of human macrophages by mechanical ventilation in vitro. Am J Physiol 1998; 275:L1040-50. 
15. Wolthuis EK, Jonge E, Schultz MJ. The role of cytokines in VALI and VASI. In: Yearbook of Intensive Care and Emergency Medicine. Springer; 2004: p 371-83.

16. Park WY, Goodman RB, Steinberg KP,et al. Cytokine balance in the lungs of patients with Acute Respiratory Distress Syndrome. Am J Respir Crit Care Med 2001; 164:1896-903.

17. Meduri GU, Kohler G, Headley S et al. Inflammatory cytokines in the BAL of patients with ARDS. Persistent elevation over time predicts poor outcome. Chest 1995; 108:1303-14.

18. Miller EJ, Cohen AB, Matthay MA. Increased interleukin- 8 concentrations in the pulmonary edema fluid of patients with acute respiratory distress syndrome from sepsis. Crit Care Med 1996; 24:1448-54.

19. Meduri G, Headley S, Kohler G et al. Persistent elevation of inflammatory cytokines predicts a poor outcome in ARDS. Plasma IL-1 beta and IL-6 levels are consistent and efficient predictors of outcome over time. Chest 1995; 107:1062-73.

20. Madtes DK, Rubenfeld G, Klima LD, et al. Elevated transforming growth factor-alpha levels in bronchoalveolar lavage fluid of patients with Acute Respiratory Distress Syndrome. Am J Respir Crit Care Med 1998; 158:424-30.

21. Dhainaut J-F, Charpentier J, Chiche J-D et al. Transforming growth factor- $B$. A mediator of cell regulation in Acute Respiratory Distress Syndrome. Crit Care Med 2003; 31:S258-64.

22. Lanchou J, Corbel M, Tanguy M et al. Imbalance between matrix metalloproteinases (MMP-9 and MMP-2) and tissue inhibitors of metalloproteinases (TIMP-1 and TIMP-2) in Acute Respiratory Distress Syndrome patients. Crit Care Med 2003; 31:536-42.

23. Vlahakis NE, Schroeder MA, Limper AH, et al. Stretch induces cytokine release by alveolar epithelial cells in vitro. Am J Physiol Lung Cell Mol Physiol 1999; 277:167-73.

24. Stüber F, Wrigge H, Schroeder S, et al. Kinetic and reversibility of mechanical ventilation-associated pulmonary and systemic inflammatory response in patients with acute lung inj ury. Intensive Care Med 2002; 28:834-41.

25. Parsons PE, Eisner MD, Thompson BT, et al. Lower tidal volume ventilation and plasma cytokine markers of inflammation in patients with acute lung injury. Crit Care Med 2005; 33:1-6.

26. Acute Respiratory Distress Syndrome Network. Ventilation with lower tidal volumes as compared with traditional tidal volumes for Acute Lung Injury and the acute respiratory distress syndrome. N England J Med 2000; 342:1301-8.

27. Amato MB, Barbas CS, Medeiros DM, et al. Effect of a protective-ventilation strategy on mortality in the Acute Respiratory Distress Syndrome. N England J Med 1998; 338:347-54.

28. Muscedere JG, Mullen JB, Gan K, Slutsky AS. Tidal ventilation at low airway pressures can augment lung injury. Am Rev Respir Dis 1994; 149:1327-34. 
29. Marini JJ, Gattinoni L. Ventilatory management of Acute Respiratory Distress Syndrome: A consensus of two. Crit Care Med 2004; 32:250-5.

30. Lim C-M, Jung H, Koh Y, et al. Effect of alveolar recruitment maneuver in early Acute Respiratory Distress Syndrome according to antiderecruitment strategy, etiological category of diffuse lung injury, and body position of the patient. Crit Care Med 2003; 31:411-8.

31. The ARDS Clinical Trials Network. Effects of recruitment maneuvers in patients with Acute Lung Injury and Acute Respiratory Distress Syndrome ventilated with high positive end-expiratory pressure. Crit Care Med 2003; 31:2592-7.

32. Grasso S, Mascia L, Del Turco M, et al. Effects of recruiting maneuvers in patients with Acute Respiratory Distress Syndrome ventilated with protective ventilatory strategy. Anesthesiology 2002; 96:795-802.

33. Medoff B D, Harris RS, Kesselman H, et al. Use of recruitment maneuvers and high positive endexpiratory pressure in a patient with Acute Respiratory Distress Syndrome. Crit Care Med 2000; 28:1210-6.

34. Papadakos PJ, Lachmann B. The open lung concept of mechanical ventilation: the role of recruitment and stabilization. Crit Care Clin 2007; 23:241-250.

35. Rouby J-J, Puybasset L, Nieszkowska A, et al. Acute respiratory distress syndrome: Lessons from computed tomography of the whole lung. Crit Care Med 2003; 31[Suppl.]:S285-95.

36. Puls A, Pollok-Kopp B, Wrigge H, et al. Effects of a single-lung recruitment maneuver on the systemic release of inflammatory mediators. Intensive Care Med 2006; 32:1080-5.

37. Talmor D, Sarge T, Legedza A, et al. Cytokine release following recruitment maneuvers. Chest 2007; 132:1434-9.

38. Rouby J-J, Constantin J-M, Girardi CRA, et al Mechanical ventilation in patients with Acute Respiratory Distress Syndrome. Anesthesiology 2004; 101:228-34.

39. Barbas CSV, De Mattos GF, Borges E R. Recruitment maneuvers and positive end-expiratory pressure/tidal ventilation titration in Acute Lung Injury/Acute Respiratory Distress Syndrome: translating experimental results to clinical practice. Crit Care 2005; 9:424-6.

40. Gattinoni L, Vagginelli F, Chiumello D, et al. Physiologic rationale for ventilator setting in acute lung injury / acute respiratory distress syndrome patients. Crit Care Med 2003; 31[Suppl.]:S300-4.

41. Durante G de, del Turco M, Rustichini L, et al. ARDSNet Lower tidal volume ventilatory strategy may generate intrinsic positive end-expiratory pressure in patients with Acute Respiratory Distress Syndrome. Am J Respir Crit Care Med 2002; 165:1271-4.

42. Lee CM, Neff MJ, Steinberg KP, et al. Effect of low tidal volume ventilation on intrinsic PEEP in patients with acute lung injury. Am J Respir Crit Care Med 2001; 163:A765. 
43. Brower RG, Lanken PN, MacIntyre N; National Heart, Lung and Blood Institute ARDS Clinical Trials Network. Higher versus lower positive end-expiratory pressures in patients with the Acute Respiratory Distress Syndrome. N England J Med 2004; 351:327-36.

44. Levy MM. PEEP in ARDS- How much is enough? N England J Med 2004; 351:389-90.

45. Grasso S, Fanelli V, Cafarelli A, et al. Effects of high versus low positive end-expiratory pressures in Acute Respiratory Distress Syndrome. Am J Respir Crit Care Med 2005; 171:1002-8.

46. Villar J, Kacmarek RM, Pérez-Méndez L, et al. A high positive end-expiratory pressure, low tidal volume ventilatory strategy improves outcome in persistente Acute Respiratory Distress Syndrome: A randomized, controlled trial. Crit Care Med 2006; 34:1311-8.

47. Meade MO, Cook DJ, Guyatt GH, et al. Ventilation strategy using low tidal volumes, recruitment maneuvers, and high positive end-expiratory pressure for acute lung injury and acute respiratory distress syndrome. A randomized controlled trial. JAMA 2008; 299:637-45.

48. Mercat A, Richard J-C, Vielle B, et al. Positive end-expiratory pressure setting in adults with acute lung injury and acute respiratory distress syndrome. JAMA 2008; 299:646-55.

49. Rouby J-J, Ferrari F, Bouhemad B, et al. Positive end-expiratory pressure in Acute Respiratory Distress Syndrome: should the "open lung strategy" be replaced by a "protective lung strategy"? Critical Care 2007; 11:180.

50. Okamoto VN, Borges JB, Amato MBP. Recruitment maneuvers in ARDS. In: Mechanical ventilation Update in Intensive CareMedicine. Springer; 2005:p 335-52.

51. Roupie E, Dambrosio M, Servillo G, et al. Titration of tidal volume and induced hypercapnia in Acute Respiratory Distress Syndrome. Am J Respir Crit Care Med 1995; 152:121-8.

52. Pelosi P, Goldner M, McKibben A, et AL. Recruitment and derecruitment during acute respiratory failure. An experimental study. Am J Respir Crit Care Med 2001; 164:122-30.

53. Crotti S, Mascheroni D, Caironi P et al. Recruitment and derecruitment during acute respiratory failure. A clinical study. Am J Respir Crit Care Med 2001; 164:131-40.

54. Jonson B. Elastic pressure-volume curves in Acute Lung Injury and Acute Respiratory Distress Syndrome. Intensive Care Medicine 2005; 31:205-12.

55. Albaiceta G, Taboada F, Parra D, et al. Tomographic study of the inflection points of the pressurevolume curve in Acute Lung Injury. Am J Respir Crit Care Med 2004; 170:1066-72.

56. Ranieri VM, Giuliani R, Fiori T, et al. Volume-pressure curve of the respiratory system predicts effects of PEEP in ARDS: “occlusion" versus "constant flow” technique. Am J Respir Crit Care Med 1994; 149:19-27. 
57. Hickling KG. Best compliance during a decremental but not incremental, positive end-expiratory pressure. A mathematical model of Acute Re spiratory Distress Syndrome Lungs. Am J Respir Crit Care Med 2001; 163: 69-78.

58. Gattinoni L, Pesenti A, Avalli L, et al. Pressure-volume curve of total respiratory system in acute respiratory failure. Computed tomographic scan study. Am Rev Respir Dis 1987; 136:730-6.

59. Malbouisson LM, Muller JC, Constantin JM, et al. Computed tomography assessment of positive endexpiratory pressure-induced alveolar recruitment in patients with Acute Respiratory Distress Syndrome. Am J Respir Crit Care Med 2001; 163:1444-50.

60. Puybasset L, Cluzel P, Chao N, et al. A computed tomography scan assessment of regional lung volume in Acute Lung Injury. Am J Respir Crit Care Med 1998; 158:1644-55.

61. Pesenti A, Tagliabue P, Patroniti N, et al. Computerised tomography scan imaging in Acute Respiratory Distress Syndrome. Intensive Care Med 2001; 27:631-9.

62. Lu Q, Malbouisson LM, Mourgeon E, et al. Assessment of PEEP-induced reopening of collapsed lung regions in Acute Lung Injury: are one or three CT sections representative of the entire lung? Intensive Care Med 2001; 27:1504-10.

63. Nieszkowska A, Lu Q, Vieira S, et al. Incidence and regional distribution of lung overinflation during mechanical ventilation with positive end-expiratory pressure. Crit Care Med 2004; 32:1496-503.

64. Vieira S, Nieszkowska A, Lu Q, et al. Low spatial resolution computed tomography underestimates lung overinflation resulting from positive pressure ventilation. Crit Care Med 2005; 33:741-9.

65. Rouby J.J, Puybasset L, Cluzel P, et al. Regional distribution of gas and tissue in acute respiratory distress syndrome. II. Physiological correlations and definitions of an ARDS Severity Score. Intensive Care Med 2000; 26:1046-56.

66. Puybasset L, Gusman P, Muller JC, et al. Regional distribution of gas and tissue in acute respiratory distress syndrome. III. Consequences for the effects of positive end-expiratory pressure. Intensive Care Med 2000; 26:1215-27.

67. Puybasset L, Cluzel P, Gusman P, et al. Regional distribution of gas and tissue in acute respiratory distress syndrome. I. Consequences for lung morphology. Intensive Care Med 2000; 26:857-69.

68. Terragni PP, Rosboch G, Tealdi A, et al. Tidal hyperinflation during low tidal volume ventilation in Acute Respiratory Distress Syndrome. Am J Respir Crit Care Med 2007; 175:160-6.

69. Gattinoni L, Caironi P, Cressoni M, ET AL. Lung recruitment in patients with the Acute Respiratory Distress Syndrome. N Engl J Med 2006; 354:1775-86.

70. Borges JB, Okamoto VN, Matos GFJ, et al. Reversibility of lung collapse and hypoxemia in early Acute Respiratory Distress Syndrome. Am J Respir Crit Care Med 2006; 174:268-78. 
71. Gattinoni L, Caironi P. Refining ventilatory treatment for acute lung injury and acute respiratory distress syndrome. JAMA 2008; 299:691-3.

72. Dreyfuss D, Saumon G. Ventilator-induced lung injury: lessons from experimental studies. Am J Respir Crit Care Med 1998; 157:294-323.

73. Ely EW, Truman B, Shintani A, et al. Monitoring sedation status over time in ICU patients: the reliability and validity of the Richmond Agitation Sedation Scale (RASS). JAMA 2003; 289:2983-91.

74. De Matos G, Borges J, Meyer E, et al. Maximal recruitment strategy guided by thoracic CT scan in severe acute respiratory distress syndrome. Crit Care 2007; 11 (Supp1 2):P188.

75. Villagrá A, Ochagavía A, Vatua S, et al. Recruitment maneuvers during lung protective ventilation in acute respiratory distress syndrome. Am J Respir Crit Care Med 2002; 165:165-70.

76. Grasso S, Mascia L, Del Turco M, et al. Effects of recruiting maneuvers in patients with acute respiratory distress syndrome ventilated with protective ventilatory strategy. Anesthesiology 2002; 96:795802.

77. Riva DR, Oliveira MBG, Rzezinski AF, et al. Recruitment maneuvers in pulmonary and extrapulmonary experimental acute lung injury. Crit Care Med 2008; 36:1-9.

78. Gattinoni L, Pelosi P, Suter PM, et al. Acute respiratory distress syndrome caused by pulmonary and extrapulmonary disease. Different syndromes? Am J Respir Crit Care Med 1998, 158:3-11.

79. Moreno R, Vincent JL, Matos R, et al. The use of maximum SOFA score to quantify organ dysfunction / failure in intensive care. Results of a prospective, multicentre study. Working group on sepsis related problems of the ESICM. Intensive Care Med 1999; 25:686-96.

80. Ferreira FL, Bota DP, Bross A, et al. Serial evaluation of the SOFA score to predict outcome in critical ill patients. JAMA 2001; 286:1754-8. 


\section{ANEXO I}

\section{Tratamentos de resgate para acidose respiratória e para hipoxemia refratária durante ventilação segundo OLC}

Em qualquer momento da ventilação com PEEP alvo, caso $\mathrm{PaCO}_{2}>70 \mathrm{mmHg}$ e pH<7,15, insuflação de gás traqueal (TGI) a 6L/min seria empregada. A TGI seria realizada com uma sonda de aspiração, inserida através do tubo orotraqueal, utilizando-se o introdutor lateral do trach-care. Esta sonda ficaria com

sua extremidade distal localizada um a dois centímetros acima da carina). Caso a $\mathrm{PaCO}_{2}$ não diminuísse com fluxo de oxigênio de 6L/min, este deveria ser aumentado para $8 \mathrm{~L} / \mathrm{min}$. TGI deveria ser desligada 15 minutos antes das coletas de gasometria arterial para que não houvesse interferência na mensuração da $\mathrm{PaO}_{2}$ e nas aferições de Pplatô e PEEP.

Caso algum paciente apresentasse $\mathrm{PaO}_{2}<70 \mathrm{mmHg}$ apesar de ventilação com PEEP alvo, seria utilizada a posição prona por 12 horas. 


\section{ANEXO II}

\section{Principais protocolos terapêuticos do Hospital Copa D'Or}

\section{Protocolos de desmame de prótese ventilatória:}

\section{A. Critérios clínicos para desmame:}

- Reversão do processo que provocou a IRpa

- Sem programação cirúrgica

- Estabilidade hemodinâmica (FC < 140bpm, 180> PAS >90mmHg)

- Sem sedação ou com infusões reduzidas de fármacos vasoativos e sedativos (Rass -2)

- Estabilidade neurológica (Glasgow $>8$ )

- Frequência respiratória $\leq 35$ irpm

- Ausência de distúrbio eletrolítico grave:

$\mathrm{pH}>7,3$ e $<7,6$

$\mathrm{PaO}_{2}>60 \mathrm{mmHg}$ com $\mathrm{FiO}_{2}<0,4$ e $\mathrm{PEEP}=5 \mathrm{cmH}_{2} \mathrm{O}$

$\mathrm{PaO}_{2} / \mathrm{FiO}_{2}>200$

- PiMáx $<-25 \mathrm{cmH}_{2} \mathrm{O}$

- Ausência de febre (temperatura axilar $<38^{\circ} \mathrm{C}$ )

- Ausência de anemia grave $(\mathrm{Hb}>8 \mathrm{~g} / \mathrm{dl})$ 
B.Esquema de desmame:

1. Pacientes entubados:

Redução gradual da PSV até 8 e PEEP $=8 \mathrm{cmH}_{2} \mathrm{O}$, com VT, FR, VM ideais para proceder extubação.

2.2. Pacientes traqueostomizados:

Esquema I - Desmame rápido:

$\cdot 1^{\circ}$ DIA- 2 períodos de 2 horas de macro

-2 DIA- 2 períodos de 3 horas de macro

- $3^{\circ}$ DIA- 3 períodos de 3 horas de macro

- $4^{\circ}$ DIA- 3 períodos de 4 horas de macro

- $5^{\circ}$ DIA- 3 períodos de 4 horas de macro

- $6^{\circ}$ DIA- 2 períodos de 6 horas de macro

$\cdot 7^{\circ}$ DIA- 2 períodos de 6 horas de macro

- $8^{\circ}$ DIA- Dorme fora de prótese com 3 Ventilações invasivas (Vi) de 120 min. ( 6:00-8:00, 14:00-16:00, 22:00-24:00)

-9 $9^{\circ}$ DIA- Dorme fora de prótese com 3 Vi de 120 min. ( 6:00-8:00, 14:00-16:00, 22:00-24:00 ) Paciente considerado desmamado!

-10 DIA- Reduzir o tempo de Vi para 60 min. ( manhã, tarde e noite de 7 em 7 horas )

-11 $1^{\circ}$ DIA- Reduzir o tempo de Vi para 30 min. ( manhã, tarde e noite )

-12 DIA- Reduzir o número de Vi para duas ao dia de 12 em 12 horas por 30 min..

•13ํDIA- APÓS ESSAS ETAPAS AVALIAR SUSPENDER AS Vi. 


\section{Esquema II}

Esquema para falha do desmame rápido

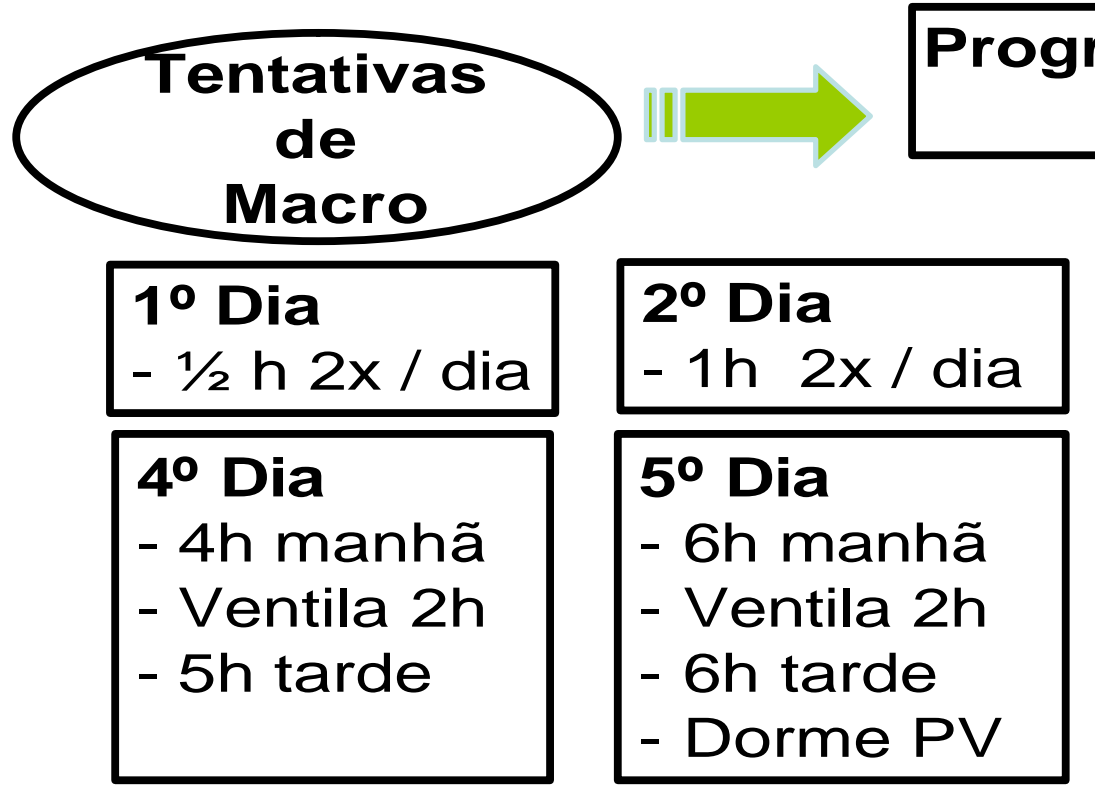

3음a

- 2h manhã

- 3h tarde

10 Noite

- 6h manhã

- 6h tarde

- 3 Ventil. 60'

- Dorme macro 


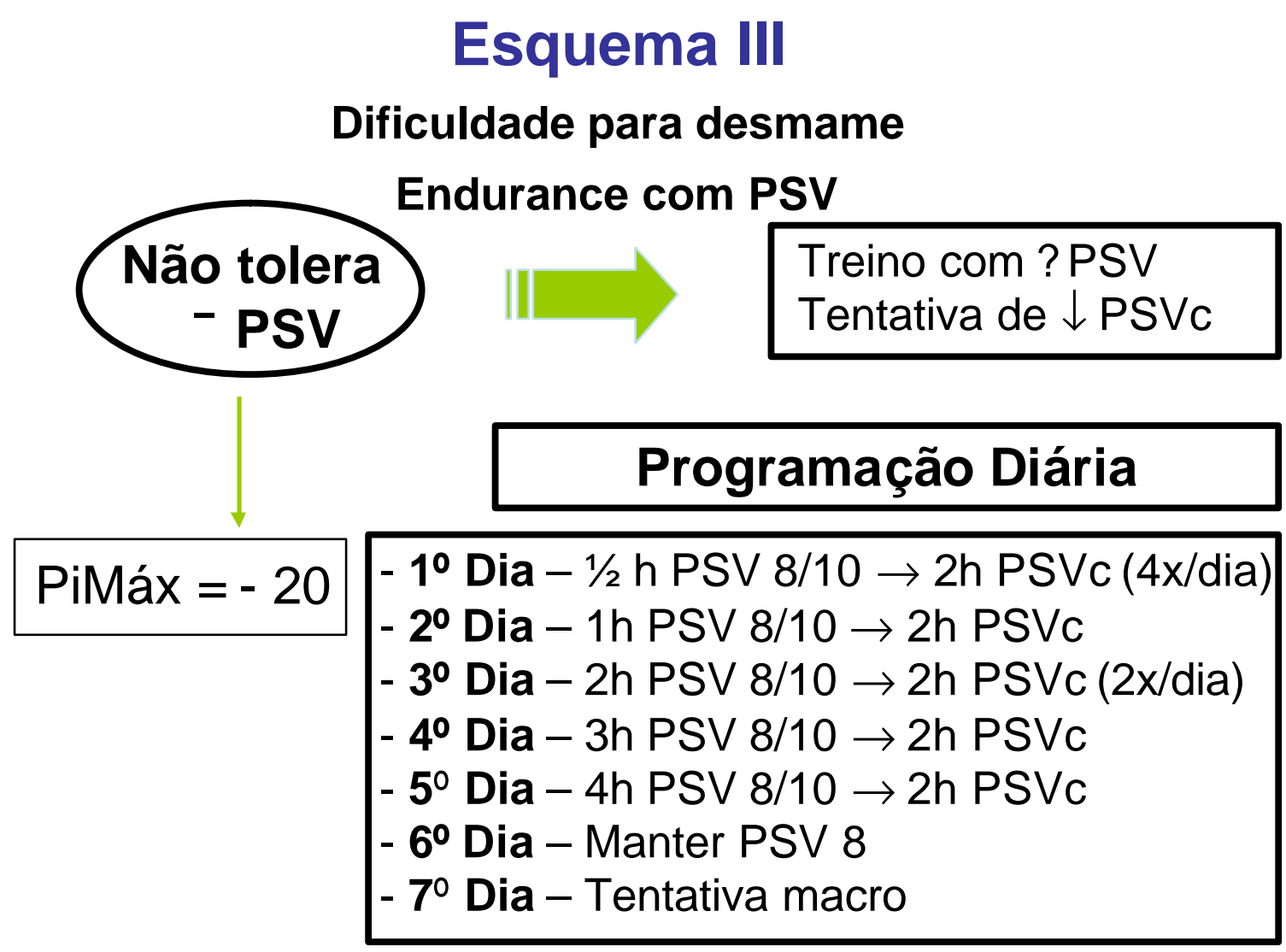




\section{Tratamento das principais infeccões na terapia intensiva:}

\section{PNEUMONIAS COMUNITÁRIAS GRAVES:}

a) Pneumonias comunitárias graves de início agudo, sem doença pulmonar prévia e Pneumonias comunitárias subseqüentes a quadros gripais:

\begin{tabular}{|c|c|}
\hline Droga de escolha & Amoxicilina + clavulanato \\
\hline Via de administração & Intravenosa (IV) \\
\hline Posologia & 1 grama (gr.) de 8/8 horas (h.) \\
\hline Duração & 10 a 14 dias \\
\hline Alternativa para alérgicos a penicilina & Moxifloxacin $400 \mathrm{mg} 1 \times$ ao dia \\
\hline Patógenos contemplados & $\begin{array}{c}\text { S. pneumoniae, M. catarrhalis, H. influenzae, } \\
\text { S.aureus }\end{array}$ \\
\hline
\end{tabular}

b) Pneumonias comunitárias graves em pacientes com doença pulmonar obstrutiva crônica e Pneumonias comunitárias graves com apresentação sub-aguda, precedida de manifestações sistêmicas não específicas (febre, cefaléia, mialgias), tosse seca e leucocitose igual ou inferior a 15.000 células/mm

\begin{tabular}{|c|c|c|}
\hline & \multicolumn{2}{|c|}{ Drogas usadas em associação } \\
\hline Drogas de escolha & Amoxicilina + clavulanato & Azitromicina \\
\hline Via de administração & \multicolumn{2}{|c|}{ Intravenosa (IV) } \\
\hline Posologia & $1 \mathrm{gr}$. de $8 / 8 \mathrm{~h}$. & $500 \mathrm{mg} 1$ vez ao dia \\
\hline Duração & 10 a 14 dias ?? & $\begin{array}{c}\text { Na confirmação de pneumonia } \\
\text { atípica o tratamento deverá se } \\
\text { estender até } 21 \text { dias }\end{array}$ \\
\hline $\begin{array}{c}\text { Alternativa para alérgicos a } \\
\text { penicilina }\end{array}$ & \multicolumn{2}{|c|}{ Moxifloxacin $400 \mathrm{mg} 1 \mathrm{x}$ ao dia } \\
\hline Patógenos contemplados & \multicolumn{2}{|c|}{$\begin{array}{c}\text { Os acima descritos acrescidos dos germes Legionella sp., M. } \\
\text { pneumoniae e Claumydophila pneumoniae. }\end{array}$} \\
\hline
\end{tabular}


c) Pneumonias comunitárias graves em pacientes com bronquiectasias:

\begin{tabular}{|c|c|c|}
\hline \multicolumn{3}{|c|}{ Drogas usadas em associação } \\
\hline Drogas de escolha & Pip/ taz & Azitromicina \\
\hline Via de administração & \multicolumn{2}{|r|}{ Intravenosa (IV) } \\
\hline Posologia & $\begin{array}{l}\text { Doses de ataque: } \\
\text { 2g./ 0,25g em } 100 \\
\text { ml. S. G.5\% } \\
\text { Manutenção: } \\
\text { 16g./ 2g. em } 500 \mathrm{ml} \\
\text { de S. G. } 5 \% \text { em } 24 \text { h. }\end{array}$ & $500 \mathrm{mg} 1$ vez ao dia \\
\hline Duração & 10 a 14 dias ?? & $\begin{array}{c}\text { Na confirmação de pneumonia atípica } \\
\text { o tratamento deverá se estender até } \\
21 \text { dias }\end{array}$ \\
\hline Alternativa para alérgicos a penicilina & \multicolumn{2}{|c|}{ Moxi + AZM (com ou sem aminoglicosídeo) } \\
\hline Patógenos contemplados & \multicolumn{2}{|c|}{ Os acima descritos somados a P. aeruginosa. } \\
\hline
\end{tabular}

\section{OU}

d) Pneumonias comunitárias graves em paciente com possível imunossupressão celular e achados sugestivos de pneumocistose: evolução arrastada (10 a 60 dias), LDH elevada, taquidispnéia progressiva , radiografia de tórax com infiltrado intersticial difuso e bilateral, presença de candidíase oral.

\begin{tabular}{|c|c|}
\hline Droga de escolha & Sulfametoxazol + trimetoprim \\
\hline Via de administração & Intravenosa (IV) \\
\hline Posologia & 15 a $20 \mathrm{mg} / \mathrm{Kg} /$ dia (trimetoprim) \\
\hline Duração & 14 a 21 dias. \\
\hline Patógenos contemplados & $\begin{array}{r}\text { Pneumocystis jiroveci, al gumas cepas de S. pneumoniae, H. } \\
\text { influenzae e M.catarrhalis. }\end{array}$ \\
\hline
\end{tabular}

\section{OBSERVAÇÃO IMPORTANTE:}

- Sempre realizar gasometria arterial, e em casos de pO2 menor que $75 \mathrm{mmHg}$, utilizar corticoesteróide antes da primeira dose de antibiótico.

- O corticóide escolhido poderá ser a prednisona $1 \mathrm{mg} / \mathrm{kg} / \mathrm{dia}$. Caso opte por outra droga utilizar a dose correspondente a estabelecida para prednisona.

- Ao iniciar terapêutica com corticóide, iniciar tratamento empírico para estrongiloidíase com Tiabendazol 15mg/ Kg 8/ 8 horas durante 3 dias. 


\section{PNEUMONIAS NOSOCOMIAIS}

Critérios diagnósticos das Pneumonias nosocomiais associadas ou não a ventilação mecânica:

Estabelecer diagnóstico com os seguintes achados:

A)exame de imagem sugestivo de infiltrado pulmonar

$$
+
$$

B)febre e /ou leucocitose e/ ou secreção traqueal purulenta.

- A especificidade aumenta quanto maior for o número de sinais listados na letra B.

- Sempre que possível proceder à coleta de material antes do início da antibioticoterapia.

- $\quad$ Em casos de pneumonias precoces, ou seja, até 4 dias de hospitalização seguir as orientações recomendadas anteriormente.

- $\quad$ Em casos de pneumonias consideradas tardias, ou seja, com 5 dias ou mais de internação seguir estas orientações:

a) Pneumonia nosocomial tardia sem uso prévio de antibioticoterapia:

\begin{tabular}{|c|c|}
\hline Droga de escolha & Pip/ taz \\
\hline Via de administração & Intravenosa (IV) \\
\hline Posologia & $\begin{array}{c}\text { Doses de ataque: } 2 \mathrm{~g} / 0,25 \mathrm{~g} \text { em } 100 \mathrm{ml} . \mathrm{S} . \mathrm{G} .5 \% \\
\text { Manutenção: } 16 \mathrm{~g} / 2 \mathrm{~g} \mathrm{em} 500 \mathrm{ml} \text { de S. G.5\% em } 24 \mathrm{~h}\end{array}$ \\
\hline Duração & 8 dias para não fermentadores \\
\hline Alternativa para alérgicos a penicilina & Ciprofloxacin 400mg de 8/ 8h. \\
\hline Patógenos contemplados & $\begin{array}{c}\text { Germes Gram + não MDR (Multidroga resistente) e } \\
\text { germes G-, incluindo P. aeruginosa }\end{array}$ \\
\hline
\end{tabular}


b) Pneumonia nosocomial tardia com uso prévio de amoxicilina + clavulanato ou de moxifloxacin:

\begin{tabular}{|c|c|c|}
\hline \multicolumn{3}{|c|}{ Drogas usadas em associação } \\
\hline Drogas de escolha & \multicolumn{2}{|c|}{ Piperacilina + tazobactam } \\
\hline Via de administração & \multicolumn{2}{|c|}{ Intravenosa (IV) } \\
\hline Posologia & \multicolumn{2}{|c|}{$\begin{array}{c}\text { Doses de ataque: } 2 \mathrm{~g} / 0,25 \mathrm{~g} \text { em } 100 \mathrm{ml} \text {. S. G. } 5 \% \\
\text { Manutenção: } 16 \mathrm{~g} / 2 \mathrm{~g} \text { em } 500 \mathrm{ml} \text { de S. G. } 5 \% \text { em } 24 \mathrm{~h} \text {. }\end{array}$} \\
\hline Duração & \multicolumn{2}{|c|}{8 dias para não fermetadores } \\
\hline $\begin{array}{l}\text { Alternativa para } \\
\text { alérgicos a penicilina }\end{array}$ & \multicolumn{2}{|c|}{ Ciprofloxacin $400 \mathrm{mg}$ de $8 / 8 \mathrm{~h}$. } \\
\hline Patógenos contemplados & $\begin{array}{l}\text { Germes Gram + não MDR e germes } \\
\text { Gram -, incluindo P. aeruginosa de } \\
\text { acordo com sensibilidade. }\end{array}$ & \\
\hline Indicação & & $\begin{array}{c}\text { Nos quadros de infecções sem } \\
\text { patógeno definido, ou nos que } \\
\text { estejam envolvidos germes } \\
\text { P.aeruginosa , A.calcoaceticcus, } \\
\text { ESBL+ }\end{array}$ \\
\hline
\end{tabular}

A piperacilina/tazobactan não pode ser infundida concomitante a genta e amica.

c ) Pneumonia nosocomial tardia com uso prévio de piperacilina + tazobactam:

\begin{tabular}{|c|c|}
\hline \multicolumn{2}{|r|}{ Drogas usadas em associação } \\
\hline Drogas de escolha & Meropenem \\
\hline Via de administração & Intravenosa (IV) \\
\hline Posologia & $\begin{array}{c}1 \mathrm{gr} \text {. em } 100 \mathrm{ml} \text {. de soro fisiológico } 0,9(\mathrm{~S} . \mathrm{F} .0,9) \text { em infusão prolongada } \\
\text { por } 3 \text { horas de } 8 / 8 \mathrm{~h} \text {. }\end{array}$ \\
\hline Duração & 8 dias para não fermentadores \\
\hline Patógenos contemplados & Germes Gram Negativos MDR \\
\hline Indicação & $\begin{array}{c}\text { Nos quadros de infecções sem } \\
\text { patógeno definido, ou nos que } \\
\text { estejam envolvidos germes } \\
\text { P.aeruginosa, A.cal coaceticcus, } \\
\text { ESBL+ }\end{array}$ \\
\hline
\end{tabular}


d) Pneumonia nosocomial tardia com uso prévio de carbapenêmico:

\begin{tabular}{|c|c|c|}
\hline \multicolumn{3}{|c|}{ Drogas usadas em associação } \\
\hline Drogas de escolha & $\begin{array}{l}\text { Sulfametoxazol + } \\
\text { trimetoprim }\end{array}$ & Piperacilina + tazobactam \\
\hline Via de administração & Intravenosa ( IV ) & Intravenosa ( IV ) \\
\hline Posologia & $\begin{array}{l}15 \text { a } 20 \mathrm{mg} / \mathrm{Kg} / \mathrm{dia} \\
\text { (trimetoprim) }\end{array}$ & $\begin{array}{l}\text { Dose de ataque: } 2 \mathrm{~g} / 0,25 \mathrm{~g} \text { em } 100 \\
\text { ml S.G.5\% } \\
\text { Manutenção: } 16 \mathrm{~g} / 2 \mathrm{~g} \text { em } 500 \mathrm{ml} \text { de } \\
\quad \text { S.G.5\% em } 24 \text { horas. }\end{array}$ \\
\hline Duração & & 14 dias \\
\hline Patógenos contemplados & \multicolumn{2}{|c|}{$\begin{array}{c}\text { S.maltophilia, B cepacea, A xylosidans, Bacilos gram negativos } \\
\text { aeróbios. }\end{array}$} \\
\hline
\end{tabular}

e ) Pneumonias nosocomiais em que haja suspeita de MRSA ( Staphylococcus aureus meticilino resistente )

\begin{tabular}{|c|c|}
\hline Droga de escolha & Teicoplanina \\
\hline Via de administração & \multicolumn{1}{|c|}{ Intravenosa (IV) } \\
\hline Posologia & $\begin{array}{l}\text { D0 }=400 \mathrm{mg} 12 / 12 \text { horas } \\
\text { D }=400 \mathrm{mg} / \mathrm{dia}\end{array}$ \\
\hline Duração & 14 dias \\
\hline Patógenos contemplados & Germes Gram Positivos e gram positivos MDR \\
\hline
\end{tabular}

f )Pneumonias nosocomiais em que haja crescimento do patógeno $A$. calcoaceticcus baumanni complex:

- $\quad$ Se sensível a ampicilina + sulbactam esta será a primeira escolha, na dose: $3 \mathrm{~g}$ IV 6/6 h.

- $\quad$ Se sensível a Ciprofloxacin , utilizar a dose de 400mg. de 8/8h associada a amicacina $15 \mathrm{mg} / \mathrm{kg} / \mathrm{dose}$ única;

- $\quad$ Em casos de Acinetobacter sp. sensíveis apenas a polimixinas utilizá-las na dose de 10.000 a 15.000 /Kg /dose IV de 12 em 12 h.. A infusão poderá ser contínua ou cada dose poderá ser infundida em 4 horas. Recomendamos que nestes casos seja feito sinergismo com rifampicina Via Oral (VO) ou Cateter NasoEntérico (CNE) na dose de 600mg.a 900mg./dia.

OBSERVAÇÕES IMPORTAN TES: 
- Na tentativa de diminuir a emergência de resistência os estudos sugerem a diminuição do tempo de antibioticoterapia para $\underline{\mathbf{8} \text { dias}}$, principalmente quando há notória resposta terapêut ica nas primeiras 72 horas de tratamento;

- Recomendamos sempre a regressão de antibióticos após resultados de cultivos com identificação de patógenos e sensibilidade.

\section{INFECCÕES DO TRATO URINÁRIO:}

16.3.a) Infecções de origem comunitária de trato urinário baixo em jovens, e sem complicações:

\begin{tabular}{|c|c|}
\hline Droga de escolha & Amoxicilina + clavulanato \\
\hline Via de administração & Intravenosa (IV) \\
\hline Posologia & 1 grama (gr.) de $8 / 8$ horas (h.) \\
\hline Duração & 10 a 14 dias \\
\hline Alternativa para alérgicos a penicilina & Moxifloxacin $400 \mathrm{mg} 1 \mathrm{x}$ ao dia \\
\hline Patógenos contemplados & S. pneumoniae, M. catarrhalis, H.influenzae, \\
S.aureus
\end{tabular}

16.3.b) Infecções de origem comunitária, de trato urinário baixo em idosos e sem complicações:

\begin{tabular}{|c|c|c|}
\hline \multicolumn{2}{|c|}{ Drogas usadas em associação } \\
\hline Drogas de escolha & Amoxicilina + clavulanato & Azitromicina \\
\hline Via de administração & \multicolumn{2}{|c|}{ Intravenosa (IV) } \\
\hline Posologia & 1 gr. de $8 / 8 \mathrm{~h}$. & $500 \mathrm{mg} 1$ vez ao dia \\
\hline Duração & 10 a 14 dias ?? & $\begin{array}{c}\text { Na confirmação de pneumonia } \\
\text { atípica o tratamento deverá se } \\
\text { estender até 21 dias }\end{array}$ \\
\hline $\begin{array}{c}\text { Alternativa para alérgicos a } \\
\text { penicilina }\end{array}$ & \multicolumn{2}{|c|}{ Moxifloxacin 400 mg 1 x ao dia } \\
\hline $\begin{array}{c}\text { Patógenos contemplados } \\
\text { Os acima descritos acrescidos dos germes Legionella sp., } M . \\
\text { pneumoniae e Claumydophila pneumoniae. }\end{array}$ \\
\hline
\end{tabular}


16.3.c) Pielonefrites comunitárias e Infecções do Trato urinário associada à prostatismo:

\begin{tabular}{|c|c|}
\hline Droga & Ciprofloxacin \\
\hline Via de administração & $\begin{array}{c}\text { Intravenosa ( IV), podendo ser modificada para via oral } \\
\text { na terapia sequencial }\end{array}$ \\
\hline Posologia & $200 \mathrm{mg}$. de $12 / 12 \mathrm{~h}$ \\
\hline Duração & 14 dias \\
\hline $\begin{array}{c}\text { Alternativa para alérgicos a } \\
\text { fluorquinolonas }\end{array}$ & Ceftriaxone $1 \mathrm{~g}$ de $12 / 12$ horas. ( IV ) \\
\hline Patógenos contemplados & $\begin{array}{c}\text { Enterobactérias e Germes Gram Positivos excluindo } \\
\text { Enterococcus Sp }\end{array}$ \\
\hline
\end{tabular}

16.3.d)Infecções de trato urinário associadas a cateter, após colheita de material para Gram e cultivo:

\begin{tabular}{|c|c|}
\hline Droga de escolha & Ciprofloxacin \\
\hline Via de administração & Intravenosa ( IV) \\
\hline Posologia & $200 \mathrm{mg}$. de $12 / 12 \mathrm{~h}$. \\
\hline Duração & 5 a 7 dias \\
\hline Alternativa para alérgicos a fluorquinolonas & Cefepime 1 g IV de 8/8 horas \\
\hline Patógenos contemplados & $\begin{array}{c}\text { Enterobactérias, P. aeruginosa e Germes } \\
\text { Gram Positivos excluindo Enterococcus Sp }\end{array}$ \\
\hline
\end{tabular}

\section{OBSERVAÇÕES IMPORTAN TES:}

- $\quad$ Caso haja o aparecimento de cocos Gram +, acrescentar ampicilina $1 \mathrm{~g}$. IV de 6/6h;

- Recomendamos sempre a regressão de antibióticos para sulfas ou aminoglicosídeos ou ampicilina ou amoxicilina+ clavulanato após resultados de cultivos com identificação de patógenos e sensibilidade;

- $\quad$ É importante lembrarmos que a maior parte destas bacteriúrias são assintomáticas, e nos casos destes pacientes a clínica de infecção associada a piúria pode determinar tratamento, mas a piúria sem clínica não é indicativa de tratamento;

\section{- A RETIRADA DO CATETER É ESSENCIAL PARA O TRATAMENTO.}


INFECCÕES DE CORRENTE SANGUÍNEA ASSOCIADA A CATETER (ICS):

\begin{tabular}{|c|c|c|}
\hline \multicolumn{3}{|c|}{ Drogas usadas em associação } \\
\hline Drogas de escolha & Teicoplanina & Piperacilina + tazobactam \\
\hline Via de administração & Intravenosa ( IV) & Intravenosa ( IV) \\
\hline Posologia & $\begin{array}{l}\text { DO ( Dia zero) - 400mg } \\
\text { 12/12horas } \\
\begin{array}{c}\text { D1 ( Dia um) - 400mg /dia } \\
\text { D2 a D7 ( Dia dois a Dia sete) } \\
\quad-400 \mathrm{mg} / \text { dia }\end{array}\end{array}$ & $\begin{array}{l}\text { Dose de ataque : } 2 \mathrm{~g} / 0,25 \mathrm{em} 100 \\
\text { ml. S.G.5\% } \\
\text { Manutenção: } 16 \mathrm{~g} . / 2 \mathrm{~g} . \text { em } 500 \\
\text { ml de S.G.5\% em } 24 \text { horas }\end{array}$ \\
\hline Duração & 7 a 14 dias & 7 dias \\
\hline $\begin{array}{l}\text { Alternativa para paciente } \\
\text { com risco de Insuficiência } \\
\text { Renal }\end{array}$ & $\begin{array}{l}\text { Teicoplanina } \\
\text { DO ( Dia zero) - 400mg } \\
\text { 12/12horas } \\
\text { D1 ( Dia um) }-400 \mathrm{mg} / \text { dia } \\
\text { D2 a D7 ( Dia dois a Dia sete) } \\
\text { - 400mg /dia }\end{array}$ & $\begin{array}{l}\text { Ajuste de dose de acordo com } \\
\text { clearance de creatinina }\end{array}$ \\
\hline Patógenos contemplados & Germes Gram Positivos MDR & $\begin{array}{c}\text { Germes Gram Negativos } \\
\text { nosocomiais mais prevalentes na } \\
\text { nossa unidade }\end{array}$ \\
\hline $\begin{array}{c}\text { Caso tenha feito uso prévio } \\
\text { de cefepime / ticarcilina }+ \\
\text { clavulanato / Piperacilina }+ \\
\text { tazobactan }\end{array}$ & & $\begin{array}{c}\text { Meropenem: } \\
\text { Doses: } 1 \text { gr. em } 100 \mathrm{ml} \text {. de soro } \\
\text { fisiológico } 0,9 \% \text { (S.F.0,9\%) em } \\
\text { infusão contínua por } 3 \text { horas cada } \\
\text { dose de } 8 / 8 \mathrm{~h} \text {. }\end{array}$ \\
\hline
\end{tabular}

\section{OBSERVAÇÕES IMPORTAN TES:}

- Sempre remover o cateter;

- Quando identificado o patógeno, restringir a cobertura exclusivamente para o mesmo;

- Em caso de bacteremia por Gram positivo, principalmente S. aureus, submeter o paciente à realização de eco transesofágico;

- Caso seja identificado o MSSA a oxacilina deverá ser usada, já que não há droga que promova maior morte celular a este grave patógeno na dose de $2 \mathrm{~g}$ IV de $4 / 4$ h.;

- Os estafilococcus coagulase negativo são contaminantes freqüentes de hemocultivos, e a opção de iniciar antibioticoterapia deve ser criteriosamente avaliada;

- Há ainda alternativas antimicrobianas para o tratamento destes patógenos e estas drogas poderão ser 
utilizadas em substituição ao glicopeptídeo, se assim o antibiograma permitir, por exemplo: $S$. haemolyticus sensível à sulfa ou quinolona;

- A rifampicina é droga de excelente ação sobre estafilococcus de pele e pode ser utilizada em terapias combinadas, principalmente em casos que as hemoculturas se mantenham persistentemente positivas.

\section{RECOMENDACÕES FINAIS:}

1) Situações em que o uso de glicopeptídeos deve ser desencorajado:

- Profilaxia cirúrgica em pacientes não alérgicos a $B$-lactâmicos;

- Uso empírico em paciente com neutropenia febril, sem fatores de risco para infecção por germes Gram positivos MDR;

- Tratamento de 1 amostra de hemocultivo positivo para estafilococcus coagulase negativo;

- Manutenção do uso da droga que foi iniciada empiricamente após resultados de cultivos com ausência de crescimento de germes Gram positivos resistentes a $B$-lactâmicos;

- Profilaxia local ou sistêmica para colonização ou infecção de cateteres;

- Descontaminação seletiva de trato digestivo;

- Descolonização de MRSA;

- Primeira escolha para tratamento de colite associada ao uso de antibióticos;

- Tratamento de MSSA em pacientes com insuficiência renal crônica pela comodidade posológica;

- Uso tópico ou por irrigação dos glicopeptídeos.

2) Diversos estudos demonstram que a emergência de patógenos Gram negativos resistentes esta relacionada ao uso abusivo de antibióticos. Para que possamos tentar colaborar com a diminuição deste fato há as seguintes recomendações:

- Regredir o antibiótico sempre que o resultado do antibiograma assim permitir;

- Não ultrapassar o número de dias estipulado para o tratamento da infecção de acordo com a sua topografia;

- Sempre que possível utilizar drogas sinérgicas. 


\section{Reposicão de Corticosteróides na Sepse:}

\section{Diagnóstico:}

Dosar o Cortisol basal nas primeiras $24 \mathrm{~h}$, no $3^{\circ}$ dia e no $5^{\circ}$ dia. Se valor sérico $<25 \mathrm{mg} / \mathrm{dL}$, faz-se o diagnóstico de Insuficiência Adrenal Relativa (a resposta positiva à administração empírica de corticosteróides também é considerada diagnóstica).

\section{Indicação:}

Todo paciente com SRIS / Sepse, em uso de amina vasopressora (noradrenalina ou dopamina).

\section{Esquema:}

Bolus de 100 mg de Hidrocortisona IV

Hidrocortisona $300 \mathrm{mg} /$ dia por 5 dias

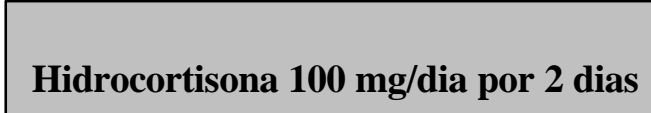

Interrupção

\section{Observações:}

1. A hidrocortisona deverá ser diluída em 50 ou $100 \mathrm{ml}$ de SF $0.9 \%$.

2. Caso seja necessário o retorno da reposição devido à re-infecção grave (com instabilidade hemodinâmica), reiniciar todo o esquema.

3. Após a suspensão da Hidrocortisona, caso seja necessária a manutenção da reposição (hipotensão não-explicada), dosar Cortisol basal e realizar, em seguida, o teste da cortrosina com $250 \mu \mathrm{g}$. Reiniciar e manter a infusão de $100 \mathrm{mg} /$ dia até a possibilidade de redução gradual, que deverá obedecer à regra abaixo:

Hidrocortisona $25 \mathrm{mg}$ IV de $8 / 8$ h por 3 dias

Hidrocortisona $25 \mathrm{mg}$ IV de 12/12 h por 3 dias

Prednisona 20 mg/dia por 5 dias. Passar para 10 $\mathrm{mg} /$ dia até a possibilidade de suspensão. 


\section{ANEXO III}

\section{Escala de Agitação e Sedação de Richmond (RASS)}

\section{Richmond Agitation Sedation Scale (RASS) *}

$\left.\begin{array}{cll}\text { Score } & \text { Term } & \text { Description } \\ \hline+4 & \text { Combative } & \text { Overtly combative, violent, immediate danger to staff } \\ +3 & \text { Very agitated } & \text { Pulls or removes tube(s) or catheter(s); aggressive } \\ +2 & \text { Agitated } & \text { Frequent non-purposeful movement, fights ventilator } \\ +1 & \text { Restless } & \text { Anxious but movements not aggressive vigorous } \\ 0 & \text { Alert and calm } & \text { Not fully alert, but has sustained awakening } \\ -1 & \text { Drowsy } & \text { (eye-opening/eye contact) to voice }(\geq \mathbf{1 0} \text { seconds) } \\ & \text { Briefly awakens with eye contact to voice (<10 seconds) } \\ -2 & \text { Light sedation } & \text { Movement or eye opening to voice } \text { (but no eye contact) }\end{array}\right\}$ Stimulation




\title{
ANEXO IV
}

\section{Informações ao Paciente e Consentimento Livre e}

\author{
Esclarecido
}

\author{
Avaliação de estratégia ventilatória seqüencial em pacientes com Lesão Pulmonar Aguda \\ (LPA)/Síndrome de Angústia Respiratória Aguda (SARA).
}

\section{Introdução}

$\mathrm{O} \mathrm{Sr}(\mathrm{a})$ está sendo convidado para participar

voluntariamente de um estudo que envolve tratamentos habitualmente utilizados em pacientes com doença pulmonar aguda. Existem controvérsias a respeito da forma ideal de ajuste do respirador destes pacientes, principalmente no que diz respeito ao uso de manobras de recrutamento (aplicação de pressão elevada para “abrir” o pulmão) e na quantidade de ar que deve ser mantida nos pulmões no final da respiração.

Antes de concordar em participar deste protocolo de pesquisa, é importante que você leia e compreenda este documento que descreve o objetivo, os procedimentos, os benefícios e riscos, os desconfortos e as precauções do estudo. Também descreve outros procedimentos alternativos que estão disponíveis para tratar sua doença e seu direito de sair do estudo a qualquer momento. Se você for participar, receberá uma cópia deste documento para guardar consigo. 


\section{Objetivo do Estudo}

O objetivo deste estudo é avaliar uma das estratégias utilizadas para ajustar o respirador em pacientes que necessitam do mesmo para respirar.

As informações coletadas durante o estudo serão analisadas por uma comissão científica, com o intuito de avaliar os efeitos decorrentes das etapas do protocolo.

\section{Procedimentos do Estudo}

O protocolo consiste nos seguintes procedimentos:

Como fazemos em todos os pacientes com esta doença, será colocado um cateter em uma veia (para administração de medicamentos) e em uma artéria (para controle da pressão arterial).

Durante todo o estudo o paciente estará dormindo de forma que não tenha nenhum desconforto.

Serão coletadas amostras de sangue e escarro para avaliarmos a produção de substâncias inflamatórias O paciente será transportado para o departamento de radiologia, onde irá realizar tomografia computadorizada, com 24 e 48 horas do início do protocolo.

Após 24 horas, caso não haja melhora na quantidade de oxigênio no sangue do paciente, será realizada uma manobra recrutativa (aplicar uma pressão mais elevada nos pulmões, através do respirador, na tentativa de abrir as unidades pulmonares). Esta manobra já é realizada (e aceita como eficaz) por vários centros.

Os médicos vinculados ao estudo estarão acompanhando toda a evolução do paciente, juntamente com os médicos responsáveis pelo tratamento. Após a alta, o grupo manterá contato para obter informações sobre as condições de saúde. 


\section{Riscos}

As complicações resultantes da colocação dos cateteres nas veias são poucas, ocorrem em cerca de $1 \%$ dos pacientes e incluem sangramento, hematoma, perfuração da pleura (membrana que reveste os pulmões), infecção e desconforto no momento da colocação do cateter. Estes riscos existirão mesmo que o paciente não participe do estudo.

Os riscos inerentes às manobras de recrutamento ocorrem também de forma infreqüente ( menos de $0,5 \%$ dos casos) e incluem perfuração da pleura, queda pressão arterial..

A dose de radiação durante a tomografia do pulmão está seguramente abaixo do nível máximo permitido pelas leis de segurança vigente (uma tomografia equivale a aproximadamente quatro radiografias do pulmão). O tempo de permanência no departamento de radiologia será em torno de 20 minutos. Durante todo o período o paciente estará sendo acompanhado pelos profissionais engajados no protocolo de pesquisa.

O risco da coleta do escarro está relacionado a uma possível queda transitória no oxigênio do sangue.No entanto, este risco é proporcional à quantidade de escarro coletada. O volume a ser coletado neste estudo é pequeno, e nestes casos, não há risco de queda significativa do oxigênio do sangue.

Há um risco durante o transporte dos pacientes do CTI para o serviço de radiologia (onde será realizada a tomografia). No entanto, este risco é bastante diminuído quando profissionais experientes realizam o transporte, e quando este transporte é feito com aparelhos que monitorizam a pressão do paciente, a oxigenação do sangue e o ritmo do coração. Em nosso hospital o transporte sempre é realizado por profissionais habilitados e com os equipamentos necessários. Não há relato de complicações durante o transporte de pacientes em nosso hospital. 


\section{Benefícios}

Não há benefícios diretos, mas este estudo poderá ajudar a entender melhor os fenômenos ligados à sua doença, e futuramente contribuir para o desenvolvimento de novas terapias e melhores formas de ajustar o respirador.

\section{Participação voluntária no estudo}

A participação neste estudo é voluntária. Você pode se recusar a participar, bem como cancelar sua participação a qualquer momento do estudo. Esta decisão não afetará de nenhuma maneira os cuidados médicos que lhe serão oferecidos.

\section{Confidencialidade}

O nome dos participantes não será mencionado em publicações ou relatórios produzidos para este estudo.

Entretanto o prontuário médico poderá ser consultado pelos profissionais envolvidos no estudo.

\section{Se você tem dúvidas}

Se você tiver qualquer dúvida sobre o estudo, por favor entre em contato com Dra. Vivian Rotman ou Dr. José Eduardo Castro no Centro de Terapia Intensiva do Hospital Copa D’Or nos telefones 2545-3475 /.2545-3472 


\section{Formulário de Informações ao Paciente e Documento de \\ Consentimento Livre e Esclarecido:}

\section{Páginas de Assinaturas}

Para participar deste estudo, você, ou seu representante legal, deve assinar esta página.

Assinando esta página, você está confirmando o seguinte:

- Que você leu todas as informações deste Formulário de Informações ao Paciente e Documento de Consentimento Livre e Esclarecido, e teve tempo para pensar no assunto.

- Todas as suas dúvidas foram respondidas até que você ficasse satisfeito(a).

- Você concorda voluntariamente em participar deste estudo de pesquisa, em seguir os procedimentos e fornecer as informações necessárias ao médico, enfermeiras e membros de sua equipe, quando requisitado.

- Você pode optar livremente por não fazer mais parte deste estudo a qualquer momento.

- Você recebeu uma cópia deste Formulário de Informações ao Paciente e Documento de Consentimento Livre e Esclarecido, para manter com você.

Nome do paciente

Representante legal do paciente

(incapacidade de assinar)

Nome do médico
Assinatura

Assinatura

Assinatura 


\section{ANEXO V}

\section{Ficha de Coleta de Dados}

\section{Dados Pessoais:}

Nome:

Tels:

Endereço:

Sexo: F( ) M( )

Data de nascimento:

Idade (anos)

Patologias Prévias:

Peso Ideal:

Altura:

$\mathrm{m}$

\section{Informações Iniciais:}

_Apache II:

SAPS II:

Tempo de evolução da IPA/SARA: horas

Etiologia da IPA/SARA:

Eco pré-SARA: Sim ( ) Não ( )

IVE : Sim ( ) Não ( )

Disfunção de VD Sim ( ) Não ( )

PAPmédia ( ) 


\section{Critérios de inclusão:}

- Familiar ou responsável assinou o termo de consentimento $\quad \mathrm{S}($ ) $\quad \mathrm{N}($ )

- Idade mínima de 18 anos $\quad \mathrm{S}($ ) N ( )

- Infiltrado pulmonar bilateral $\quad \mathrm{S}(\mathrm{)} \quad \mathrm{N}($ )

- $\mathrm{PaO}_{2} / \mathrm{FIO}_{2}<300$, nos parâmetros ventilatórios determinados $\mathrm{S}($ ) $\quad \mathrm{N}($ )

- Ausência de congestão pulmonar $\quad \mathrm{S}($ ) $\quad \mathrm{N}($ )

- ?T da LPA/SARA de, no máximo, 48 horas $\quad \mathrm{S}($ ） N( )

\section{Critérios de exclusão:}

- DPOC com bolhas subpleurais pré-existentes $\quad \mathrm{S}($ ) $\quad \mathrm{N}($ )

- Instabilidade hemodinâmica $\quad \mathrm{S}($ ) N ( )

- FV ou TV durante a internação $\quad \mathrm{S}() \quad \mathrm{N}(\mathrm{l})$

- Barotrauma estabelecido ou fístula broncopleural $\quad \mathrm{S}($ ) $\quad \mathrm{N}($ )

- Dreno de tórax $\quad \mathrm{S}(\mathrm{r}) \mathrm{N}(\mathrm{)}$

- Risco de hipertensão intracraniana $\quad \mathrm{S}($ ) $\quad \mathrm{N}($ )

- PCR nas últimas 48 horas $\quad \mathrm{S}(\mathrm{r} \quad \mathrm{N}(\mathrm{)}$

- Risco iminente de morte nas próximas 48 horas $\quad \mathrm{S}($ ) $\quad \mathrm{N}($ )

- Doença terminal com decisão de limitação de cuidados $\quad \mathrm{S}($ ) $\quad \mathrm{N}($ )

- Gravidez S( ) N( )

- Peso superior a $140 \mathrm{~kg} \quad \mathrm{~S}(\mathrm{)} \quad \mathrm{N}(\mathrm{r})$ 


\section{Momento Basal:}

Data:

\section{Gasometria Arterial Padrão:}

$\mathrm{pH} \_\mathrm{PaCO}_{2}$

$\mathrm{PO}_{2}$

$\mathrm{HCO}_{3}$

BE

$\mathrm{SaO}_{2}$

\section{Hemodinâmica:}

Lactato

PAM $\mathrm{SVO}_{2}$ IC $\mathrm{POAP}$ PVC FTC SVI

\section{Aminas Vasoativas:}

$\operatorname{Sim}(\quad)$

Não ( )

Noradrenalina: $\mu \mathrm{g} / \mathrm{kg} / \mathrm{min}^{\mathrm{a}}$

Dobutamina: $\mu \mathrm{g} / \mathrm{kg} / \mathrm{min}^{\mathrm{a}}$

\section{Sedação:}

Midazolan $\mathrm{mg} / \mathrm{kg} / \mathrm{h}^{\mathrm{a}}$

Fentanil $\mu \mathrm{g} / \mathrm{kg} / \mathrm{min}^{\mathrm{a}}$

Propofol $\mathrm{mg} / \mathrm{kg} / \mathrm{h}^{\mathrm{a}}$

Bloqueador neuromuscular: Sim ( ) Não ( )

a ? Cálculo obtido a partir do total de mg utilizados nas 12 - 24 horas anteriores

\section{Modificadores de prognóstico nas $12-24 \mathrm{~h}$ anteriores:}

Uso de Hidrocortisona: Sim ( ） Não ( )

Haemoglucotest? Valor máximo:

Dripping de Insulina: Sim ( ) Não ( )

Valor mínimo

Uso de Xigris $\circledR_{\text {: Sim }}(\quad$ ) Não ( ）

\section{Pressão intra-abdominal:}

Valor máximo:

Valor mínimo: 


\section{Interleucinas:}

Mini-BAL:

Sangue Arterial:

\section{Mecânica Ventilatória:}

\section{Momento 1}

(ARDS net $24 \mathrm{~h}$ )

Parâmetros ventilatórios:

$\mathrm{PCV} / \mathrm{PRVC} \quad \mathrm{VT} \_$PEEP__ FR___ Pplatô___ $\mathrm{FIO}_{2}$

FR I:E

\section{Gasometria Arterial:}

$\mathrm{pH}$ $\mathrm{PaCO}_{2}$ $\mathrm{PO}_{2}$ $\mathrm{HCO}_{3}$ $\mathrm{BE}$ $\mathrm{SaO}_{2}$

$\mathrm{PaO}_{2} / \mathrm{FIO}_{2}$ :

Hemodinâmica:

Lactato $\mathrm{SVO}_{2}$ IC $\mathrm{ScVO}_{2}$

PAM POAP PVC FTC SVI

\section{Aminas Vasoativas:}

$\operatorname{Sim}(\quad)$

$$
\text { Não ( ） }
$$

Noradrenalina: $\mu \mathrm{g} / \mathrm{kg} / \mathrm{min}^{\mathrm{a}}$

Dobutamina: $\mu \mathrm{g} / \mathrm{kg} / \mathrm{min}^{\mathrm{a}}$

Sedacão:

Midazolan ___ $\mathrm{mg} / \mathrm{kg} / \mathrm{h}^{\mathrm{a}}$

Fentanil __ $\mu \mathrm{g} / \mathrm{kg} / \mathrm{h}^{\mathrm{a}}$ 
Bloqueador neuromuscular: Sim ( ) Não ( )

a ? Cálculo obtido a partir do total de mg utilizados nas 12 - 24 horas anteriores, após início da intervenção

\section{Modificadores de prognóstico nas $12-24 \mathrm{~h}$ anteriores:}

Uso de Hidrocortisona: Sim ( ） Não （）

Haemoglucotest ? Valor máximo:
Dripping de Insulina: Sim $(\quad)$

Uso de Xigris@: Sim ( ） Não ( ）

Pressão intra-abdominal:

Valor máximo:___ Valor mínimo:

Interleucinas:

Mini-Bal

Sangue Arterial:

\section{Mecânica Ventilatória:}

Manobra recrutativa: $\operatorname{Sim}(\quad)$

Não ( )? Mantido na estratégia ARDSNET

$\underline{\text { Primeira manobra recrutativa com } \mathrm{PEEP}=17}$ :

Hemodinâmica durante a manobra:

?PAM(pré-1min após)

?IC

?POAP

?FTC

?SVI

?PVC

Gasometria Arterial após a manobra:

$\mathrm{pH}$

$\mathrm{PaCO}_{2}$

$\mathrm{PO}_{2}$

$\mathrm{HCO}_{3}$

$\mathrm{BE}$

$\mathrm{SaO}_{2}$

$\mathrm{PaO}_{2} / \mathrm{FIO}_{2}$ após a manobra:

Segunda manobra recrutativa com $P E E P=19:$

Realizada: $\operatorname{Sim}($ ) Não ( )

Hemodinâmica durante a manobra: 
?PAM(pré-1min após)

?IC

?POAP

?FTC

?SVI

?PVC

Gasometria Arterial após a manobra:

$\mathrm{pH}$

$\mathrm{PaCO}_{2}$

$\mathrm{PO}_{2}$

$\mathrm{HCO}_{3}$

$\mathrm{BE}$

$\mathrm{SaO}_{2}$

$\mathrm{PaO}_{2} / \mathrm{FIO}_{2}$ após a manobra:

Terceira manobra recrutativa com PEEP $=21$ :

Realizada: Sim ( ) Não ( )

Hemodinâmica durante a manobra:

?PAM(pré-1min após) ?IC

?POAP

?FTC

?SVI

?PVC

Gasometria Arterial após a manobra:

$\mathrm{pH} \_\mathrm{PaCO}_{2}$

$\mathrm{PO}_{2}$

$\mathrm{HCO}_{3}$

$\mathrm{BE}$

$\mathrm{SaO}_{2}$

$\mathrm{PaO}_{2} / \mathrm{FIO}_{2}$ após a manobra:

Parâmetros ventilatórios finais:

PCV / PRVC

VT

PEEP

FR

Pplatô

$\mathrm{FIO}_{2}$

FR

$\mathrm{I}: \mathrm{E}$

Momento 2:

(OLC 24 h)

Parâmetros ventilatórios:

PCV / PRVC

VT

PEEP

FR

Pplatô

$\mathrm{FIO}_{2}$

FR

I:E

Gasometria Arterial:

$\mathrm{pH}$

$\mathrm{PO}_{2}$

$\mathrm{HCO}_{3}$

$\mathrm{BE}$

$\mathrm{SaO}_{2}$

$\mathrm{PaO}_{2} / \mathrm{FIO}_{2}$ :

Hemodinâmica:

Lactato

PAM

$\mathrm{SVO}_{2}$

IC $\mathrm{ScVO}_{2}$ POAP PVC FTC SVI 


\section{Aminas Vasoativas:}

$\operatorname{Sim}($ )

Não ( )

Noradrenalina: $\mu \mathrm{g} / \mathrm{kg} / \mathrm{min}^{\mathrm{a}}$

Dobutamina: $\mu \mathrm{g} / \mathrm{kg} / \mathrm{min}^{\mathrm{a}}$

\section{Sedação:}

Midazolan $\mathrm{mg} / \mathrm{kg} / \mathrm{h}^{\mathrm{a}}$

Fentanil $\mu \mathrm{g} / \mathrm{kg} / \mathrm{min}^{\mathrm{a}}$

Propofol $\mathrm{mg} / \mathrm{kg} / \mathrm{h}^{\mathrm{a}}$

Bloqueador neuromuscular: Sim ( ) Não ( )

a ? Cálculo obtido a partir do total de mg utilizados nas 12 - 24 horas anteriores, após início da intervenção

\section{Modificadores de prognóstico nas $12-24 \mathrm{~h}$ anteriores:}

Uso de Hidrocortisona: Sim ( ） Não ( ）

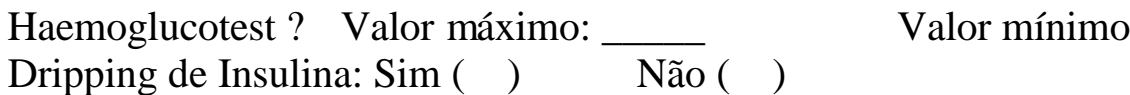

Uso de Xigris@: Sim ( ） Não （）

\section{Pressão intra -abdominal:}

Valor máximo:

Valor mínimo:

\section{Inte rleucinas:}

Mini-BAL:

Sangue Arterial:

\section{Mecânica Ventilatória:}




\section{Acompanhamento:}

\section{1- Extubação:}

\section{$\operatorname{Sim}(\quad)$}

data:

?T de VM: dias

Parâmetros ventilatórios pré-extubação:

PCV / PRVC

VT PEEP FR Pplatô $\mathrm{FIO}_{2}$

FR I:E

Gasometria Arterial pré-extubação:

$\mathrm{pH}$ $\mathrm{PaCO}_{2}$ $\mathrm{PO}_{2}$ $\mathrm{HCO}_{3}$ $\mathrm{BE}$ $\mathrm{SaO}_{2}$

$\mathrm{PaO}_{2} / \mathrm{FIO}_{2}$ :

Gasometria Arterial 24 h pós-extubação:

$\mathrm{pH}$ $\mathrm{PaCO}_{2}$ $\mathrm{PO}_{2}$ $\mathrm{HCO}_{3}$ $\mathrm{BE}$ $\mathrm{SaO}_{2}$

$\mathrm{PaO}_{2} / \mathrm{FIO}_{2}$ :

Não ( )

TQT data:

\section{2- Liberação de VM:}

$\operatorname{sim}($ ) data: I___ ?T de VM: dias

3- Data da alta do CTI:

\section{4- Re-internações no CTI:}

\begin{tabular}{|c|l|l|l|l|}
\hline Data & & & & \\
\hline Motivo & & & & \\
& & & & \\
& & & & \\
\hline
\end{tabular}


5- Gasometria arterial no $14^{0}$ dia:

\begin{tabular}{|c|c|c|c|c|c|c|}
\hline $\mathrm{pH}$ & $\mathrm{PaCO}_{2}$ & $\mathrm{PaO}_{2}$ & $\mathrm{HCO}_{3}$ & $\mathrm{BE}$ & SAT. $\mathrm{O}_{2}$ & Lactato \\
\hline & & & & & & \\
\hline
\end{tabular}

\section{6- Gasometria arterial no $28^{\circ}$ dia:}

\begin{tabular}{|c|c|c|c|c|c|c|}
\hline $\mathrm{pH}$ & $\mathrm{PaCO}_{2}$ & $\mathrm{PaO}_{2}$ & $\mathrm{HCO}_{3}$ & BE & SAT. $\mathrm{O}_{2}$ & Lactato \\
\hline & & & & & & \\
\hline
\end{tabular}

\section{Alta hospitalar:}

$\operatorname{sim}(\quad$ data:_ VM crônica: $\operatorname{sim}(\quad)$ não ( )

não ( ) óbito: $\operatorname{sim}($ ) não ( )

\section{Escores SOFA:}

SOFA $D_{---}$

\begin{tabular}{|c|c|c|c|c|c|}
\hline FA Score & 0 & 1 & 2 & 3 & 4 \\
\hline $\begin{array}{l}\text { Respiração } \\
\mathrm{PaO}_{2} / \mathrm{FIO}_{2} \\
\end{array}$ & $>400()$ & $=400(\mathrm{)}$ & $<300()$ & $<200()$ & $<100()$ \\
\hline $\begin{array}{c}\text { Coagulação } \\
\text { Plaquetas } / \mathrm{mm}_{3}\end{array}$ & $>150.000()$ & $=150.000()$ & $<100.000()$ & $<50.000($ ) & $<20.000()$ \\
\hline $\begin{array}{c}\text { Fígado } \\
\text { Bilirrubina } \\
\text { Total (mg/dl) }\end{array}$ & $<1,2()$ & $1,2-1,9()$ & $2-5,9(\quad)$ & $6-11,9()$ & $>12()$ \\
\hline $\begin{array}{l}\text { Hemodinâmica } \\
\text { Hipotensão }\end{array}$ & $\begin{array}{c}\text { Sem hipotensão } \\
(\text { ) }\end{array}$ & $\begin{array}{c}\text { PAM }<70 \\
(\text { ) }\end{array}$ & $\begin{array}{c}\text { Dopamina }(<5) \text { * } \\
\text { Dobuta }(n) * \\
()\end{array}$ & $\begin{array}{c}\text { Dopa }(<5) * \\
\text { Nora }(<0,1) \\
(\quad)\end{array}$ & $\begin{array}{c}\text { Dopa }(>15) \text { * } \\
\text { Nora }(>0,1) \text { * } \\
(\quad)\end{array}$ \\
\hline SNC Glasgow & 15() & $14-13()$ & $12-10()$ & $9-6()$ & $>6()$ \\
\hline $\begin{array}{c}\text { znal Creat. }(\mathrm{mg} / \mathrm{dl}) \\
\text { Ou } \\
\text { Déb. urinário }\end{array}$ & $<1,2$ ( ) & $1,2-1,9()$ & $2-3,4()$ & $\begin{array}{l}3,5-4,9 \\
<500()\end{array}$ & $\begin{array}{c}>5 \\
<200(\text { ) }\end{array}$ \\
\hline
\end{tabular}

Drogas vasoativas administradas por, no mínimo 1 horas em $\mu / \mathrm{kg} / \mathrm{min}$ 
